University of Rhode Island

DigitalCommons@URI

Open Access Master's Theses

1997

\title{
Investigations into the Causes of Early Larval Mortality in Cultured Summer Flounder (Paralichthys dentatus L.)
}

David Alves

University of Rhode Island

Follow this and additional works at: https://digitalcommons.uri.edu/theses

\section{Recommended Citation}

Alves, David, "Investigations into the Causes of Early Larval Mortality in Cultured Summer Flounder (Paralichthys dentatus L.)" (1997). Open Access Master's Theses. Paper 1128.

https://digitalcommons.uri.edu/theses/1128

This Thesis is brought to you for free and open access by DigitalCommons@URI. It has been accepted for inclusion in Open Access Master's Theses by an authorized administrator of DigitalCommons@URI. For more information, please contact digitalcommons-group@uri.edu. 


\section{INVESTIGATIONS INTO THE CAUSES OF EARLY LARVAL MORTALITY IN CULTURED SUMMER FLOUNDER (Paralichthys dentatus L.)}

BY

DAVID ALVES

A THESIS SUBMITTED IN PARTIAI FULFILLMENT OF THE REQUIREMENTS OF THE DEGREE OF MASTER OF SCIENCE

IN

ZOOLOGY

UNIVERSITY OF RHODE ISLAND

1997 


\section{MASTER OF SCIENCE THESIS}

OF

DAVID ALVES

APPROVED:

Thesis Committee

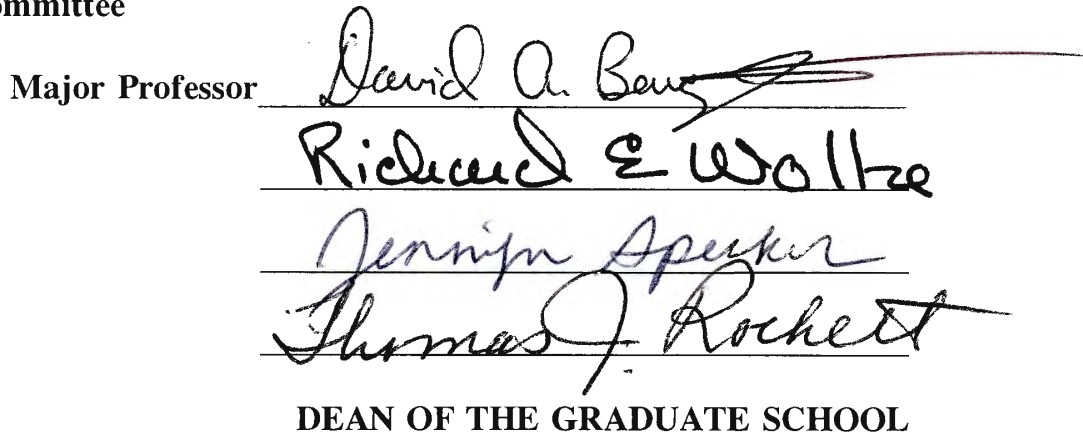

UNIVERSITY OF RHODE ISLAND

1997 


\section{ABSTRACT}

Experiments were conducted to investigate larval mortality in cultured summer flounder during the first two weeks after hatch. The importance of feeding success, parentage, addition of algae, water quality, and the microbial community to mortality during this period were investigated. Larvae were raised in $2-L$ bowls at initial densities of 50 and 75/L with light aeration, 12L:12D photoperiod, and regular 1 -L water changes. In all experiments mortalities were recorded and removed daily. In the first two experiments daily samples of larvae were taken to assess feeding success and to relate that to survival. The second experiment investigated the effects of both feeding success and the addition of algae to larval culture bowls on larval survival. The third experiment investigated the effects of water quality and bacterial load on survival during the experimental period. The first two experiments indicated that failure to establish feeding is probably not the cause of catastrophic mortality of the larvae, although a statistical relationship existed between feeding incidence and survival in two of six cases. High variability $(34 \pm$ $38 \% \mathrm{n}=82$ ) in survival was seen in the first two experiments (both within and between parental crosses) suggesting that catastrophic mortalities were due to rearing conditions rather than gamete quality. The addition of algae to larval cultures increased survival from $13 \pm 24 \% \quad(n=33)$ during the 
first experiment to $46 \pm 39 \%(n=49)$ during the second experiment. The final experiment indicated that larval mortality was not linked to the measured microbial or water quality conditions. The relationship between the percentage of floating eggs at time of fertilization and survival at $10 \mathrm{DAH}$ was found to be not significant, providing further evidence that gamete quality was not as important as rearing conditions in these experiments. 


\section{ACKNOWLEDGMENTS}

This publication is sponsered in part by NOAA, Office of Sea Grant, United States Department of Commerce, under grant \#NA36RG0503.

Any work of this nature is by necessity a collaboration, it takes input from a great many people to put it together. First and foremost I would like to thank Dr. David A. Bengtson. His unfailing good humor, good suggestions, slight prods in direction and good conversation all went into making my stay here an enjoyable learning experience. I would like to thank my committee, Dr's J.L. Specker and R.E. Wolke, who always had good suggestions and were more than generous in allowing me use of their laboratories and access to the expertise of the people in their labs.

Over the years of my university career I have been fortunate to have had a few outstanding teachers. Dr's L.J. Kling and M. Tyler of the University of Maine are two who share a special place as outstanding educators. Special thanks to Dr. M.L. Gallagher who helped when I needed it, and didn't when I didn't think I did, and in general was a very good friend.

Over the two years at the University of Rhode Island, I was fortunate to have the assistance of many people. Special thanks go to Sheila Polofsky for teaching me 
histology. Liyue Huang and Mitsuyo Kishida for taking the time to teach me some critical lab techniques. Amy Silva cheerfully assisted and kept me straight on what was happening in conducting experiments 3,4 and 5. Salinda Daley helped out in experiments 4 and 5. Thanks to Ed Baker, Robin Katersky, and Marina Huber, who, in turn, managed the hatchery over the two years of my stay.

Thanks to my peers, the graduate student mafia in the zoology department, Nancy Clancy for discussions on statistics, Tim Fort for loans of equipment and competition in tetris, "Trey" Bruggeman, Sean Grace, Barbara Malloy, Ward Francis, among others, your camaraderie made my stay much easier. To the people who really run the place, Sandy Koerner, Cindy Lamb Roderick, Andy Mack, and Ralph Napolillo for help with the nitty gritty of functioning in an academic department.

I thank Dr. D. Nelson for discussions on microbiology and assistance from his lab, Dr. J.L. Cohen for teaching me statistics while using the english language and Dr. J.T. DeAlteris for use of his graphics production equipment.

Special thanks to my oldest friend Bob Lunsford, and his family Pam, and Kevin, for many years of friendship, support and love. Thanks to steve Koopman for being a good friend. 
If I've left anybody out, forgive me, there were so many of you. To all the previously mentioned, the good parts of this work are due to you, the bad parts are all my doing.

"Given the opportunity, any system will undergo spontaneous change in that direction resulting in an increase in entropy, entropy being a measure of randomness or disorder." The second law of thermodynamics.

"Everything existing in the universe is the fruit of chance and necessity." Democritus

"What a long strange trip it's been." Grateful Dead. 


\section{PREFACE}

This thesis was prepared in the manuscript format as outlined in the University of Rhode Islands guidelines for thesis preparation. A manuscript, three appendices, and a bibliography have been included. The manuscript, prepared for submission to the Journal of the World Aquaculture Society, is titled INVESTIGATIONS INTO THE CAUSES OF EARLY LARVAL MORTALITY IN CULTURED SUMMER FLOUNDER (ParalichthyS dentatus L.). The first appendix is a review of the Iiterature pertinent to my research. The second appendix consists of the data from the five experiments, conducted in November 1995, February 1996, May 1996, October 1996 and February 1997 that make up the bulk of my research. The third appendix is a listing of the statistical source tables and graphs from the analyses done in the manuscript. The final section of this thesis is a bibliography of the complete thesis. 
ABSTRACT .................... ii

ACKNOWLEDGMENTS................. iv

PREFACE...................... vii

TABLE OF CONTENTS.................. viii

LIST OF TABLES ................. ix

LIST OF FIGURES.................. $\mathrm{x}$

INVESTIGATIONS INTO THE CAUSES OF EARLY LARVAL

MORTALITY IN CULTURED SUMMER FLOUNDER

(Paralichthys dentatus L.)

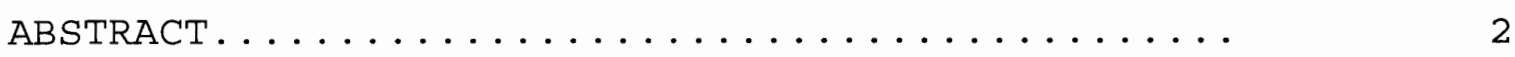

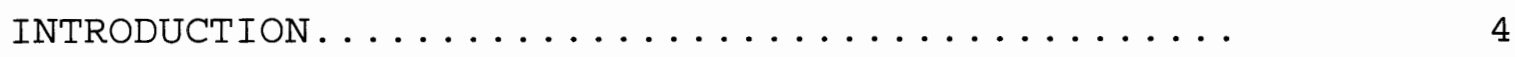

METHODS \& MATERIALS ................. 8

RESULTS ........................ 16

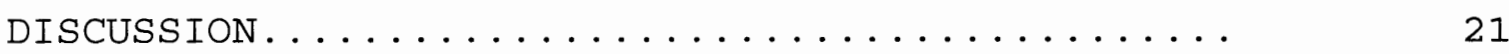

LITERATURE CITED.................... 53

\section{APPENDIX I}

LITERATURE REVIEW. . . . . . . . . . . .

APPENDIX II

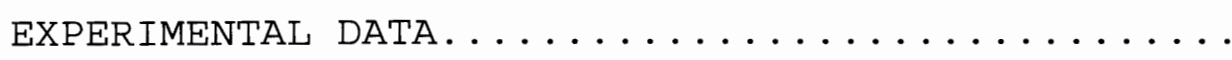

APPENDIX III

STATISTICAL FORMULAS, TABLES \& GRAPHS......... 


\section{LIST OF TABLES}

Table

Page

1. Summary of conditions for all experiments. Experiment, trial cross, male parent, number of replications of each treatment, temperature range recorded during each experiment, the \% of eggs that were floating at fertilization, the hatching mortality (in \% and standard deviation), and total volume (mL) of eggs

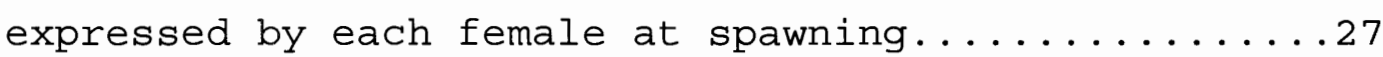

2. Survival results from all three experiments and trials, including combined clear treatments (experiment 1, all replicates, and experiment 2, clear water replicates), and combined green water treatments (experiment 2 , green water treatments and experiment 3). All statistics are for $10 \mathrm{DAH}$, including $\mathrm{n}$ for replicates, range (\%), mean (\%), standard deviation $(\%)$, and coefficient of variation $[(\operatorname{mean} / \mathrm{SD}) \mathrm{x} 100] \ldots \ldots 28$ 
Figure

Page

2B. Daily measurement of $\%$ survival and $\%$ of larvae with food in gut in experiment 1 trial 2. Letters in graphs refer to individual male $\mathrm{X}$ female crosses listed in Table 1. Lines show survival of replicates. Bars indicate percent of daily sample with food in gut. Both use percentage on $y$ axis. Black bar corresponds to open square survival line, white bar to open circle survival line, striped bar to open triangle points survival line. Unfed controls are represented by lines

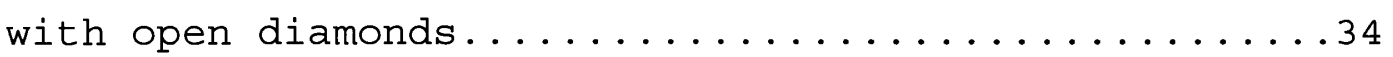

3A. Daily measurement of $\%$ survival of unfed controls in experiment 2 trial 1, 5 replicates in clear control, green control had two replicates discarded when they inadvertently had rotifers added. Letters in graphs refer to treatment: $C C=$ clear control, no algae added. GC=green control, algae added. Lines show survival of replicates. Bars indicate percent of daily sample with algae in gut. Both use percentage on $y$

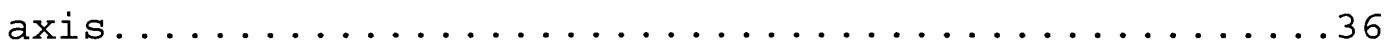

3B. Daily measurement of $\%$ survival and $\%$ larvae with food in gut in fed treatments in experiment 2 trial 1, 5 replicates in each treatment. Letters in graphs refer to treatment: RC=rotifers rinsed, no algae added. 
$R G=$ rotifers rinsed and algae added. NRC=rotifers not rinsed and no algae added. NRG=rotifers not rinsed and algae added. Lines show survival of replicates. Bars indicate percent of daily sample with food in gut. Both use percentage on $y$ axis. Black bar corresponds to open square points on survival line, white bar to open circles, striped bar to open triangles, grey bar to solid line, horizontal striped bar to open

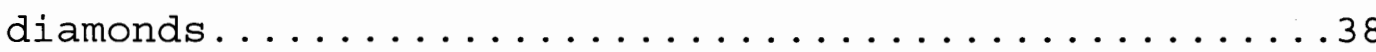

4A. Daily measurements of $\%$ survival and $\%$ larvae with food in gut for cross 1 in experiment 2 trial 2. Number and letters in upper left corner of graph indicate cross and treatment. FA indicates fed, with addition of algae; FNA=fed, no algae; CA=control, algae added; $C N A=$ control, no algae added. Lines show survival of replicates. Bars indicate percent of daily sample with food in gut. Both use percentage on $y$ axis. Black bar corresponds to open square points on survival line. White bar to open circles, striped bar to open triangles, grey bar to solid line, horizontal striped bar to open diamonds................... 
4B. Daily measurements of $\%$ survival and $\%$ larvae with food in gut for cross 2 in experiment 2 trial 2. Number and letters in upper left corner of graph indicate cross and treatment. FA indicates fed, with addition of algae; $F N A=f e d$, no algae; $C A=c o n t r o l$, algae added; $C N A=$ control, no algae added. Lines show survival of replicates. Bars indicate percent of daily sample with food in gut. Both use percentage on y axis. Black bar corresponds to open square points on survival line, white bar to open circles, striped bar to open triangles, grey bar to solid line, horizontal striped bar to open diamonds...................

4C. Daily measurements of $\%$ survival and $\%$ larvae with foodin gut for cross 3 in experiment 2 trial 2 . Number and letters in upper left corner of graph indicate cross and treatment. FA indicates fed, with addition of algae; $F N A=f e d$, no algae; $C A=$ control, algae added; CNA=control, no algae added. Lines show survival of replicates. Bars indicate percent of daily sample with food in gut. Both use percentage on y axis. Black barcorresponds to open square points on survival line, white bar to open circles, striped bar to open triangles, grey bar to solid line, horizontal striped bar to open diamonds...................44 
5A. Daily measurements of $\%$ survival and $\%$ larvae with food in gut for fed replicates in experiment 3. In all graphs the individual replicates are represented by the following symbols; bowl 1 by a diamond ( ), bowl 2 by a square ( $\boldsymbol{\square})$, bowl 3 by a triangle (4), bowl 4 by a cross (x), and bowl 5 by an asterisk (*). The first graph indicates the survival curves of the five replicates. The next graph shows results of plating of samples from each bowl on marine agar. The $\mathrm{Y}$ axis is exponential notation of colony forming units per $\mathrm{mL}$ of sample. The third graph indicates colony forming units per $\mathrm{mL}(\mathrm{CFU} / \mathrm{mL})$ grown on Thiosulfate-Citrate-Bile Salts-Sucrose (TCBS) selective media. These are presumed Vibrio colonies......................46

5B. Daily measurements of $\%$ survival and $\%$ larvae with food in gut for unfed control replicates in experiment 3. In all graphs the individual replicates are represented by the following symbols; bowl 1 by a diamond ( ), bowl 2 by a square ( $\boldsymbol{\square})$, bowl 3 is by a triangle (4), bowl 4 by a cross (x), and bowl 5 by an asterisk (*). The first graph indicates the survival curves of the five replicates. The next graph shows results of plating of samples from each bowl on marine 
agar. The $\mathrm{Y}$ axis is exponential notation of colony forming units per $\mathrm{mL}$ of sample. The third graph down indicates colony forming units per $\mathrm{mL}(\mathrm{CFU} / \mathrm{mL})$ grown on Thiosulfate-Citrate-Bile Salts- Sucrose (TCBS) selective media. These are presumed Vibrio colonies..............48

5C. Indicates the introduced, in rotifer and algae cultures, and background, in the blank, colony forming units on marine and TCBS agar. On this graph the rotifer culture marine agar colony forming units per $\mathrm{mL}$ is represented by a diamond ( ), rotifer culture colony forming units per mL on TCBS is represented by a square ( $\mathbf{\square}$ ). Algal culture colony forming units per $\mathrm{mL}$ on marine agar is represented by a triangle (4). The background colony formers, as represented by the levels found in the negative control, is represented by a cross $(\mathrm{x}) \ldots \ldots \ldots \ldots 50$

6. Scatter plots with survival at $10 \mathrm{DAH}$ on the $\mathrm{Y}$ axis, average percentage of food in guts of the daily sampling of larvae (on days when larvae were alive) per repetition bowl on the $\mathrm{X}$ axis. Top graph is all repetition bowls without algae added, i.e. experiment 1 trial $1 \& 2$, and experiment 2 trial $1 \& 2$ treatments 
which did not have algae added. Lower graph is repetition bowls which had algae added, i.e. experiment 2 trial $1 \& 2$ green treatments...............52 
INVESTIGATIONS INTO THE CAUSES OF EARLY LARVAL MORTALITY IN CULTURED SUMMER FLOUNDER (Paralichthys dentatus L.) 


\section{ABSTRACT}

Experiments were conducted to investigate larval mortality in cultured summer flounder during the first two weeks after hatch. The importance of feeding success, parentage, addition of algae, water quality, and the microbial community to mortality during this period were investigated. Larvae were raised in $2-\mathrm{L}$ bowls at initial densities of 50 and 75/L with light aeration, 12L:12D photoperiod, and regular $1-\mathrm{L}$ water changes. In all experiments mortalities were recorded and removed daily. In the first two experiments daily samples of larvae were taken to assess feeding success and to relate that to survival. The second experiment investigated the effects of both feeding success and the addition of algae to larval culture bowls on larval survival. The third experiment investigated the effects of water quality and bacterial load on survival during the experimental period. The first two experiments indicated that failure to establish feeding is probably not the cause of catastrophic mortality of the larvae, although a statistical relationship existed between feeding incidence and survival in two of six cases. High variability $(34 \pm$ $38 \% \mathrm{n}=82$ ) in survival was seen in the first two experiments (both within and between parental crosses) suggesting that catastrophic mortalities were due to rearing conditions rather than gamete quality. The addition of algae to larval cultures increased survival from $13 \pm 24 \%(\mathrm{n}=33)$ during the 
first experiment to $46 \pm 39 \%(n=49)$ during the second experiment. The final experiment indicated that larval mortality was not linked to the measured microbial or water quality conditions. The relationship between the percentage of floating eggs at time of fertilization and survival at 10 DAH was found to be not significant, providing further evidence that gamete quality was not as important as rearing conditions in these experiments. 
The culture of larval marine fish has long been a problem. In the Northwestern Atlantic, a pleuronectiform flatfish, the summer flounder (Paralichthys dentatus L.) is a popular species for commercial and sport fishing. As with many species, the population of this fish has declined (NOAA/NMFS, 1993) to the point where severe restrictions on the allowed catch have been put in place. These restrictions may make both commercial aquaculture and/or stock enhancement economically feasible. Either of these ventures would benefit from increased hatchery efficiency in production of juvenile fish.

A period of high mortality during the larval stage occurs from hatch through first feeding. Successful first feeding, in which the larvae make the transition from endogenous to exogenous nutrient supply, is critical to survival. Smigielski (1975) found that in summer flounder, 90-95\% of mortalities occurred within one week of hatch. The literature on summer flounder is not as extensive as other commercially important flatfish cultured in Europe and Asia, but the importance of successful first feeding to larval survival is well documented in turbot (Anthony, 1910; Dhert et al., 1994; Jones, 1973; Jones et al., 1981; Minkoff \& Broadhurst, 1994; Planas, 1994), striped mullet (Eda et al., 1990; Tamaru et al., 1994), halibut (Naas et al., 1992), sole (Devauchelle et al., 1987), spot (Govoni, 1981), 
winter flounder (Buckley et al., 1991), southern flounder (Daniels et al., 1996), and plaice (Shelbourne, 1964; Wyatt, 1972), among many others.

A major consideration in early larval feeding is the relationship between larval mouth gape and prey size (Houde, 1978; Beck \& Bengtson, 1982; Appelbaum, 1985; Leger et al., 1987 van der Meeren, 1991; Watanabe \& Kiron, 1994; Lavens et al., 1995;). This relationship is critical in the hatchery setting where it is usual practice to provide a single prey species for the cultured larvae. An associated factor would be developmental problems of the jaw apparatus, which would affect ingestion of prey. Abnormal jaw development has been a concern in halibut culture (Pittman et al., 1987; Morrison \& MacDonald, 1995;) and has been commented on in summer flounder culture (Bisbal, 1993).

The addition of algae to larval culture systems (the so-called green-water method, as opposed to the clear-water method) seems to have become an accepted practice (Eda et al., 1990; Reitan et al., 1993; Naas et al., 1992; Tamaru et al., 1994; stottrup et al., 1995). The advantages of the addition of algae to the larval fish culture include nutrition (rotifers in tanks maintain nutritional values via continued uptake of algae) (Reitan et al., 1993), antibacterial properties of algae (Kellam \& Walker, 1989, Strottrup et al., 1995), and enhanced feeding with increased turbidity (Boehlert \& Morgan, 1985). However Dhert et al. 
(1994) came to the conclusion that the addition of algae was not necessary during the rotifer feeding stage in turbot culture. In our laboratory, it has become de facto practice to add algae to larval culture tanks. One study in our laboratory (Ainley, unpublished data) showed that addition of algae significantly increased survival of summer flounder from 5-42 days after hatch (DAH).

For the last six years we have been investigating the potential of summer flounder for aquaculture, with emphasis on the larval stages through metamorphosis. We routinely placed thousands of newly hatched larvae from each individual male $\mathrm{x}$ female cross into a $150 \mathrm{~L}$ aquarium. Some of these batches survived and grew well, while others did not. Because we did not rear and examine replicate batches from each cross we do not know whether early larval survival rates were being determined by gamete quality (e.g., due to nutritional provisioning of eggs or genetics) or tank conditions (e.g., water quality factors or bacterial contamination), or a combination of the two. While large variability has been reported in larval culture survival (Smigielski, 1975; Klein-MacPhee, 1981; Eda et al., 1990; Buckley et al., 1991; Reitan et al., 1993; Stottrup et al., 1995), generally few authors in the aquaculture literature report inter-replicate variability, or they have had too few replicates to determine if there is a significant variance. 
These experiments, conducted over a two year period, were designed to investigate larval first feeding mortality. The first experiment, consisting of two trials, was designed to investigate the variability within and between crosses and determine the degree to which larval mortality at the critical first feeding was a result of a failure of the larvae to initiate feeding. Such failure might be due to a mismatch in larval mouth gape and prey size, to a jaw development abnormality which affected the larvae's ability to ingest prey or to a digestive tract problem which interfered with the digestion and assimilation of the prey.

The second experiment, consisting of two trials, was designed to elaborate on the findings of the first experiment. In these trials we continued the quantification of mortality and initiation of first feeding. Additionally, this experiment was designed to investigate whether the addition of algae to the culture medium and rinsing of the rotifers before being offered significantly affected survival or variability.

The third experiment, consisting of a single trial, investigated whether the inter-replicate variability in survival was associated with bacterial flora, water quality, or some combination of the two. 


\section{METHODS AND MATERIALS}

\section{BROODSTOCK CULTURE \& SPAWNING}

Flounder broodstock were maintained at the Narragansett Bay campus of the University of Rhode Island in single pass flow-through tanks. Water was passed through a sand filter, and either heated, cooled, or left at ambient temperature and mixed to obtain the desired water temperature. The broodstock were fed three times weekly with local fish or squid and were conditioned for spawning via photoperiod and temperature manipulation. Broodstock were anesthetized using 2-phenoxyethanol (Gilderhus \& Marking, 1987) during all procedures requiring handling except for stripping of gametes. Spawning was hormoneinduced with repeated injections of carp pituitary extract at $2 \mathrm{mg} / \mathrm{kg}$ (Smigielski, 1975) over a two week period. Eggs and milt were collected separately in dry containers. The milt was activated with a small amount of seawater, added to the dry eggs, and allowed to stand for three to five minutes. Seawater $(100 \mathrm{ml})$ was added and the fertilized eggs were poured into a graduated cylinder and allowed to stand for five to ten minutes, after which total volume of eggs and volume of floating eggs were determined. The floating eggs were assumed to be of good quality, whereas sinking eggs were assumed to be of poor quality. The floating eggs were then poured into $37-\mathrm{I}$ aquaria with seawater filtered to 
$10 \boldsymbol{\mu m}$, and salinity adjusted to approximately 34 with the addition of 100 seawater. An antibiotic (Maracyn) with 200 mg erythromycin activity was added. Temperature was maintained at $20 \pm 2^{\circ} \mathrm{C}$, mild aeration was provided, and a 12:12 photoperiod was maintained. Developing embryos floating at the surface were collected daily with a nylon screen and transferred to a clean aquarium, salinity adjusted to 34 and antibiotic added. For the purposes of this series of experiments, single male X female crosses were used. Although we were limited by the amount of milt produced, whenever possible one male was used to fertilize as many separate batches of eggs as possible. This was done to minimize male influence on the results.

\section{LARVAL CULTURE METHODOLOGY}

Before the start of each trial all bowls, covers, tubing, air stones and tools were disinfected with a dilute bleach mixture, rinsed well, and dried. Experimental chambers were black-plastic-wrapped 190-mm diameter bowls containing $2 \mathrm{~L}$ of sea water filtered to $10 \boldsymbol{\mu m}$, provided with light aeration and a 12L:12D light regime. At two days after fertilization, one day before hatching, eggs were counted and distributed to the experimental chambers which were then randomly assigned to treatments and repetitions. One liter of water was exchanged every other day beginning 3 days after hatch $(D A H)$. Temperature varied as to the time 
of year that the trials were conducted (Table 1). Starting 2 DAH rotifers, Brachionus plicatilis, at a density of $5000 / \mathrm{L}$ were added and that density was maintained throughout the experiment. Rotifers were cultured using the algae Tetraselmis suecica and Isochrysis galbana. Larval flounder normally begin to feed at approximately $3 \mathrm{DAH}$ (Bisbal \& Bengtson, 1995). Mortalities were removed and replaced with larvae from the same cross, up to $3 \mathrm{DAH}$, to ensure that the experiment started out with the desired number of larvae per replicate bowl. Bowls were checked for mortalities daily and mortalities were recorded and removed. Daily, beginning on $3 \mathrm{DAH}$, a random sample of ten larvae was removed and examined under a dissecting microscope for presence of food in gut and developmental abnormalities. Table 1 provides data on crosses, number of replicates per cross, temperature ranges during experiments, percentage of floating eggs, hatch mortality, and volume of eggs expressed.

\section{EXPERIMENT 1, Clear-water trials.}

Experiment one consisted of two trials. In trial one a single male's milt was used to separately fertilize eggs from four females. In trial two milt from one male was crossed separately with eggs from four females, milt from another male was crossed separately with eggs from two other females, and milt from a third male was crossed with eggs of one other female. From each cross there were four replicate 
bowls of 100 embryos each. One bowl of the four was maintained as an unfed control and three bowls were fed rotifers taken from a culture maintained in the laboratory. On days three and ten (initiation of first feeding and the end point of these trials) larvae were measured for total length and fixed in neutral buffered formalin for histological analysis. Samples were embedded in paraffin blocks and serial sagittal sections of $6 \boldsymbol{\mu m}$ were prepared. Prepared slides were stained with hematoxylin and eosin, or every other slide in a series was stained with a MalloryHeidenhain trichrome stain, chosen to investigate cartilage development of the jaw apparatus (Humason, 1962; Bisbal \& Bengtson, 1995a). Determination of development and condition of larvae was done by examination and comparison of musculature myofibrils (striated closely packed parallel to notochord in healthy larvae vs. undistinguishable pattern of fibrils without parallel orientation, and separations between muscle fibers caused by cellular degradation in starved larvae), organization of hepatic tissue (compact continuous liver tissue organization in healthy larvae vs. unorganized hepatic tissue with interstitial spaces in starved larvae), anterior intestinal mucosa (continuous and uninterrupted with a distinct brush border, columnar cells were systematically arranged and folded in healthy larvae vs. discontinuous mucosa with irregular and shrunken cells in the starved larvae), and cells in the posterior anterior 
intestine (signs of pinocytosis in healthy larvae which was absent in starved specimens) (Bisbal \& Bengtson, 1995c). Jaw development was determined by staining with MalloryHeidenhain trichrome stain. Condition of jaw development was determined by presence and form of Meckel's cartilage, the ethmoidian plate, and the associated soft tissue.

\section{EXPERIMENT 2, Green-water trials.}

Experiment two consisted of two trials. The first trial was conducted using a single male $\mathrm{X}$ female cross. A 2 X 3 factorial design with 5 replicate bowls per treatment was used. The first factor was culture medium (algae added to the seawater, or not) and the second factor was feeding condition (larvae fed rinsed rotifers, larvae fed unrinsed rotifers, or larvae not fed). Rinsed rotifers consisted of the rotifers being sieved and rinsed with clean seawater before being offered to larvae. Unrinsed treatments consisted of rotifers added directly from the rotifer culture to the treatments. Algae, a mixture of equal volumes of $T$. suecica and I. galbana, was added to the appropriate culture bowls at a rate of $50 \mathrm{ml}$ per day. Density of rotifers was maintained at 5000/L throughout the trial. This trial began on $3 \mathrm{DAH}$, as in the previous trials, but was extended to last until $14 \mathrm{DAH}$ to allow for 
the possible extended survival due to any nutritional value (Van der Meeren, 1991; Stottrup, 1994) of algae in the unfed, algae added, controls. The culture methodology of experiment 1 was followed with some changes: a) the number of larvae per bowl at the start of the trial was increased to 150 to account for sampling during the increased length of the trial, and b) larvae were measured on days 3, 10, and 14 after hatch. Daily samples were fixed in neutral buffered formalin for possible future histological examination.

In trial 2 of this experiment the milt from one male was used to fertilize separate batches of eggs from three females. Trial 2 was designed as a $2 \times 2 \times 3$ factorial with factor one being culture medium (algae added to the seawater, or not), factor two being feeding condition (larvae fed rinsed rotifers, or larvae unfed), and factor three being cross (cross one, cross two, or cross three). Each cell of the experiment had five replicate bowls.

\section{EXPERIMENT 3, Bacterial-water quality trial.}

A single male $x$ female cross was cultured using ten bowls with 150 larvae each. All bowls had algae, a mixture of equal volumes $\underline{T}$. suecica and $I$. galbana, added at a rate of $50 \mathrm{~mL}$ per day. Five replicate bowls were maintained as unfed controls, while five replicate bowls were fed rinsed rotifers beginning 2 DAH. One additional bowl, maintained as a negative control, was filled with seawater, provided 
aeration and covered, but had no addition of algae or larvae. Bacterial load in each bowl was determined via enumeration of colony forming units (CFU). Samples ( $1 \mathrm{~mL}$ ) were taken at 2 DAH from algae culture, rotifer culture, larval bowls, sea water supply and negative control bowl, before the addition of algae and rotifers to the larval cultures, serially diluted with sterile seawater, and plated in triplicate. Thereafter a sample (1 mL) from each bowl was serially diluted and plated on the appropriate medium (below) every other day until $14 \mathrm{DAH}$ when the experiment was terminated. The sterile sea water supply was also plated, but without dilution. All bacterial enumeration was done in triplicate, and plates were incubated at $22^{\circ} \mathrm{C} \pm 2^{\circ} \mathrm{C}$. CFU enumeration was conducted at 24,48 , and 72 hours after bacterial cultures were established. A marine agar (DIFCO) was used for overall CFU enumeration, a thiosulfate-citratebile salt-sucrose (TCBS) agar (DIFCO) was used to select for Vibrio spp., and a Cetrimide agar (DIFCO) was used to select for Pseudomonas spp. Fish larvae were randomly selected and removed from the culture vessels at the rate of ten per day. This removal was done to mirror the progression of densities established in the previous experiments. Larvae were discarded after removal.

Water quality was measured every other day, before water in each culture bowl was changed. Parameters measured were ammonia-nitrogen, dissolved oxygen (DO), nitrite- 
nitrogen, $\mathrm{pH}$, and temperature. DO was measured with a commercially available meter (Otterbine sentry III), other parameters were quantified colorimetrically with a commercially available test kit (LaMotte model AQ-4).

\section{STATISTICAL ANALYSIS.}

Regression analyses (Sokal \& Rohlf, 1969) were conducted of survival on $10 \mathrm{DAH}$ to the average of the daily percentage of food in the gut for each replicate, and to percentage of floating eggs at time of fertilization to survival at $10 \mathrm{DAH}$ (mean for each parental cross). Analysis of variance (ANOVA) was conducted for each trial using survival as the dependent variable. Percentages were arcsine transformed prior to analysis. An overall treatment effect was calculated via a standard $\boldsymbol{\omega}^{2}$ (Keppel, 1991) which is a procedure for measuring the strength of association. All analyses were done using the SYSTAT statistical program. All analyses had, a priori, the significance level set at $\alpha=0.05$ (Cowles \& Davis, 1982). 


\section{RESULTS}

\section{EXPERIMENT 1, Clear-water Trials.}

In trial 1 survival ranged from $0-80 \%$ (mean $28 \% \pm 32 \%$ at $10 \mathrm{DAH}, \mathrm{n}=12$ ) among replicate bowls (Fig. 1). When the average percentage of larvae with food in gut (for days when there were larvae alive) for each replicate was regressed against the survival in that replicate at $10 \mathrm{DAH}$ the relationship was not significant $\left(r^{2}=0.24, P>0.05\right)$. Low levels of jaw or skeletal deformities were noticed in both the daily samples and mortalities, (totals in the first two experiments, four trials, were 84 and 90, respectively, out of 17,150 total larval observations, $0.48 \%$ and $0.52 \%$ respectively). Complete mortality was observed in some fed replicates beginning at $5 \mathrm{DAH}$, whereas complete mortality was not observed in the unfed replicates until $9 \mathrm{DAH}$. ANOVA at $10 \mathrm{DAH}$ showed no significant effects on survival from cross, food in gut, hatching mortality, or length at 3 DAH of larvae.

Survival in trial 2 ranged from $0-60 \%$ (mean $5 \% \pm 15 \%$ at $10 \mathrm{DAH}, \mathrm{n}=21$ ) (Fig. 2, $\mathrm{A} \& \mathrm{~B}$ ). When the average percentage of larvae with food in gut (for days when there were larvae alive) for each replicate was regressed against the survival in that replicate at $10 \mathrm{DAH}$ the relationship was weak and not significant $\left(r^{2}=0.14, P>0.05\right)$. ANOVA at 10 DAH showed no significant effect of food in gut, cross, hatching 
mortality, or length at $3 \mathrm{DAH}$ of larvae on survival. It is noteworthy that the unfed controls from crosses B, C,E and F (Fig. 2, A \& B) survived longer than did the fed treatments. Histological analysis of the larvae showed that development of the digestive tract, and mucosal epithelium appeared to proceed normally, as did cartilage development in the jaw apparatus.

\section{EXPERIMENT 2, Green-water trials.}

Overall, experiment 2, trial 1, was characterized by high survival $(0-93 \%$, mean $75 \pm 30 \%$ at $10 \mathrm{DAH}$, mean $48 \pm 37 \%$ at $14 \mathrm{DAH}, \mathrm{n}=19$ ) (Fig. $3 \mathrm{~A}$ and $3 \mathrm{~B}$ ) in all fed treatments. No significant effects of algae additions or rinsing of rotifers on survival rates was seen. The unfed controls exhibited the typical survival curves, good survival until approximately $7 \mathrm{DAH}$, then a rapid decline (Fig. IA \& 2, A \& B) as seen in previous trials. In the replicates which did not have algae added, average percent of larvae with food in gut (for days when larvae were alive) regressed on survival at 10 DAH exhibited a relationship that was not significant $\left(r^{2}=0.39, P>0.05\right)$. In the replicates which did have algae added, average percentage of larvae with food in gut (for days when larvae were alive) regressed on survival at $10 \mathrm{DAH}$ exhibited a weak relationship that was not significant $\left(r^{2}=0.05, P>0.05\right)$. 
Trial two in experiment 2 (mean survival $28 \pm 32 \%$ at $10 \mathrm{DAH}, 4 \pm 12 \%$ at $14 \mathrm{DAH}, \mathrm{n}=30$ ) revealed a much different picture than trial one (Fig. 4A, 4B, and 4C). ANOVA at 10 $\mathrm{DAH}$ showed significant effects of algae $\left(\mathrm{F}_{(1,24)}=13.79\right.$, $\mathrm{P}<0.05)$ and cross $\left(\mathrm{F}_{(2,24)}=3.64, \mathrm{P}<0.05\right)$. An analysis of the strength of association showed algae to have a standard $\omega^{2}$ of 0.25 and crosses a standard $\omega^{2}$ of 0.10 , implying that 25 and $10 \%$ of the variation was due to the effects of algae and cross respectively. On the other hand, ANOVA at day 14 revealed no significant differences in effect of algae and cross on survival. A regression of the average percentage of larvae with food in gut (for days on which larvae were alive) on survival at $10 \mathrm{DAH}$, for replicates with no algae added, was significant $\left(r^{2}=0.33, P<0.05\right)$. The same analysis done on bowls which did have algae added showed a slightly stronger relationship which was also significant $\left(r^{2}=0.44\right.$, $P<0.05)$.

\section{EXPERIMENT 3, Bacterial-water quality trial.}

Survival ranged from $0-85 \%$ (mean $81 \pm 14 \%$ at $10 \mathrm{DAH}$, mean $59 \pm 35 \%$ at $14 \mathrm{DAH}, \mathrm{n}=5)$ in the fed replicates, with only one replicate exhibiting complete mortality before the end of the experiment (Fig. 5A). Colony forming units enumerated on the marine agar showed a trend in all replicates to increase towards the end of the experiment. Presumed Vibrio spp. appeared early in the experiments, but 
then disappeared by $10 \mathrm{DAH}$. Pseudomonas were never detected on the cetrimide agar in any of the larval (fed or control), rotifer, algal cultures, or in seawater alone. In the unfed controls (Fig. 5B) the same trends were evident: an initial Vibrio presence which then decreased and an initially low CFU on the marine agar followed by a increase.

In the rotifer culture there was a low but consistent presence of presumed Vibrio spp. The CFU on marine agar was consistently higher than the Vibrio CFU on the TCBS agar. The algal culture never showed CFU on TCBS agar, but showed relatively high levels of $\mathrm{CFU}$ on the marine agar. The negative control never developed CFU on TCBS agar, and had low levels of $\mathrm{CFU}$ on marine agar.

Water quality parameters varied over a small range in DO $(5.5 \pm 1.0 \mathrm{ppm})$ and nitrite $\left(\mathrm{NO}_{2}-\mathrm{N}\right)$ (from undetectable to $0.3 \mathrm{ppm}$ ). Ammonia (TAN) levels generally were in a range of undetectable to $1.0 \mathrm{ppm}$. There were spikes in ammonia (levels of $3.0 \mathrm{ppm}$ in two bowls, one fed and one unfed) on 9 DAH which did not correspond to higher mortality in those bowls. The fed replicate with high mortality did not show any unusual water quality parameters during the course of the experiment.

\section{COMBINED RESULTS}

Regression of percentage of floating eggs at time of fertilization on survival at $10 \mathrm{DAH}$ for all crosses used in 
the experiments showed weak, non-significant relationships for both green $\left(r^{2}=0.017, P>0.05\right)$ and clear $\left(r^{2}=.003\right.$, P>0.05) treatments. Thus, percentage of floating eggs is not a good predictor of larval survival.

Survival of individual replicates ranged from 0-98\%. Mean survival for all replicates in a given cross treated in the same manner ranged from 3-81\%. Coefficients of variation (CV) ranged from 20-430 for all replicates $(n=87)$. The mean survival for all clear water replicates (no algae added) was $23 \pm 33 \%(n=58), C V=150$, compared to the mean for green water replicates (algae added) of $59 \pm 37 \%(\mathrm{n}=29)$, $\mathrm{CV}=60 \quad$ (Table 2).

Plots of data points relating average daily percentages of food in gut with survival at $10 \mathrm{DAH}$ for each replicate bowl in experiments $1 \& 2$ indicate interesting differences between bowls with and without algae (Fig. 6). In bowls without algae, if average food in gut was below about $40 \%$, survival was $0 \%$, whereas, if average food in gut was above about $40 \%$, survival varied from 0-90\%. In bowls with algae, only one replicate had average food in gut below about $60 \%$, but those above about $60 \%$ had survival levels from 0-90\%. It appears that some aspect of algae addition may have increased the average percentage of larvae with food in the gut.

Statistical source tables, regression equations, and graphs are located in Appendix III. 


\section{DISCUSSION}

This series of experiments has yielded data that 1) quantifies the variability in survival within and between crosses and treatments, 2) indicates that inability to initiate first feeding is probably not the sole cause of mortality, 3)demonstrates that there was a significant statistical relationship between feeding and survival in only two cases out of six examined, 4) suggests that some as yet unidentified, factor(s) in the rearing environment is(are) the cause of catastrophic mortality, 5) suggests that green water can sometimes improve survival, and

6) demonstrates that there is no relationship between percentage of floating eggs at time of fertilization and larval survival through the critical first feeding period. The fact that the results are equivocal (sometimes green water results in higher survival, sometimes not; sometimes feeding was correlated with survival, sometimes not) demonstrates the complexities of larval rearing.

Bromage et al. (1994) in their discussion of egg quality argue persuasively for the reporting of all data from egg batches, including instances of $100 \%$ mortality, and not just the overall statistics. The range (0-93\%, mean 34 $\pm 38 \%, \mathrm{n}=82$ ) of results reported here demonstrates that to report means of replicates or of treatments would not fully represent the results. It is worth noting that there is a 
dearth of information on inter-replicate variability in the published aquaculture literature (although many experimental researchers, e.g. Houde 1978; Buckley et al. 1991, do report variability). Many researchers either do not mention the parentage of the larvae worked with or use few replications in experiments.

These experiments showed that inability to establish first feeding on prey, Brachionus plicatilis, by larvae was probably not the cause of catastrophic mortality in summer flounder culture. Analysis of the data, whether by visual inspection on an individual replicate basis or by statistical methods on summarized information, leads to equivocal findings. For example, in some replicates survival dropped quickly yet the daily sampling showed $80 \%$ of the larvae with food in their guts (Fig. 1, A \& B). Conversely, other replicates exhibited high survival while the percentage of larvae with food was relatively low (Fig. 1, D). This inconsistent pattern is repeated throughout this series of experiments. Regression analyses of feeding incidence on survival were similarly inconsistent, with significant results obtained in only one third of the cases. One pattern that is consistent and clear is the lack of similarity between the survival curves of the unfed control replicates and the fed treatments. If the fed larvae were not ingesting or not gaining nutritive value from the prey offered, then the survival curves of the fed replicates 
should consistently mirror those of the unfed controls. Yet, it is clear that none of the fed controls, green or clear (e.g., in experiment 2, trial 1), mirrors the unfed replicates (Fig. 3A\&3B). The one instance where survival curves of the fed treatments showed any similarity to those of the unfed controls was in experiment 2, trial 2 (Fig. 4A), which was the only trial to show a significant relationship between food in gut and survival at $10 \mathrm{DAH}$. Histological examination did not detect signs of starvation as described by Bisbal \& Bengtson(1995c). Some observations of skeletal deformities were observed but these deformities never reached the proportions (27\%) reported by Andrades et al. (1996) in sea bream.

The apparent strength of certain crosses ( $A \& D$ in experiment 1 trial 1 , the single cross in experiment 2 trial 1 , cross 3 in experiment 2 trial 2, and the single cross in experiment 3) suggests the importance of egg quality to early larval survival. Kjorsvik et al. (1990) and Bromage et al. (1994) made strong arguments that egg quality is a major limiting factor in larval marine fish culture. Here we have shown that there is no relationship between floating eggs at time of fertilization and survival at $10 \mathrm{DAH}$. The emphasis on breeding and broodstock nutrition in more mature animal husbandry fields is well known. The findings of this series of experiments suggest that research into these fields might decrease the variability found in early larval 
summer flounder culture. Bromage et al. (1994) suggest that three factors have been found to significantly affect egg quality, 1) bacterial colonization of the egg surfaces, 2) broodstock nutrition, and 3) overripening of the eggs in vivo.

Although we consider egg quality important, it does not diminish or is secondary to the importance of tank environment. A striking result in experiment 1 trial 2 was the early demise of the fed replicates in crosses B, C, E, and F. These results suggested mortality was related to rotifer additions to the bowls which might be affecting individual tank environments, as evidenced by the interreplicate variability seen in experiment 2, trial 1 (Fig. 3B). While the full range of effects of the addition of algae are unknown, the addition of algae might have multiple advantageous effects on tank environment which include: a) reduction in bacterial load in enrichment and culture (Kellam \& walker, 1989), b) increased feeding due to turbidity (Boehlert \& Morgan, 1985), c) maintenance of rotifer nutritional value to the larvae (Lubzens et al., 1989), and d)therapeutic properties (Austin et al., 1992). There was no indication of direct nutritional value from the addition of algae to the larvae. The lack of significant differences between the unfed control replicates in experiment 2 trial $1 \& 2$, with and without the addition of algae, provide evidence of this. A similar result was also 
reported by Qasim (1955). We did notice that summer flounder larvae did ingest algae at low levels. The possibility of algal nutrient value (Naas et al., 1992), the possible presence of enzymes appropriate for algae digestion in larval fish (Baragi \& Lovell, 1986), and physical stimulation of digestive enzyme release even due to inert particles (Hjelmeland et al., 1988) has been reported. The difference in patterns of percent food in gut between the clear and green water treatments (Fig. 6) suggests that the addition of algae does enhance the feeding response in larval summer flounder.

The findings of Nicolas et al. (1989) on the relative levels of bacteria in algal, rotifer and larval turbot culture mirrors what was found in our experiments. Significant levels of pathogenic bacteria in larval fish culture utilizing emulsion enrichment of rotifers have been reported by Perez Benavente \& Gatesoupe (1987), Angulo et al. (1988), Gatesoupe (1990), Skjermo \& Vadstein (1993), and Toranzo et al. (1993), among others. The highest levels of bacteria measured in our system did not appear to translate into increased mortality. The relatively low levels of bacteria reported here may be due to our use of algae alone for enrichment and culture of rotifers.

The complexity resulting from the multiple factors (and their potential interactions) affecting larval fish culture make progress in this area difficult. We still have not 
identified the causes of the catastrophic mortalities observed in some replicates. Because such mortalities occur in only some replicates resulting from each cross, we conclude that the cause is principally related to the rearing environment. Gamete quality is important as indicated by some crosses having higher survival. We conclude that continued research on the water quality and microbial environment is necessary in conjunction with research into gamete quality. 
Table 1. Summary of conditions for all experiments.

Experiment, trial cross, male parent, number of replications of each treatment, temperature range recorded during each experiment, the \% of eggs that were floating at fertilization, the hatching mortality (in $\%$ and standard deviation), and total volume (mL) of eggs expressed by each female at spawning.

Exp/trial/ \# Temperature $\%$ floating $\%$ Hatch Volume eggs cross/male Reps \pm range ${ }^{\circ} \mathrm{C}$ eggs Mort $\pm S D$ Expressed ML

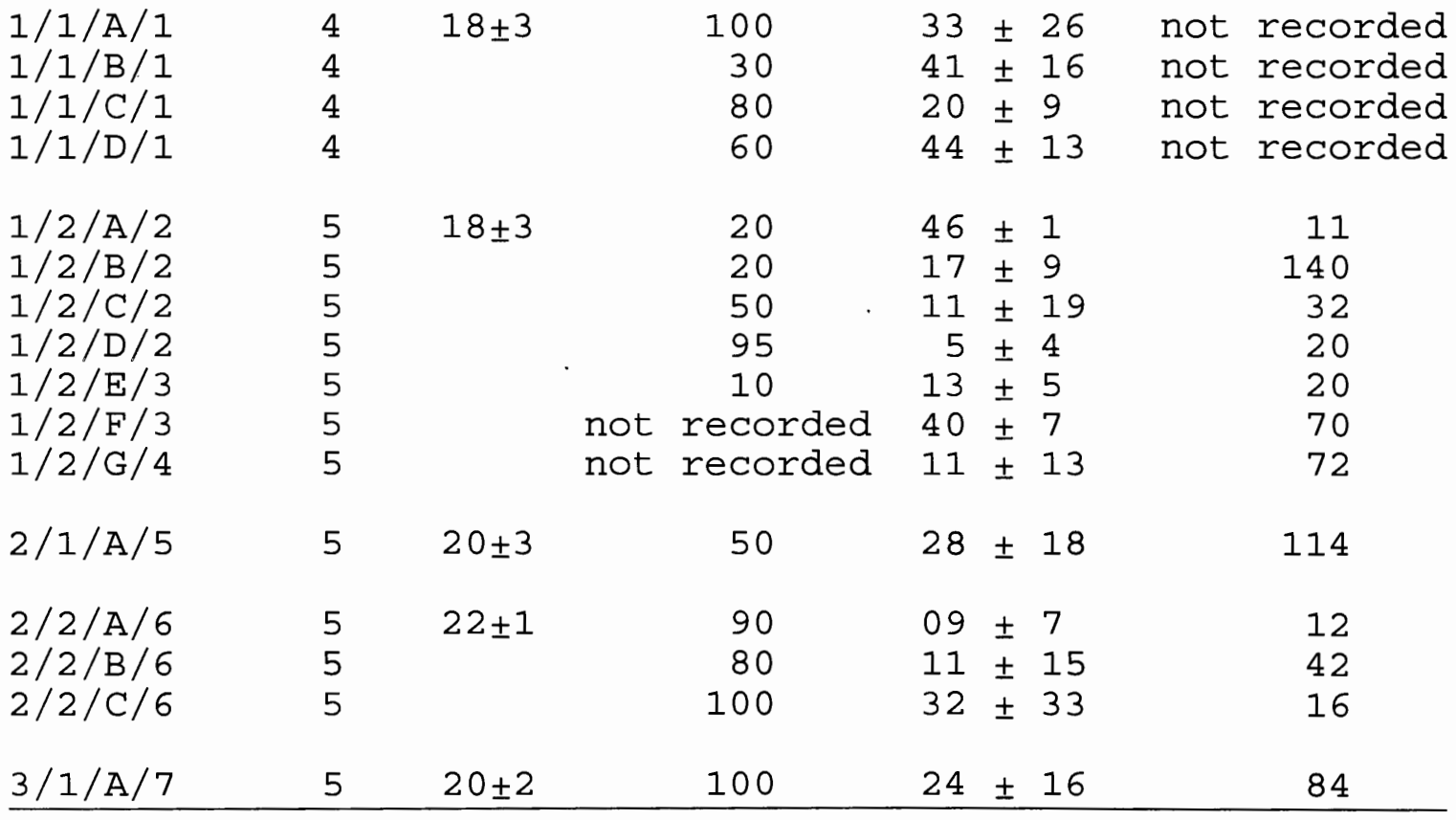


Table 2. Survival results from all three experiments and trials, including combined clear treatments (experiment 1 , all replicates, and experiment 2, clear water replicates), and combined green water treatments (experiment 2 , green water treatments and experiment 3). All statistics are for $10 \mathrm{DAH}$, including $\mathrm{n}$ for replicates, range (\%), mean (\%), standard deviation (\%), and coefficient of variation [(mean/SD) x 100].

\begin{tabular}{|c|c|c|c|c|c|c|c|c|}
\hline & ). 1 & & $\operatorname{Exp}$ & 2 & & $\operatorname{Exp} 3$ & & \\
\hline $\mathrm{T}-1$ & $T-2$ & & $\Gamma-1$ & $T-2$ & & & Com & ined \\
\hline & & G & C & G & C & & Green & Clear \\
\hline 12 & 21 & 9 & 10 & 15 & 15 & 5 & 29 & 58 \\
\hline $0-80$ & $0-60$ & $0-98$ & $38-94$ & $0-81$ & $0-66$ & $59-92$ & $0-98$ & $0-94$ \\
\hline 26 & 3 & 72 & 78 & 45 & 12 & 81 & 59 & 23 \\
\hline 33 & 13 & 41 & 17 & 34 & 19 & 14 & 37 & 33 \\
\hline 130 & 430 & 60 & 20 & 80 & 160 & 20 & 60 & 150 \\
\hline
\end{tabular}


Figure 1. Daily measurements of $\%$ survival and $\%$ of larvae with food in gut in experiment 1 trial 1. Letters in graphs refer to individual male $\mathrm{X}$ female crosses listed in Table 1 . Lines show survival of replicates. Bars indicate percent of daily sample with food in gut. Both use percentage on $y$ axis. Black bar corresponds to open square survival line, white bar to open circle survival line, striped bar to open triangle points survival line. Control survival is given in graph A only, represented by open diamond. 


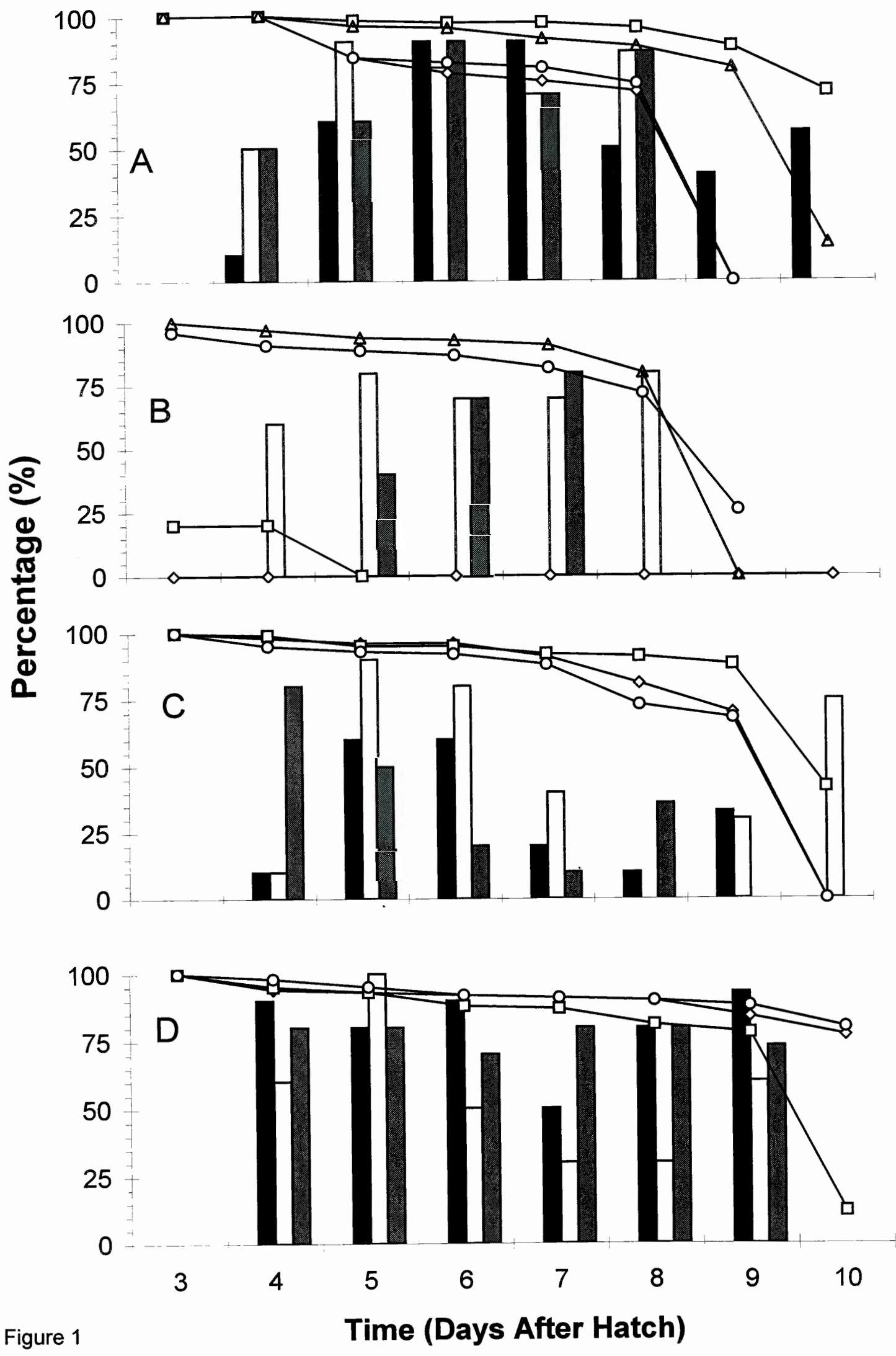


Figure 2A. Daily measurement of $\%$ survival and $\%$ of larvae with food in gut in experiment 1 trial 2. Letters in graphs refer to individual male $\mathrm{X}$ female crosses listed in Table 1. Lines show survival of replicates. Bars indicate percent of daily sample with food in gut. Both use percentage on $y$ axis. Black bar corresponds to open square survival line, white bar to open circle survival line, striped bar to open triangle points survival line. Unfed controls are represented by lines with open diamonds. 

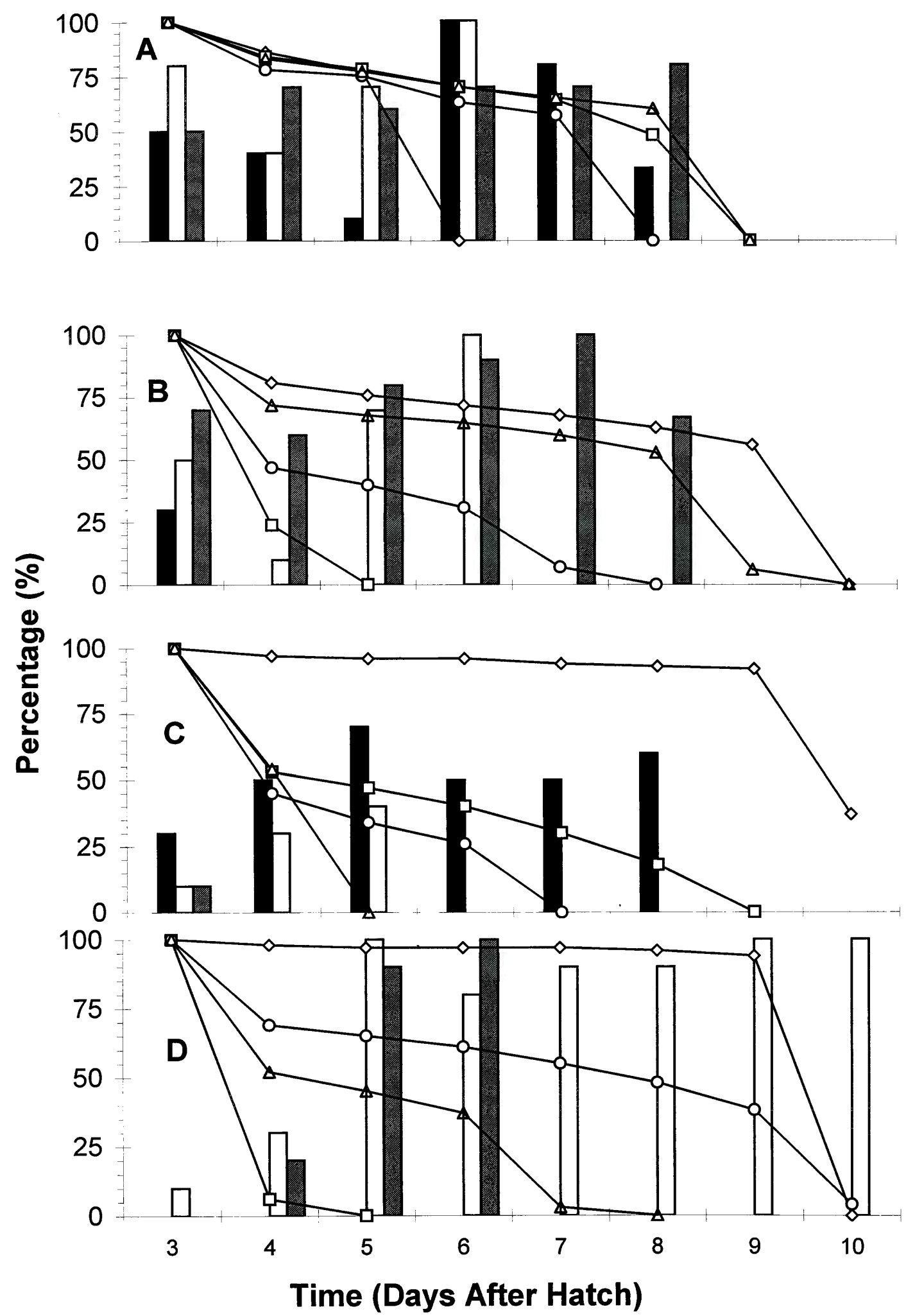

Figure 2A 
Figure 2B. Daily measurement of $\%$ survival and $\%$ of larvae with food in gut in experiment 1 trial 2. Letters in graphs refer to individual male $\mathrm{X}$ female crosses listed in Table 1 . Lines show survival of replicates. Bars indicate percent of daily sample with food in gut. Both use percentage on $y$ axis. Black bar corresponds to open square survival line, white bar to open circle survival line, striped bar to open triangle points survival line. Unfed controls are represented by lines with open diamonds. 

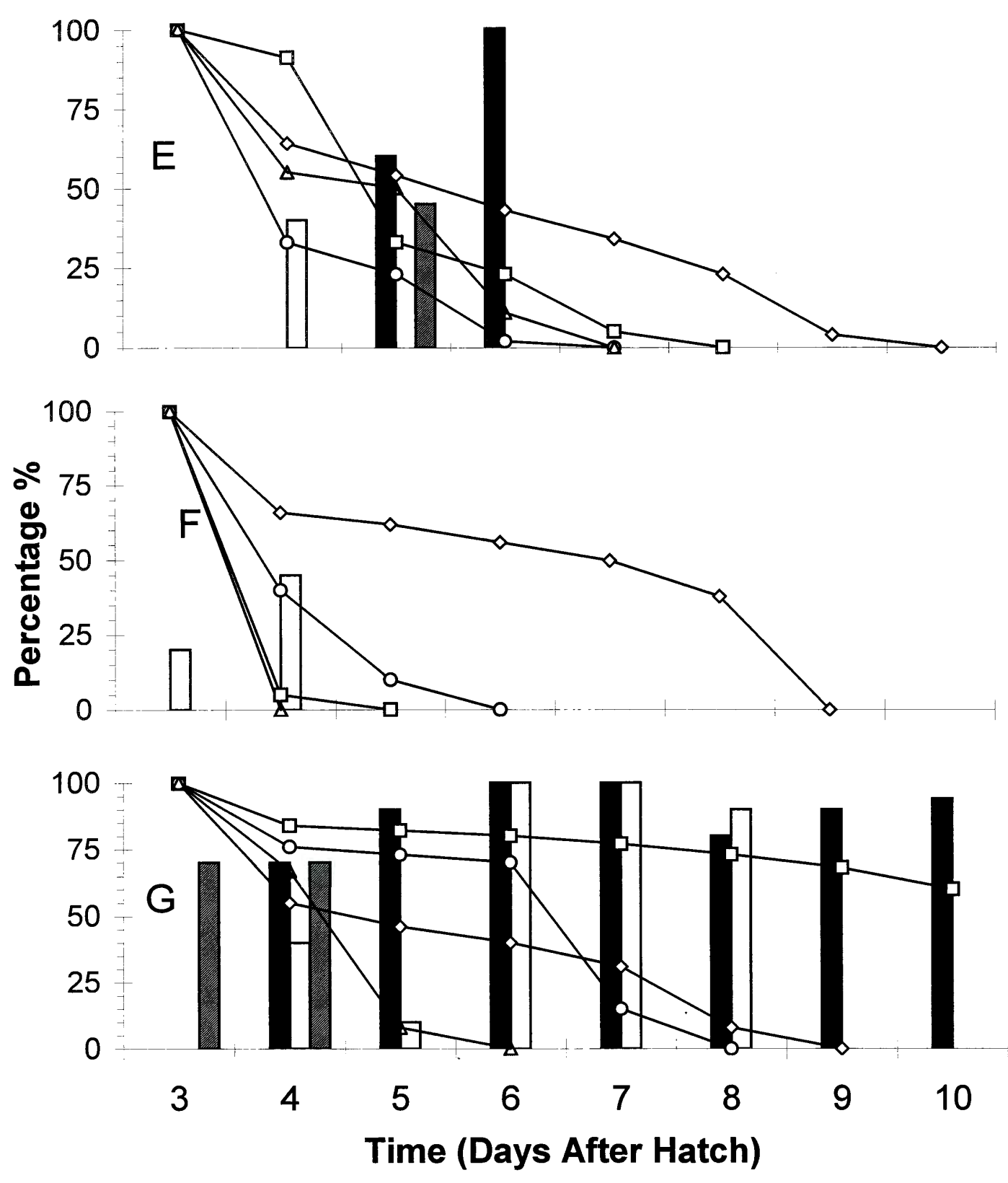

Figure 2B 
Figure 3A. Daily measurement of $\%$ survival of unfed controls in experiment 2 trial 1, 5 replicates in clear control, green control had two replicates discarded when they inadvertently had rotifers added. Letters in graphs refer to treatment: CC=clear control, no algae added. $\mathrm{GC}=$ green control, algae added. Lines show survival of replicates. Bars indicate percent of daily sample with algae in gut. Both use percentage on $y$ axis. 


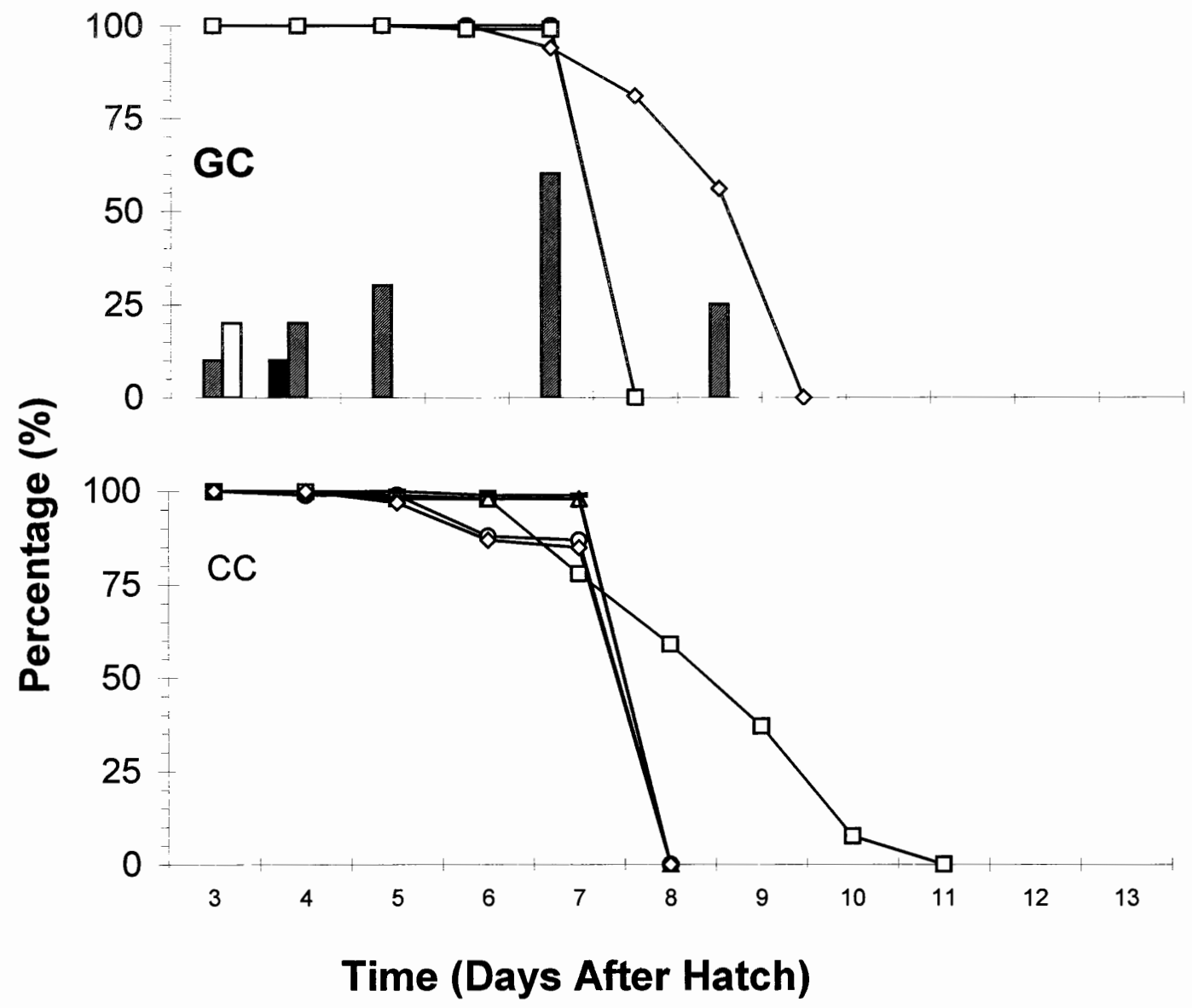

Figure $3 \mathrm{~A}$ 
Figure 3B. Daily measurement of $\%$ survival and $\%$ larvae with food in gut in fed treatments in experiment 2 trial 1 , 5 replicates in each treatment. Letters in graphs refer to treatment: $R C=$ rotifers rinsed, no algae added. $R G=r o t i f e r s$ rinsed and algae added. NRC=rotifers not rinsed and no algae added. NRG=rotifers not rinsed and algae added. Lines show survival of replicates. Bars indicate percent of daily sample with food in gut. Both use percentage on $y$ axis. Black bar corresponds to open square points on survival line, White bar to open circles, striped bar to open triangles, grey bar to solid line, horizontal striped bar to open diamonds. 

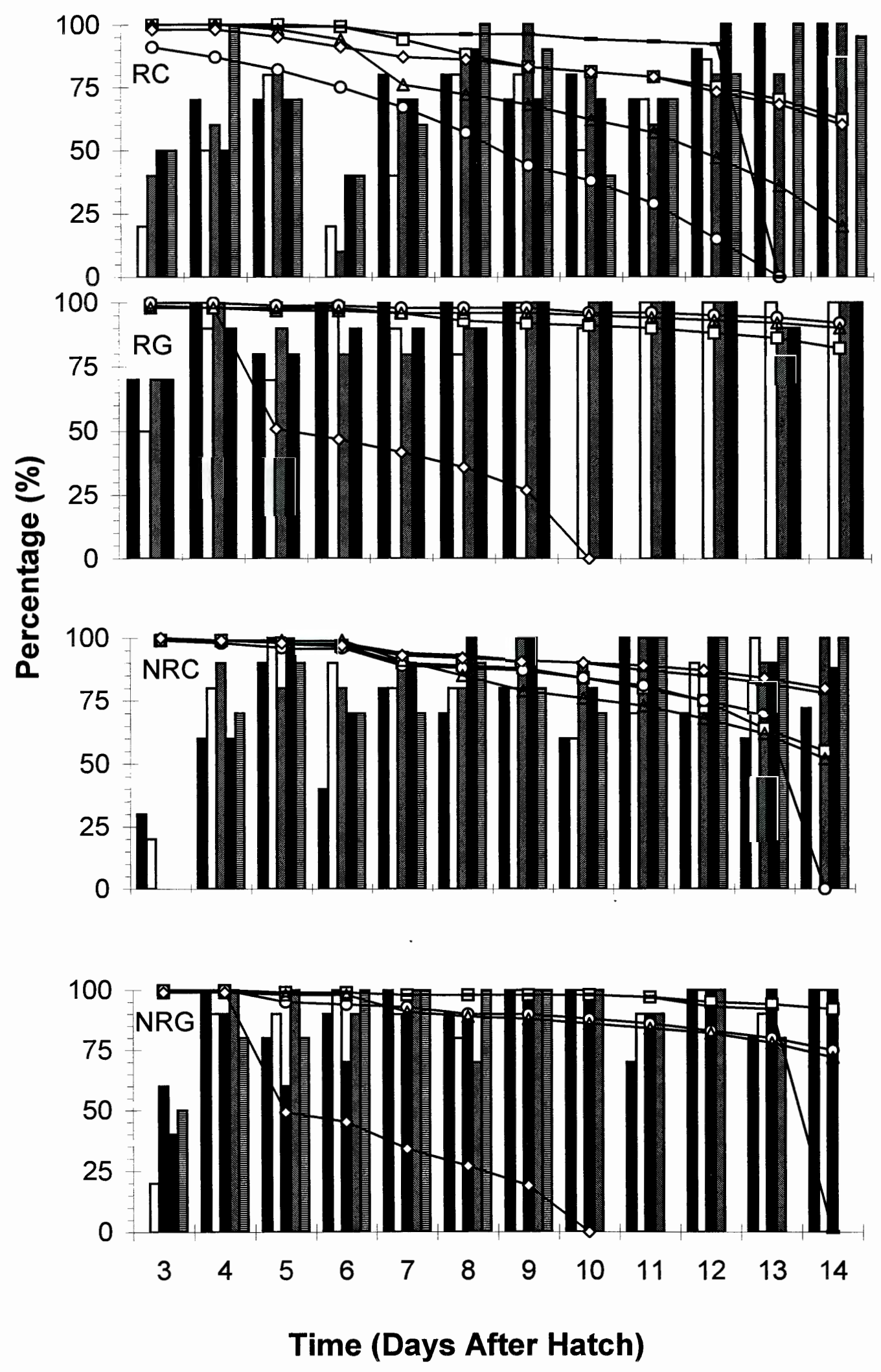

Figure 3B 
Figure 4A. Daily measurements of $\%$ survival and $\%$ larvae with food in gut for cross 1 in experiment 2 trial 2. Number and letters in upper left corner of graph indicate cross and treatment. FA indicates fed, with addition of algae; FNA=fed, no algae; CA=control, algae added; CNA=control, no algae added. Lines show survival of replicates. Bars indicate percent of daily sample with food in gut. Both use percentage on y axis. Black bar corresponds to open square points on survival line. White bar to open circles, striped bar to open triangles, grey bar to solid line, horizontal striped bar to open diamonds. 


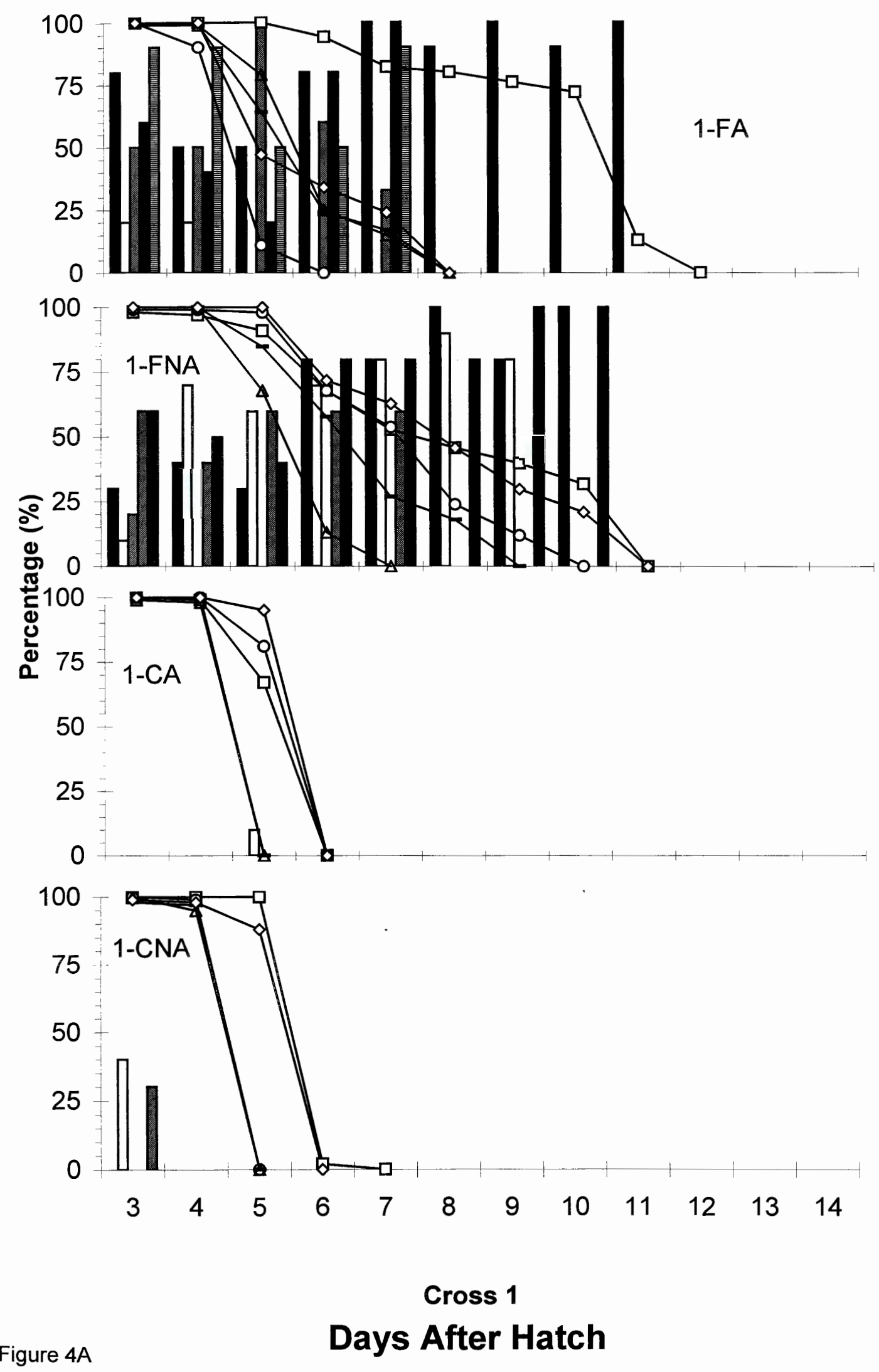


Figure 4B. Daily measurements of $\%$ survival and $\%$ larvae with food in gut for cross 2 in experiment 2 trial 2. Number and letters in upper left corner of graph indicate cross and treatment. FA indicates fed, with addition of algae; $F N A=f e d$, no algae; $C A=c o n t r o l$, algae added; CNA=control, no algae added. Lines show survival of replicates. Bars indicate percent of daily sample with food in gut. Both use percentage on y axis. Black bar corresponds to open square points on survival line. White bar to open circles, striped bar to open triangles, grey bar to solid line, horizontal striped bar to open diamonds. 


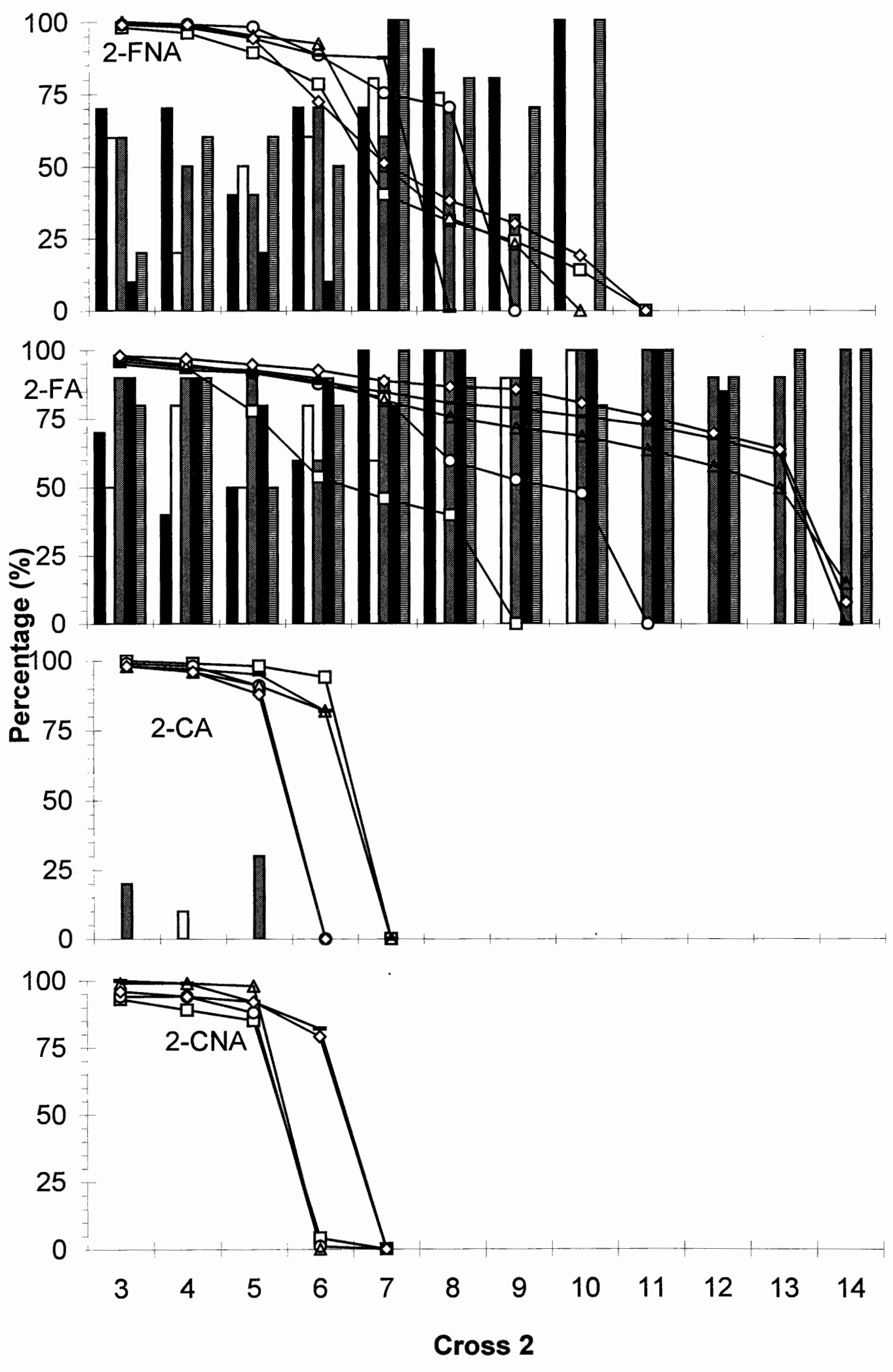

Figure 4B

Days After Hatch 
Figure 4C. Daily measurements of survival and $\%$ larvae with food in gut for cross 3 in experiment 2 trial 2. Number and letters in upper left corner of graph indicate cross and treatment. FA indicates fed, with addition of

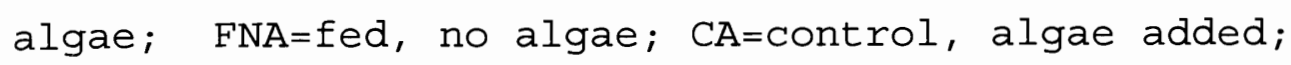
CNA=control, no algae added. Lines show survival of replicates. Bars indicate percent of daily sample with food in gut. Both use percentage on $\mathrm{y}$ axis. Black bar corresponds to open square points on survival line. White bar to open circles, striped bar to open triangles, grey bar to solid line, horizontal striped bar to open diamonds. 


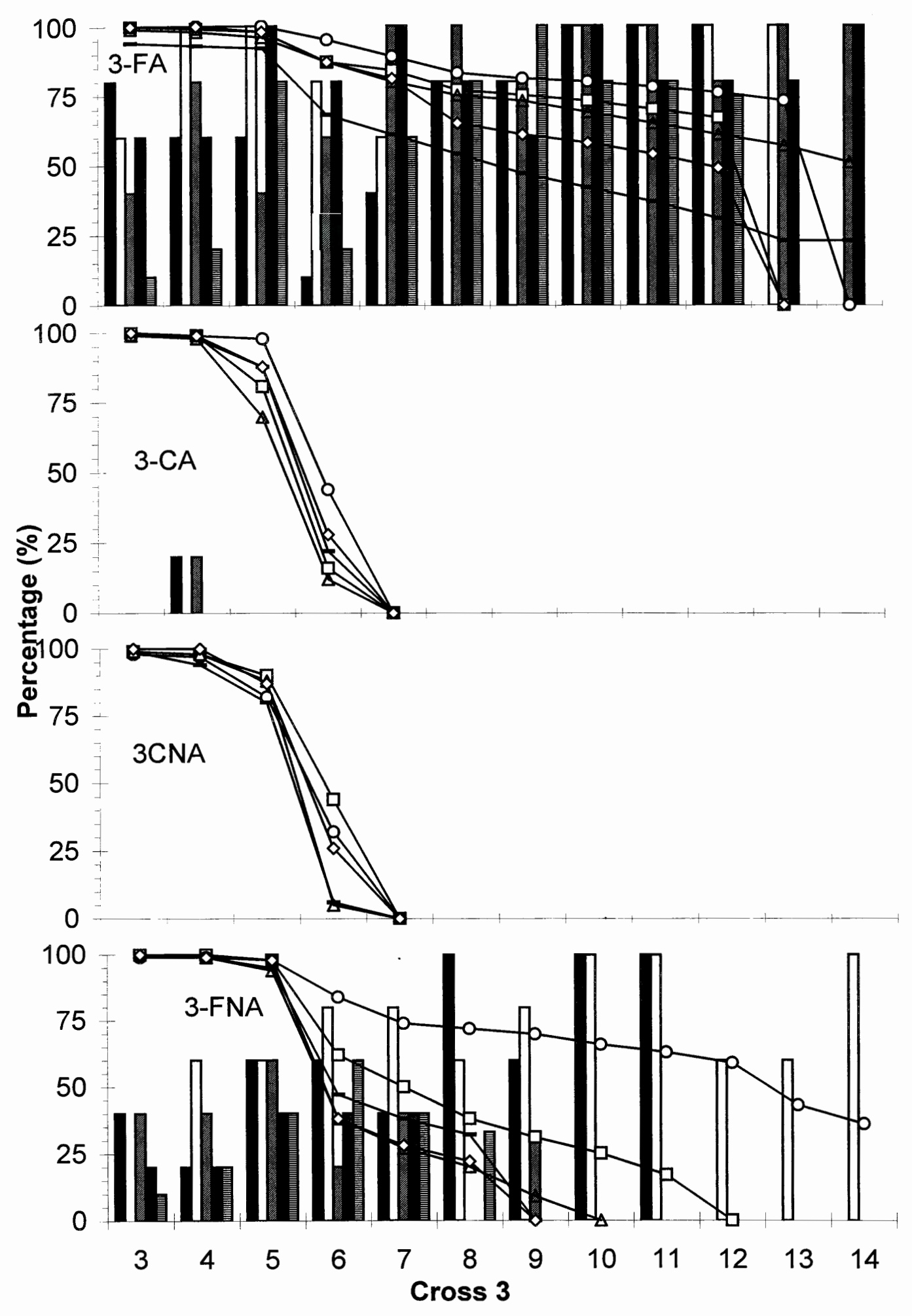

Figure 4C

Time (Days After Hatch) 
Figure 5A. Daily measurements of $\%$ survival and $\%$ larvae with food in gut for fed replicates in experiment 3 . In all graphs the individual replicates are represented by the following symbols; bowl 1 with a diamond ( ), bowl 2 by a square ( $\boldsymbol{\|})$, bowl 3 is represented by a triangle (4), bowl 4 by a cross ( $x)$, and bowl 5 is represented by a asterisk (*). The first graph indicates the survival curves of the five replicates. The next graph shows results of plating of samples from each bowl on marine agar. The $Y$ axis is exponential notation of colony forming units per $\mathrm{mL}$ of sample. The third graph indicates colony forming units per $\mathrm{mL}$ (CFU/mL) grown on Thiosulfate-Citrate-Bile salts-Sucrose (TCBS) selective media. These are presumed Vibrio colonies. 

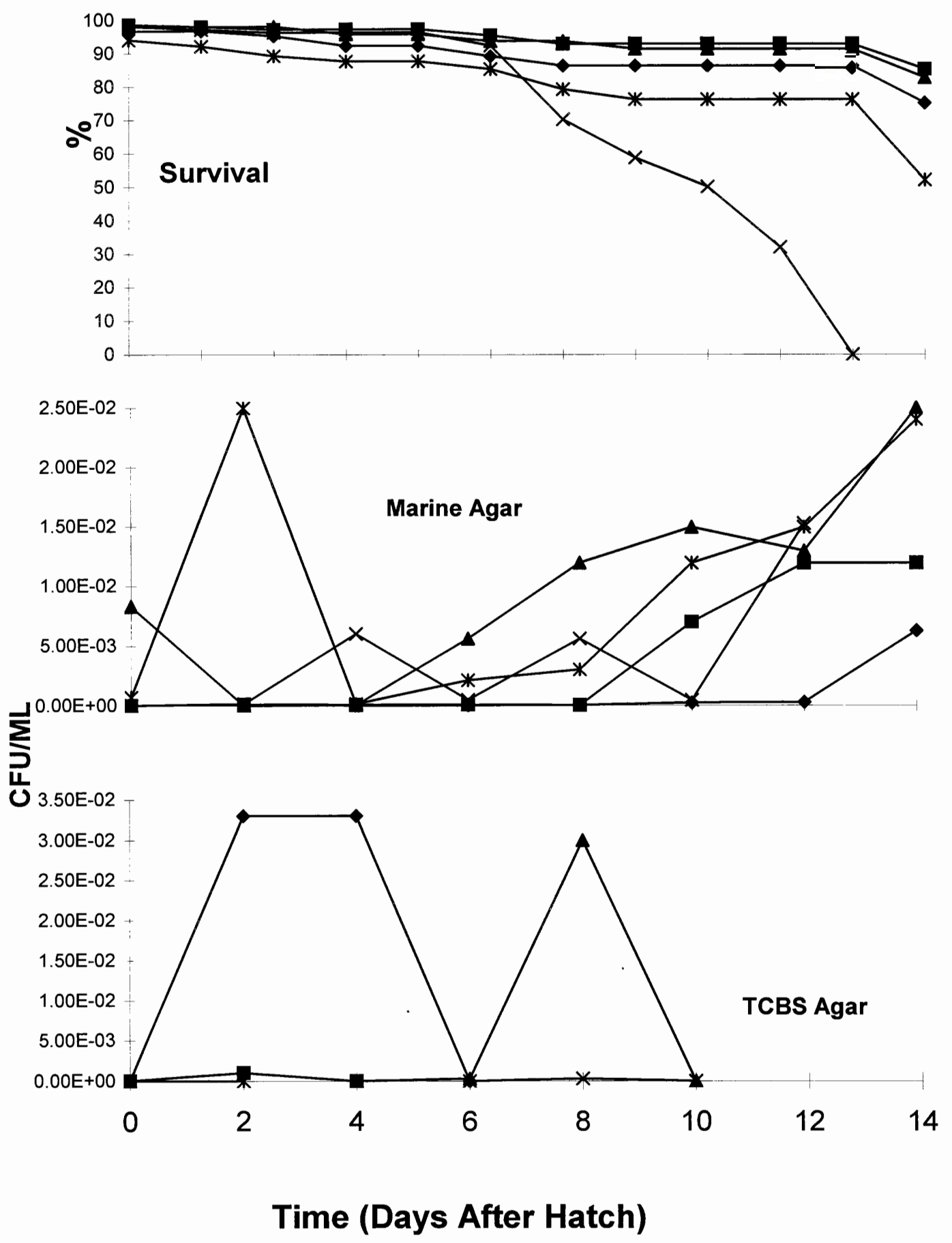

Figure $5 \mathrm{~A}$ 
Figure 5B. Daily measurements of $\%$ survival and $\%$ larvae with food in gut for unfed control replicates in experiment 3. In all graphs the individual replicates are represented by the following symbols; bowl 1 with a diamond ( ), bowl 2 by a square ( $\boldsymbol{\square})$, bowl 3 is represented by a triangle (4), bowl 4 by a cross ( $\mathrm{x}$ ), and bowl 5 is represented by a asterisk (*). The first graph indicates the survival curves of the five replicates. The next graph shows results of plating of samples from each bowl on marine agar. The $\mathrm{Y}$ axis is exponential notation of colony forming units per mL of sample. The third graph down indicates colony forming units per $\mathrm{mL}$ (CFU/mL) grown on Thiosulfate-Citrate-Bile Salts-Sucrose (TCBS) selective media. These are presumed Vibrio colonies. 

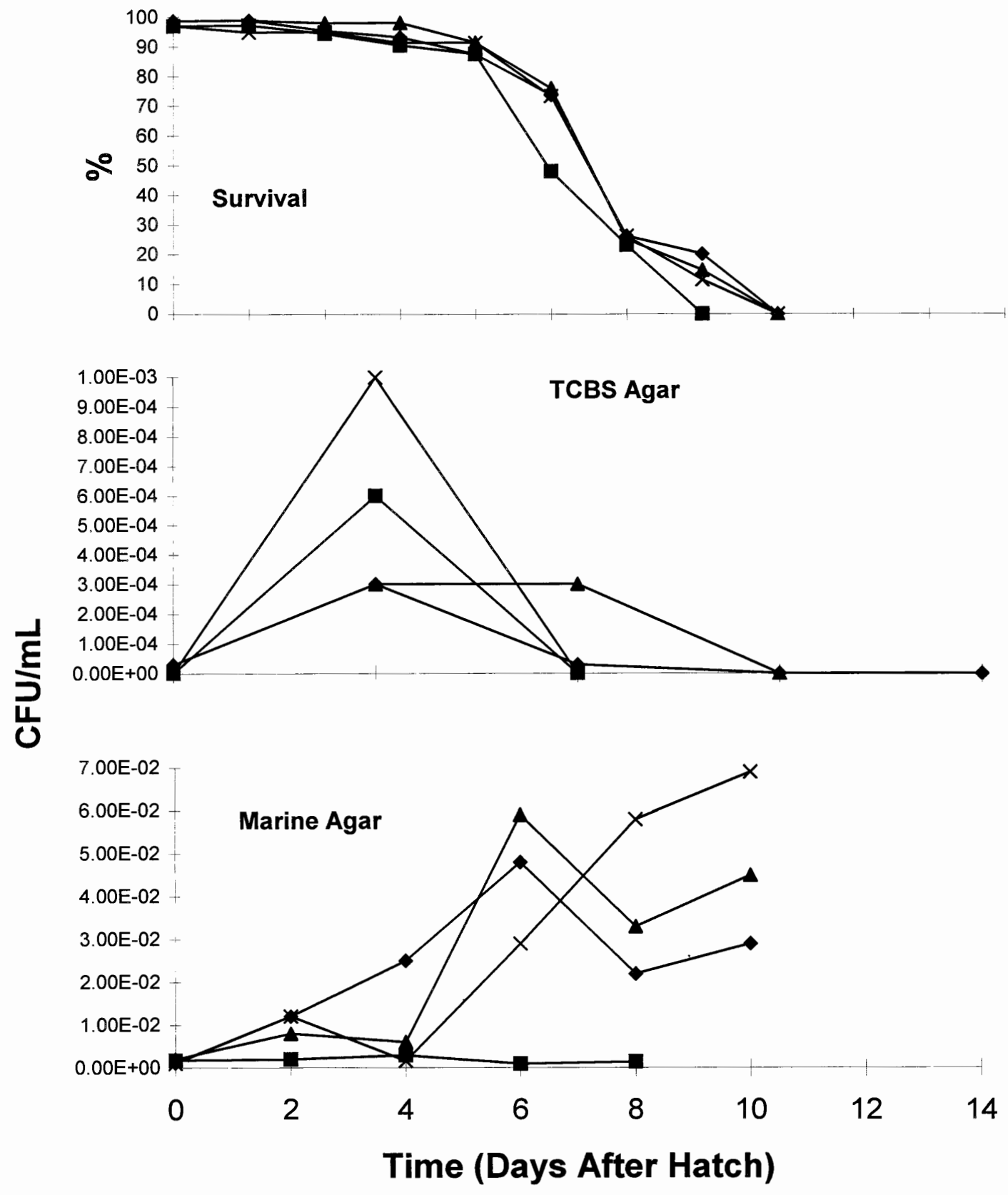

Figure 5B 
Figure 5C. Indicates the colony forming units on marine and TCBS agar from rotifer and algae cultures (introduced), and in the blank (negative control). On this graph the rotifer culture marine agar colony forming units per $\mathrm{mL}$ are indicated by a diamond ( ), rotifer culture colony formers on TCBS are represented by a square ( $\boldsymbol{\square})$. Algal culture colony forming units on marine agar are represented by a triangle (4). The background colony formers, as represented by the levels found in the negative control, are represented by a cross $(x)$. 
岁

Introduced and Background CFU's

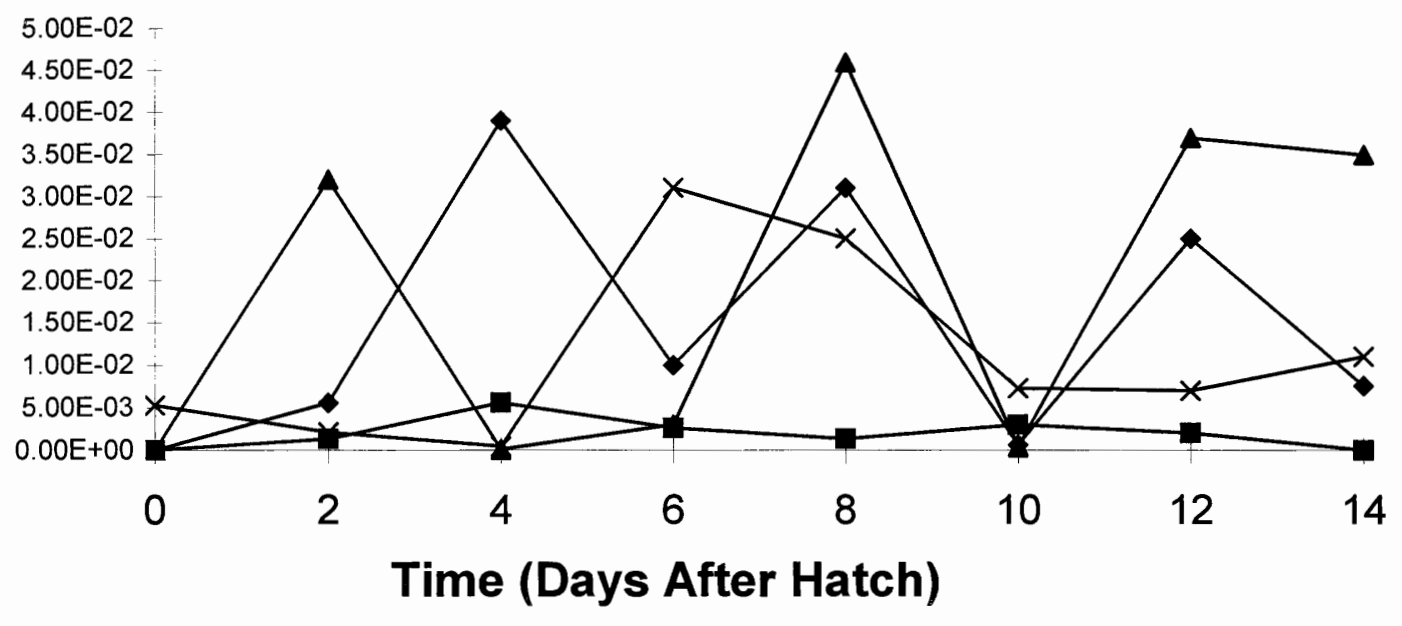

Figure 5C 
Figure 6. Scatter plots with survival at $10 \mathrm{DAH}$ on the $\mathrm{Y}$ axis, average percentage of food in guts of the daily sampling of larvae (on days when larvae were alive) per replicate bowl on the $\mathrm{X}$ axis. Top graph is all replicates bowls without algae added, i.e. experiment 1 trial 1 \& 2 , and experiment 2 trial 1 \& 2 treatments which did not have algae added. Lower graph is replicates which had algae added, i.e. experiment 2 trial 1 \& 2 green treatments. 


\section{With out Algae}

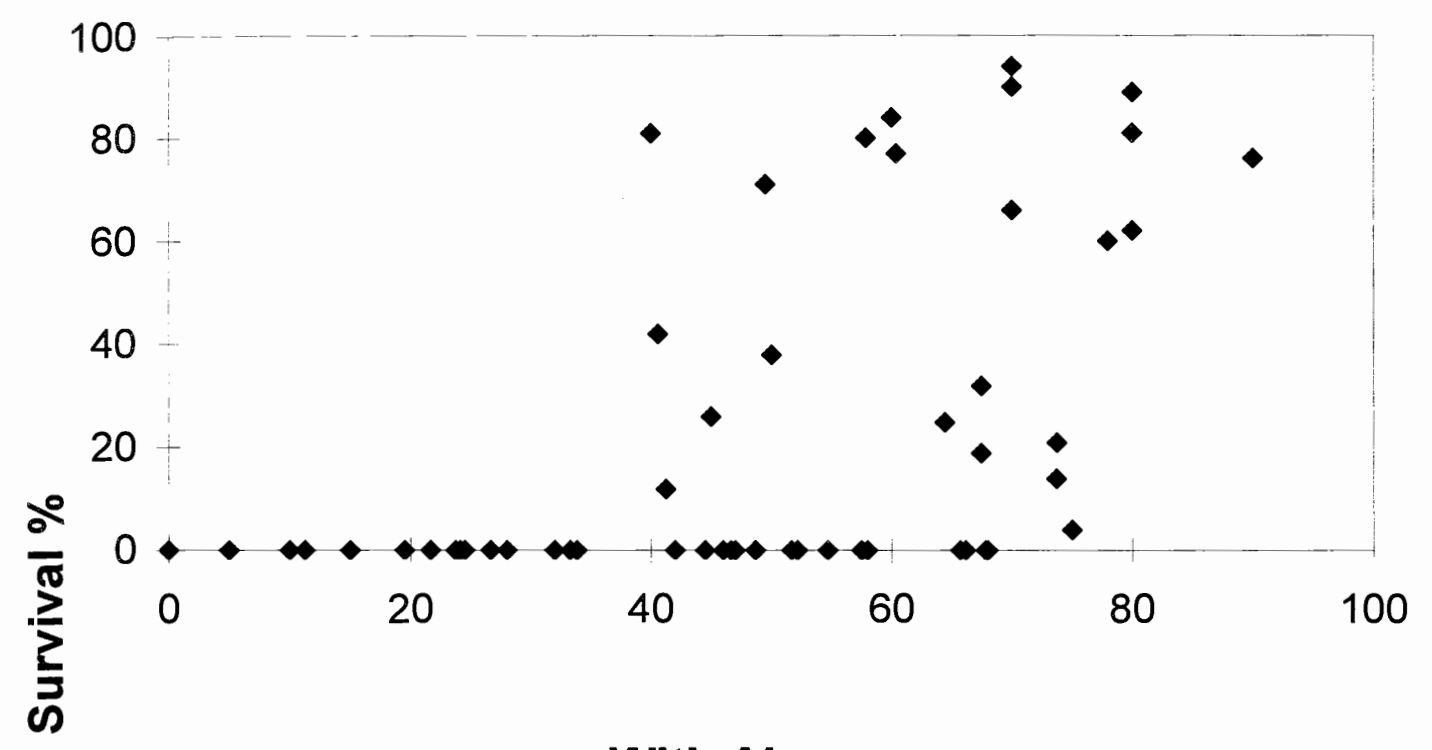

With Algae

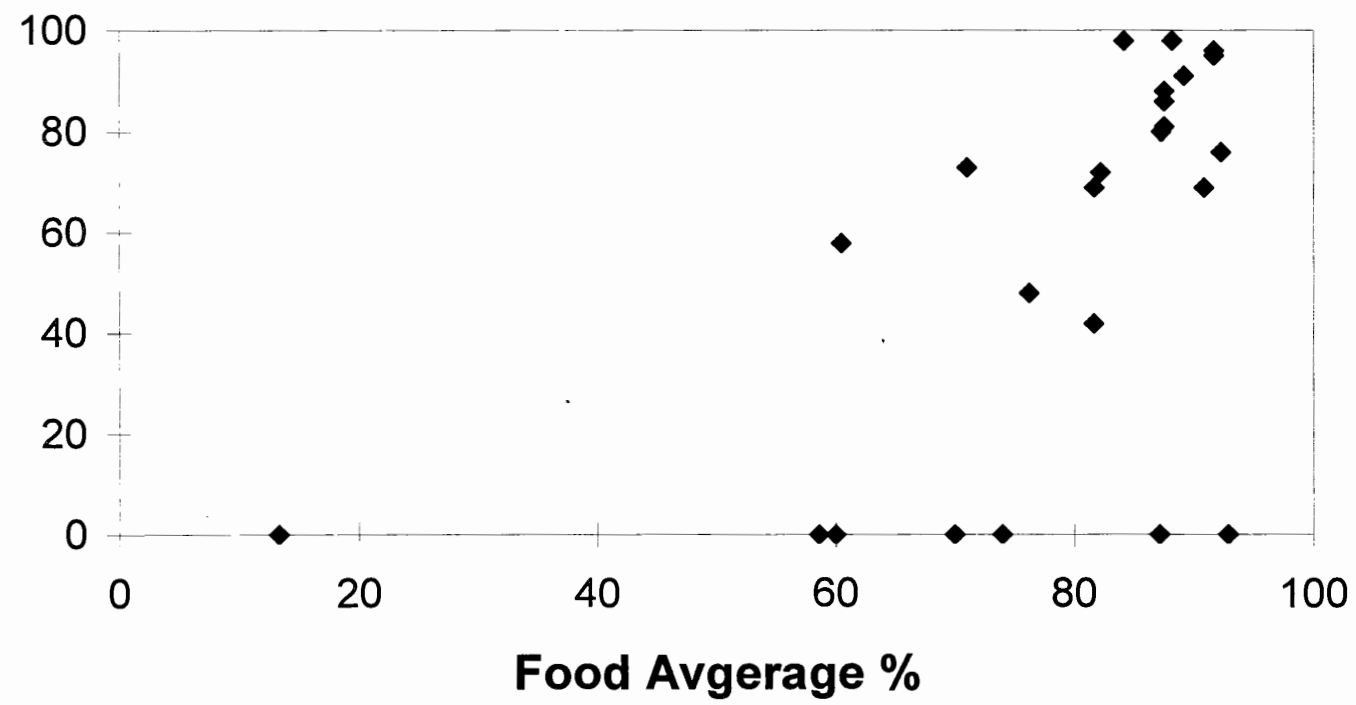

Figure 6 


\section{LITERATURE CITED}

Andrades, J.A., J. Becerra \& P. Fernandez-Llebrez. (1996) Skeletal deformities in larval, juvenile and adult stages of cultured gilthead sea bream (Sparus aurata L.). Aquaculture 141:1-11.

Angulo, L., D. Garcia, C. Bolano, F. Grana \& M. YRiveiro.(1988) Caracterizacion de la flora bacteriana asociada a los cultivos de rodaballo (Scopthalmus maximus). Thalassas $6: 83-87$.

Anthony, R. (1910) The cultivation of the turbot. Proceedings of the 4 th International Fishery Congress, Washington, 1908, Pt. 2. Published as Bulletin of the United Sates Bureau of Fisheries 28:861-870.

Appelbaum, S. (1985) Rearing of the dover sole, Solea solea L., through its larval stages using artificial diets. Aquaculture 49:209-221.

Austin, B., E. Baudet \& M. Stobie. (1992) Inhibition of bacterial fish pathogens by Tetraselmis suecica. Journal of Fish Disease 15:55-61.

Baragi, V., \& R.T. Lovell. (1986) Digestive enzyme activities in striped bass from first feeding through larval development. Transactions of the American Fisheries Society 115:478-484. 
Beck, A.D. \& D.A. Bengtson. (1982) International study on Artemia XXII: Nutrition in aquatic toxicology-Diet quality of geographical strains of the brine shrimp, Artemia. Aquatic toxicology and Harzard Assessment: Fifth Conference, ASTM STP 766. J.G. Pearson, R.B. Foster, \& W.E. Bishop, Eds. American Society for Testing and Materials. pp. 161-169.

Bisbal, G.A. \& D.A. Bengtson. (1995a) Development of the digestive tract in larval summer flounder. Journal of Fish Biology 47:277-291.

Bisbal, G.A. (1993). Early feeding in larval summer flounder, Paralichthys dentatus: gut development and starvation effects.Ph.D. dissertation, University of Rhode Island, Kingston, RI 02881, 138 pp.

Bisbal, G.A. \& D.A. Bengtson. (1995b) Effects of delayed feeding on survival and growth of summer flounder Paralichthys dentatus larvae. Marine Ecology Progress Series 121:301-306.

Bisbal, G.A. \& D.A. Bengtson. (1995C) Description of the starving condition in the summer flounder, Paralichthys dentatus, early life history stages. Fishery Bulletin $93: 217-230$.

Boehlert, G.W. \& J.B. Morgan (1985) Turbidity enhances feeding abilities of larval Pacific herring, clupea harengus pallasi. Hydrobiologia 123:161-170. 
Bromage, N., M. Bruce, N. Basavaraja, K. Rana, R. Shields, C. Young, J. Dye, P. Smith, M. Gillespie \& J. Gamble. (1994) Egg quality determinants in finfish: The role of overripening with special reference to the timing of stripping in the atlantic halibut Hippoglossus hippoglossus. Journal of the World Aquaculture Society $25(1): 13-21$.

Buckley, L.J., A.S. Smigielski, T.A. Halavik, E.M.

Caldarone, B.R. Burns \& G.C. Lawrence. (1991) Winter flounder Pseudopleuronectes americanus reproductive success. I. Among-location variability in size and survival of larvae reared in the laboratory. Marine Ecology Progress Series 74:117-124.

Cowles, M. \& C. Davis. (1982). On the origins of the .05

level of statistical significance. American

Psychologist $37(5): 553-558$.

Daniels, H.V., D.L. Berlinsky, R.G. Hodson \& C.V. Sullivan. (1996). Effects of stocking density, salinity and light intensity on growth and survival of southern flounder Paralichthys lethostigma larvae. Journal of the World Aquaculture Society 27(2):153-159.

Devauchelle, N., J.C. Alexandre, N. Le Corre \& Y. Letty.

(1987) Spawning of sole (Solea solea) in captivity. Aquaculture 66:125-147. 
Dhert, P., P. Lavens, M. Dehasque \& P. Sorgeloos. (1994) Improvements in the larviculture of turbot Scophthalmus maximus:zootechnical and nutritional aspects, possibility for disease control. In Turbot culture: Problems and prospects. P. Lavens \& R.A.M. Remmerswaal (Eds). European Aquaculture Society. Special Publication No. 22, Gent, Belgium.

Eda, H., R. Murashige, Y. Oozeki, A. Hagiwara, B. Eastham, P. Bass, C.S. Tamaru \& C.S. Lee. (1990) factors affecting intensive larval rearing of striped mullet, Mugil cephalus. Aquaculture 91:281-294.

Gatesoupe, F.-J. (1990) The continuous feeding of turbot larvae, Scophthalmus maximus, and control of the bacterial environment of rotifers. Aquaculture 89:139148 .

Gilderhus, P.A. \& L.L. Marking. (1987). Comparative efficacy of 16 anesthetic chemicals on rainbow trout. North American Journal of Fisheries Management. 7:288292 .

Govoni, J.J. (1981) Alimentary canal development and its relation to the early life history of spot, Leiostomus xanthurus. Rapports et Proces-verbaux des Reunions Conseil internationale pour L'Exploration de la Mer $178: 314-315$. 
Hjelmeland, K., B.H. Pedersen \& E.M. Nilssen. (1988) Trypsin content in intestines of herring larvae, clupea harengus, ingesting inert polystyrene spheres or live crustacea prey. Marine Biology 98:331-335.

Houde, E.D. (1978) Critical food concentrations for larvae of three species of subtropical marine fishes. Bulletin of Marine Science 28(3):395-411.

Humason, G.L. (1962) Animal tissue techniques. W.H. Freeman $\&$ Co.

Jones, A., R.A. Prickett \& M.T. Douglas. (1981) Recent developments in techniques for rearing marine flatfish larvae, particually turbot (Scophthalmus maximus L.) on a pilot commercial scale. Rapports et Proces-verbaux des Reunions Conseil internationale pour L'Exploration de la Mer 178:522-526.

Jones, A. (1973) Observations on the growth of turbot larvae Scophthalmus maximus L. reared in the laboratory. Aquaculture 2:149-155.

Kellam S.J. \& J.M. Walker (1989) Antibacterial activity from marine microalgae in laboratory culture. British Phycology Journal 24:191-194

Keppel, G. (1991) Design and Analysis, A researcher's handbook. 3ed ed. Prentice Hall.

Kjorsvik, E., A. Mangor-Jensen, \& I. Holmefjord (1990) Egg quality in fishes. Advances in Marine Biology 26:71113 . 
Klein-MacPhee, G. (1981) Effects of stocking density on survival of laboratory cultured summer flounder (Paralichthys dentatus) larvae. Rapports et Procesverbaux des Reunions Conseil internationale pour L'Exploration de la Mer 178:505-506.

Lavens, P., P. Sorgeloos, P. Dhert \& B. Devresse. (1995)

Larval foods. In Broodstock management and egg and larval quality. N.R. Bromage \& R.J. Roberts(Eds). Blackwell science, Oxford.

Leger, P., D.A. Bengtson, P. Sorgeloos, K.L. Simpson \& A.D. Beck. (1987) The nutritional value of Artemia:a review. In Artemia research and its applications. Vol 3. P. Sorgeloos, D.A. Bengtson, W. Decleir \& E. Jaspers (Eds) Universa Press, Wetteren, Belgium.

Lubzens, E., A. Tandler \& G. Minkoff. (1989) Rotifers as food in aquaculture. Hydrobiologia 186/187:387-400. Meeren, T. v.d. (1991) Algae as first food for cod larvae, Gadus morhua L.: filter feeding or ingestion by accident? Journal of Fish Biology 39:225-237.

Minkoff, G., \& A.P. Broadhurst. (1994) Intensive production of turbot, Scophthalmus maximus, fry. In Turbot culture: Problems and prospects. P. Lavens \& R.A.M. Remmerswaal (Eds). European Aquaculture Society. Special Publication No. 22, Gent, Belgium. 
Morrison, C.M. \& C.A. MacDonald. (1995) Normal and abnormal jaw development of the yolk-sac larva of atlantic halibut Hippoglossus hippoglossus. Diseases of Aquatic Animals 22:173-184.

Naas, K.E., T. Næss, \& T. Harboe (1992) Enhanced first feeding of halibut larvae (Hippoglossus hippoglossus L.) in green water. Aquaculture 105:143-156. Nicholas, J.L., E. Robic \& D. Ansquer. (1989) Bacterial flora associated with a trophic chain consisting of microalgae, rotifers and turbot larvae:influence of bacteria on larval survival. Aquaculture 83:237-248. NOAA/NMFS. (1993). Fisheries of the U.S. U.S. Department of Commerce. Silver Spring, MD.

Perez Benavente, G. \& F.J. Gatesoupe. (1988) Bacteria associated with cultured rotifers and artemia are detrimental to larval turbot, Scophthalmus maximus L. Aquacultural Engineering 7:289-293 .

Pittman, K., A.B. Skiftesvik \& L. Berg. (1990) Morphological and behavioral development of halibut, Hippoglossus hippoglossus (L.) larvae. Journal of Fish Biology $37: 455-472$.

Planas, M. (1994) R\&D on production systems. In Turbot culture: Problems and prospects. P. Lavens \& R.A.M. Remmerswaal (Eds). European Aquaculture Society. Special Publication No. 22, Gent, Belgium. 
Qasim, S.Z. (1955) Rearing experiments on marine teleost larvae and evidence of their need for sleep. Nature $175: 217-218$.

Reitan, K.I., J.R. Rainuzzo, G. Oie \& Y. Olsen. (1993) nutritional effects of algal addition in first-feeding of turbot (Scophthalmus maximus L.) larvae. Aquaculture 118:257-275.

Shelbourne, J.E. (1964) The artificial propagation of marine fish. Advances in Marine Biology 2:1-83.

Skjermo, J. \& O. Vadstein. (1993) Characterization of the bacterial flora of mass cultivated Brachionus plicatilis. Hydrobiologia 255/256:185-191.

Smigielski, A.S. (1975) Hormone-induced spawning of the summer flounder and rearing of the larvae in the laboratory. Progressive Fish Culturist $37(1): 3-8$. Sokal, R.R. \& F.J. Rohlf. (1969) Biometry. The principles and practice of statistics in biological research. W.H. Freeman \& Co.

Strottrup, J.G., K. Gravningen, \& N.H. Norsker. (1995) The role of different algae in the growth and survival of turbot larvae (Scophthalmus maximus L.) in intensive rearing systems. International council on exploration of the sea marine Science Symposium 201:173-186. 
Tamaru, C.S., R. Murashige, \& C-S Lee. (1994) The paradox of using background phytoplankton during the larval culture of striped mullet, Mugil cephalus L. Aquaculture 119:167-174 .

Toranzo, A.E., B. Novoa, J.L. Romalde, S. Nunez, S. Devesa, E. Marino, R. Silva, E. Martinez, A. Figueras \& J.L. Barja. (1993) Microflora associated with healthy and diseased turbot (Scophthalmus maximus) from three farms in northwest Spain. Aquaculture 114:189-202.

Watanabe, T., \& V. Kiron. (1994) Prospects in larval fish dietetics. A review. Aquaculture 124:223-251.

Wyatt, T. (1972). Some effects of food density on the growth and behavior of plaice larvae. Marine Biology 14:210216 . 


\section{APPENDIX I}

\section{LITERATURE REVIEW}

In the western North Atlantic, summer flounder, Paralichthys dentatus L., a pleuronectiform flatfish, is a popular target species for sport and commercial fishing. A concise summary of the habitat, spatial and temporal distribution of larvae, juvenile, and adult stages is found in Able \& Kaiser(1994). Morse (1981) found that the males are generally smaller than the females. Smith \& Fahay (1970) described of the eggs and larvae of summer flounder from both wild-caught and laboratory-cultured specimens. Martin \& Drewry (1978) provided an abbreviated synopsis of summer flounder biology. Powell \& Henley (1995) described the egg and larval development of congeneric gulf and southern flounders from specimens reared in the laboratory. Generally the literature on the culture of summer flounder is sparse, especially when compared to that of turbot in Europe and japanese flounder in Asia. Some of the early work was done during the 1970's by Smigielski (1975) who showed that summer flounder can be induced to spawn with repeated injections of carp pituitary extract, that black sided aquaria were better than clear for larval culture, that addition of microalgae is advantageous, and that there was extreme variability is survival of larvae. KleinMacPhee (1981) worked on stocking density in cultured summer 
flounder found that 20 larvae per liter was best in clear water. Later Bisbal \& Bengtson (1993, 1995a,b,c) published a series of papers detailing the development of the digestive tract in larval summer flounder, effects of delayed feeding on survival and growth, and a description of the starving condition in the larval summer flounder.

One of the difficulties in larval marine fish culture is a determination of what is normal, viz the morphology of the larvae. It is of course extremely difficult to come to some conclusion on this topic. One would expect that morphologically abnormal larvae would suffer higher predation than normal larvae in nature. In the laboratory predation does not occur and the artificially high densities of prey provided results in an artificially higher survival rate. Nankee (1981) documented abnormalities of larval fish in Long Island Sound including Paralichthys dentatus and, although he described types of abnormalities found, he did not provide the percentage of larvae that were found with deformities. Andrades et al. (1996) investigated the amount of skeletal deformities found in cultured sea bream, finding that approximately $27 \%$ of the larvae had these deformities, with 5\% surviving through metamorphosis. Fournie et al. (1996) attempted to document base line data for gross abnormalities in estuarine fishes in two biogeographic provinces; of 214 summer flounder sampled in the Virginian province in 1991, no abnormalities were reported. Grudger 
(1935) reported on partially ambicolorate summer flounder that were landed at a Boston pier. He stated that summer flounder seem to be particularly susceptible to abnormal coloration, and that this is often found coupled with eye migration and fin ray abnormalities. The problem with abnormal coloration is seen often in cultured flounder and is apparently related to a nutritional deficiency of highly unsaturated fatty acids (HUFA) in larval stages of Japanese flounder Paralichthys olivaceus (Kanazawa, 1993), turbot Scophthalmus maximus (Dhert et al. 1994) and summer flounder Paralichthys dentatus (Baker \& Bengtson, 1996)

In contrast to the sparse literature on summer flounder culture, literature on turbot culture is quite extensive. Anthony (1910) detailed the history of larval turbot culture in France and England during the previous 15 years. Describing what makes a valuable aquaculture species, he made points that are still valid almost a 100 years later. Anthony also credited two French aquaculturists, FabreDomergue \& Bietrix, with coining the term "critical period" in early larval life history. I believe that knowledge of the history of my area of research is important, because none of us have the time to keep reinventing the wheel. Shelbourne's (1964) treatise on the artificial propagation of marine fish includes not only valuable information on the history of larval culture, but also covers the discussions at the time on stock enhancement. His treatment includes 
the practical value of hatchery culture and the evidence for and against stock enhancement.

Larval development, from bilaterally symmetrical pelagic larva to benthic flatfish, is an interesting series of morphological, behavioral, and biochemical developments. Al-Maghazachi \& Gibson (1984) divided the process in turbot into 5 distinct phases, each sub-divided into substages, based on gross morphological changes. During this time period, the digestive tract also undergoes functional and morphological changes, described for summer flounder by Bisbal \& Bengtson (1995). Segner et al. (1994) describe this developmental sequence in turbot. The latter authors proposed a division of the development of organs found in larvae into two groups, 1) those found in the larvae at hatch, differentiated into functional organs, and 2) those which are not present in the larvae, but develop during metamorphosis. Padros et al. (1993) followed the histopathological events during the critical first feeding stage and noted that progressive bacterial colonization of the intestine was seen in turbot larvae, especially in the more mature larvae of the cohort. These authors suggested that the immune system of the larval flatfish is less well developed than that of other teleost which might account for the increases susceptibility to bacterial infections. Cousin \& Baudin-Laurencin (1987) and Cousin et al. (1986) examined development of the turbot in a pair of histological 
studies. Govoni et al. (1986) reviewed the physiology of digestion in larval fish, suggesting that further research into functional changes during the morphological changes is needed. Fukuhara (1988) studied the development, morphological and functional, of Limanda yokohamae and related it to the behavioral changes leading to metamorphosis. Fukuhara (1986) had looked at the Japanese flounder with the same outlook two years earlier, adding ecological changes as well. One of the concerns noted by Bisbal (1993) in earlier experiments was jaw apparatus maldevelopment. Morrison \& MacDonald (1995) looked at this in halibut, and came to the conclusion that, at least in halibut, it was due to a secondary bacterial infection. Pittman et al. (1990) described the morphological and behavioral development of halibut larvae.

Appelbaum et al. (1983) looked at the olfactory and gustatory development in the sole, in the hope that knowledge of larval responses to prey could be a first step towards developing an artificial diet for larval marine fishes. A program of research and the components important to the development of larval diets was outlined by Bengtson (1993).

An important component to larval culture, one that has to a large extent not been investigated, is egg quality and broodstock nutrition. In more mature animal husbandry fields, the importance of broodstock management has been 
explored. As marine fish culture is a relatively new endeavor, compared to land animal culture, other concerns have been considered more pressing than broodstock management. Kjorsvik et al. (1990) reviewed egg quality in fishes, including a discussion of quality characteristics, and factors of importance for egg quality. Bromage et al. (1994) discussed the role of over-ripening of halibut eggs as a quality determinant. Authors of both articles mentioned the assessment of egg quality by separating and estimating percentages of floating eggs to sunken eggs, a procedure practiced in my work. The Bromage article has an interesting discussion of accurate assessment of egg quality, in which he stressed that just reporting mean (pooled) survival and fertilization rates is misleading. Another misleading reporting method is to exclude repetitions that have $0 \%$ survival. The reporting of the full inter-replicate variability, while not presenting the data in the best light, is critical to truly gaining understanding of the processes of larval survival.

Devauchelle et al. (1988) discussed spawning of turbot in captivity over a 12 year period. The authors reported on the use of photoperiod and temperature manipulation, and the effects on hatching success. Devauchelle et al. (1987) reported on the same parameters, also over a 12 year period, on the spawning of sole in the laboratory. Berlinsky et al. (1996) reported on the induced spawning of southern flounder 
using gonadotropin analogues. Suquet et al. (1995) reported on optimal time and ratio of sperm:egg interaction, with a time of 3 minutes recommended for sperm:egg interaction. Howell \& Scott (1989) discussed the ovulatory cycle and egg deterioration. Post-ovulatory deterioration is a concern in my work, as the determination of optimum spawning stage has not been investigated in summer flounder.

The variability of larval survival in summer flounder is a major finding of my work. While this variability is critical to experimental design and findings, it is often glossed over in the literature. Smigielski (1975) found survival to metamorphosis for summer flounder to be between 0 and $5 \%$, with a mean of $1.3 \% \pm 2.0 \%$. He did not report survival during the critical first feeding stage, nor did he report parentage. Klein-MacPhee (1981), using two replicates per treatment, reported mean survival to 30 days after hatch of $0,11.8,37.4,0.9$, and $0.6 \%$ for stocking densities of $5,10,20,40$, and $80 \mathrm{fish}$ per liter respectively. Bisbal \& Bengtson (1995) report survival (pooled mean of three replicates) of up to $40 \%$ at a culture temperature of $12.5^{\circ} \mathrm{C}$, and $90 \%$ at $21^{\circ} \mathrm{C}$. This is the extent of summer flounder survival data that I found. Data for other species also indicate that first feeding mortality is extremely high. Buckley et al. (1991) found that larval winter flounder survival ranged from 0.07 to $6 \%$. Shelbourne (1964) reported survival through metamorphosis of plaice 
larvae to be 0.1 to $6.6 \%$ over the span of five years, 19571961. Qasim (1955) reported between 0 and $40 \%$ survival of Banius pholis L. at 32 days after hatch. Planas (1994), in his review of different production systems for turbot larval culture, reported a survival range of 1 to $37 \%$ for 18 experiments. Minkoff \& Broadhurst (1994), in their discussion of intensive turbot fry production in Europe, stated that while survival of larvae can be $40-50 \%$ in the first month, rearing success is unpredictable. These authors reported that, up to 9 days after hatch, egg and larval quality have the largest impact on survival. They reported mortalities of $25-80 \%$ during the critical early larval stages from hatch to first feeding. Dhert et al. (1994) reported survival up to $20 \%$, but did not report parentage or the number of repetitions used. Although Olesen \& Minck (1983) reported in the abstract of their article survival of turbot larvae of $40 \%$, they actually showed results from 7 experiments, with survival ranging from 9 to $40 \%$. I assume that the survival rates are a pooled mean, but no standard deviation was reported. In one of the early works of the "modern era", Jones (1973) reported survival of turbot larvae to be very low, less than 1\% overall. In a later research effort, Jones et al. (1981) reported mortality to be greatest 5-12 days after hatch. Overall survival ranged from 3-6\%, with individual batches ranging from $0-25 \%$. In other species of fish survival rates 
vary, but the early larval period during the transition from endogenous to exogenous feeding remains a critical time. Næss et al. (1996) reported 69\% survival during the first 15 days after the initiation of feeding for halibut, with $20 \%$ of the mortality occurring between days 3 and 6 . Appelbaum (1985) reported survival rates between 20 and 90\% for sole larvae during the critical first-feeding stage. Eda et al. (1990), working with striped mullet, reported larval survival of $11.5 \pm 6.3 \%$ and $34.3 \pm 11.1 \%$ during two years of experiments.

Larval nutrition, and the development of an artificial feed for larvae is long term goal of research into the early larval stages of fish culture. We currently rely on the culture of live prey, rotifers and Artemia. Lubzens et al. (1989) reviewed the culture of rotifers and their suitability as first prey for larval marine fishes. Scott \& Baynes (1978) reported on the nutritional value of rotifers when they were cultured on different algae and at different temperatures. Leger et al. (1987) reviewed the use of Artemia in larval culture. The development of an artificial diet for larval culture is an active area of research. In reviews by Dabrowski (1986), Watanabe \& Kiron (1994) and Lavens et al. (1995) it was noted that this goal is still not at hand. 
An area of active research is the bacterial milieu of larval culture. Levin et al. (1972) reported that Vibrio anguillarum was isolated from winter flounder and found to be the cause of disease. Austin (1983) reported on the bacterial microflora found in a coastal fish farm and isolated 30 different bacteria, including Vibrio and Pseudomonas species. Tanasomwang \& Muroga (1988) investigated the intestinal flora of Japanese flounder larvae and found that the levels of bacteria decreased with the transition from live to artificial diets, with the two largest groups represented being Vibrio and Pseudomonas. Angulo et al. (1988) found that, of the bacteria associated with turbot culture tanks in Spain, Vibrio and Pseudomonas represented the largest percentage. Perez Benavente \& Gatesoupe (1988) found that when rotifers were disinfected before being presented to larval turbot, survival rates improved. Iida et al. (1989) found that a viral disease was responsible for mass mortality in Japanese flounder culture. They isolated it to the point they hypothesized that a herpes virus was responsible. Nicolas et al. (1989) examined the bacteria associated with the trophic chain of algae, rotifers and turbot larvae and concluded that Vibrio found in the guts of larval turbot were probably introduced by the rotifers. Kellam \& Walker (1989) studied the antibiotic activity associated with marine microalgae, and found that Tetraselmis suecica, a species that I use in my 
experiments, has antibacterial properties. Gatesoupe (1990) found that, by rinsing rotifers and offering them in pulses, rather than all at once, he reduced the bacteria associated with larval culture and improved survival and growth in turbot. Although he reported survival between 22 and $82 \%$, he did not report the number of repetitions or the parentage of the larval cultures. Toranzo et al. (1993) investigated the bacterial differences in three Spanish turbot farms. Their finding that all farms had high levels of Vibrio and Pseudomonas species led to their conclusion that good husbandry is the most cost effective way of controlling bacterial disease. Skjermo \& Vadstein (1993) investigated the bacterial levels associated with enrichment of rotifers. They found that the bacterial levels increased, and the species composition shifted, with addition of enrichment, then decreased and returned to the original composition with passage of time. Hernandez-Cruz et al. (1994) found that the addition of antibiotics, to the culture vessels or to the rotifers before feeding, did not significantly improve survival and growth of sea bream larvae. The authors also found that rotifers and larvae that were treated with antibiotics had lower Omega-3 HUFA levels than those that were not treated.

Since Qasim (1955) workers have investigated the possibility that algae is a contributor to early larval nutrition. Van der Meeren (1991) concluded that cod do 
indeed ingest algae, possibly through a filter feeding mechanism, although he did not test whether larvae fed algae had better survival rates than larvae without algae. Austin et al. (1992) tested the use of Tetraselmis suecica as an antibacterial preparation in the culture of fish, using various disease-causing bacteria from salmonid culture. They found that $T$. suecica did reduce bacteria numbers in culture tanks and, when used therapeutically, reduced mortalities in already infected fish. Naas et al. (1992) found that the use of green water led to increased feeding rates in halibut larvae cultures. Finding that both growth and survival were enhanced, the authors concluded that there was no indication that the larvae were feeding on the algae; the improvement was likely due to turbidity effects. Boehlert \& Morgan (1985) found that turbidity increased feeding in larval herring, a possible advantage in the addition of algae to the culture medium. The authors postulated that larvae might be able to pick out prey better with the additional contrast provided by algae. Reitan et al. (1993) looked at the nutritional effects of the addition of algae to larval turbot culture. They found that the culture of larvae together with rotifers and algae was better than just the enrichment of rotifers with algae prior to the addition of rotifers to the larval tanks. The authors concluded that two effects were at work: 1) that rotifer HUFA levels were maintained in the larval culture 
vessels when algae was maintained, an indirect nutritional effect. 2) that the larvae exhibited enhanced ingestion rates when algae was present, the possible effect of turbidity or microbial changes. Tamaru et al. (1994) found a paradox in the addition of algae to larval striped mullet culture: ammonia levels were increased in cultures with the addition of algae, but so were growth and survival, and no differences in $\mathrm{DO}, \mathrm{pH}$, or salinity existed between the two treatments. Stottrup et al. (1995) investigated 5 species of algae for their effects on larval turbot culture and found that growth and survival differed depending on the species of algae used. The use of Isochrysis led to increased within-treatment variation. 


\section{APPENDIX II}

\section{EXPERIMENTAL DATA}

EXPERIMENT 1, TRIAL 1.

Trial 1 was conducted from November 3-21, 1995. Four individual female $X$ male crosses were used, with 4 replicates per cross. They are referred to as A, B, C and D series.

"A" series eggs were from fish 402 (Female) crossed with fish 30 (Male). Spawned on Nov. 3 at $5: 30$ pm, 100\% of the eggs floated in seawater after fertilization. "B" series eggs were from fish 29 (Female) crossed with fish 30 (Male). Spawned on Nov. 6, no time recorded, $30 \%$ of the eggs floated.

"C" series eggs were from fish 20 (Female) crossed with fish 30 (Male). Spawned on Nov. 9, no time recorded, $80 \%$ of the eggs floated.

"D" series eggs were from fish 243 (Female) crossed with fish 30 (Male). Spawned on Nov. 9, no time recorded, $60 \%$ of these eggs floated.

Table 1. Results of trial 1 showing day after hatch, percent survival, percent of daily sampling with food in gut for the 13 replicates from 4 parental crosses. \%s for percent survival. $\%$ F for percent of daily sample which had 
food in gut. DAH for day after hatch. Same letter before replicate number signifies same parental cross. Replicate 1, cross 1, was unfed control.

Table 1.

\begin{tabular}{|c|c|c|c|c|c|c|c|c|c|c|c|c|}
\hline Rep & \multicolumn{2}{|c|}{$\mathrm{A} 1$} & \multicolumn{2}{|c|}{ A2 } & \multicolumn{2}{|c|}{ A3 } & \multicolumn{2}{|c|}{$\mathrm{A} 4$} & \multicolumn{2}{|c|}{ B5 } & \multicolumn{2}{|c|}{ B6 } \\
\hline$\overline{\mathrm{DAH}}$ & $\div \mathrm{S}$ & $\div \mathrm{F}$ & $\% S$ & $\% F$ & $\div S$ & $\% F$ & $\frac{\circ S}{\circ S}$ & $\% F$ & $\div 5$ & $\% \mathrm{~F}$ & $\div 5$ & $\div \mathrm{F}$ \\
\hline 3 & 100 & 0 & 100 & 0 & 100 & 0 & 100 & 0 & 20 & 0 & 96 & 0 \\
\hline 4 & 100 & 0 & 100 & 10 & 100 & 50 & 100 & 50 & 20 & 0 & 91 & 0 \\
\hline 5 & 84 & 0 & 98 & 60 & 84 & 90 & 96 & 60 & 0 & & 89 & 60 \\
\hline 6 & 78 & 0 & 97 & 90 & 82 & 80 & 95 & 90 & & & 87 & 80 \\
\hline 7 & 75 & 0 & 97 & 90 & 80 & 70 & 91 & 70 & & & 82 & 70 \\
\hline 8 & 71 & 0 & 95 & 50 & 74 & 86 & 88 & 86 & & & 72 & 70 \\
\hline 9 & 0 & & 88 & 40 & 0 & & 0 & & & & 26 & 80 \\
\hline 10 & & & 71 & 56 & & & & & & & 0 & \\
\hline
\end{tabular}

\begin{tabular}{|c|c|c|c|c|c|c|c|c|c|c|c|c|c|}
\hline Rep & B7 & & C8 & C9 & \multicolumn{2}{|c|}{$\mathrm{C} 10$} & \multicolumn{2}{|c|}{ D11 } & \multicolumn{3}{|c|}{ D12 } & \multicolumn{2}{|l|}{ D13 } \\
\hline$\overline{\mathrm{DAH}}$ & $\% S \%$ & & $\div S \div F$ & $\div S \div F$ & & $\% F$ & & $S \quad \% F$ & & $5 \%$ & & $\div S$ & $\frac{\circ}{\circ}$ \\
\hline 3 & 100 & 0 & 10010 & 100 & 0 & 100 & 0 & 100 & 0 & 100 & 0 & 100 & 0 \\
\hline & 97 & 0 & 98 & 99 & 10 & 95 & 80 & 94 & 90 & 95 & 60 & 98 & 80 \\
\hline & 94 & 40 & 96 & 95 & 90 & 93 & 50 & 93 & 80 & 93 & 100 & 95 & 80 \\
\hline & 93 & 70 & 96 & 95 & 80 & 92 & 20 & 92 & 90 & 88 & 50 & 92 & 70 \\
\hline & 91 & 80 & 91 & 92 & 40 & 88 & 10 & 91 & 50 & 87 & & 91 & 80 \\
\hline & 80 & 80 & 8130 & 91 & 0 & 73 & 40 & 90 & 80 & 81 & 30 & 90 & 80 \\
\hline 9 & 0 & & $\begin{array}{lll}70 & 3\end{array}$ & 88 & 30 & 68 & 36 & 84 & 90 & 78 & 60 & 88 & 70 \\
\hline 10 & & & 0 & 42 & 75 & 0 & & 77 & 93 & 12 & 60 & 80 & 73 \\
\hline
\end{tabular}

Table 2. Combined survival results from trial 1 showing day after hatch, range, mean, and standard deviation.

\begin{tabular}{lccc}
\hline $\mathrm{DAH}$ & Range & Mean & SD \\
3 & $20-100$ & 93 & 22 \\
4 & $20-100$ & 92 & 22 \\
5 & $0-98$ & 85 & 26 \\
6 & $0-97$ & 84 & 26 \\
7 & $0-97$ & 82 & 25 \\
8 & $0-95$ & 77 & 24 \\
9 & $0-88$ & 49 & 41 \\
10 & $0-80$ & 24 & 32 \\
\hline
\end{tabular}




\section{EXPERIMENT 1, TRIAL 2.}

The second trial in this series of experiments was conducted from February 6-19, 1996. This trial consisted of 7, designated A through G, individual female $x$ male crosses, with 4 replicates of each cross.

"A" series eggs were from fish number 475 (female) crossedwith fish number 464 (male), $11 \mathrm{~mL}$ of eggs were extruded, and $20 \%$ of these floated.

"B" series eggs were from fish number 461 (female) crossed with fish number 439 (male), $140 \mathrm{~mL}$ of eggs were extruded, $20 \%$ of these floated.

"C" series eggs were from fish number 457 (female) crossed with fish number 439 (male), $32 \mathrm{~mL}$ of eggs were extruded, $50 \%$ of these floated.

"D" series eggs were from fish number 480 (female) crossed with fish number 439 (male), $20 \mathrm{~mL}$ of eggs were produced, $95 \%$ of these floated.

"E" series eggs were from fish number 449 (female) crossed with fish number 439 (male, $20 \mathrm{~mL}$ of eggs were extruded, $10 \%$ of which floated.

"F" series eggs were from fish number 427 (female) crossed with fish number 406 (male), $70 \mathrm{~mL}$ of eggs were produced, percentage of floaters was not reported.

"G" series of eggs were from fish number 429 (female) crossed with fish number 406 (male), $72 \mathrm{~mL}$ of eggs were 
extruded, percentage of floating eggs was not reported.

Table 3. Results of trial 2 showing day after hatch, percent survival, percent of daily sampling with food in gut for the 28 replicates from 7 parental crosses. \%S for percent survival. $\% \mathrm{~F}$ for percent of daily sample which had food in gut. DAH for day after hatch. Same letter before replicate number signifies same parental cross. Replicates with number 1 indicate unfed controls.

Table 3 .

\begin{tabular}{|c|c|c|c|c|c|c|c|c|c|c|c|c|c|c|c|c|}
\hline \multirow{2}{*}{$\begin{array}{c}\text { Rep } \\
\text { DAH }\end{array}$} & & \multirow{2}{*}{$\begin{array}{c}A 1 \\
\% S \% F\end{array}$} & \multicolumn{3}{|c|}{ A2 } & \multicolumn{2}{|c|}{$\mathrm{A} 3$} & \multicolumn{2}{|c|}{ A4 } & \multicolumn{2}{|c|}{ B1 } & \multicolumn{3}{|c|}{ B2 } & \multicolumn{2}{|c|}{$\overline{B 3}$} \\
\hline & & & & $\% \mathrm{~S}$ & $\% \mathrm{~F}$ & $\div S$ & $\% \mathrm{~F}$ & $\div 5$ & $\% \mathrm{~F}$ & & $\div S \% F$ & & & $5 \mathrm{~F}$ & & $S \div F$ \\
\hline 3 & 100 & $\begin{array}{ll}0 & 0\end{array}$ & 100 & 05 & 50 & 100 & 00 & 10 & 50 & 100 & 000 & & 10030 & & 100 & 50 \\
\hline 4 & 86 & 60 & 84 & $4 \quad 4$ & 0 & 78 & 80 & 83 & 70 & 81 & 00 & & 2400 & & 47 & 10 \\
\hline 5 & 77 & $\begin{array}{ll}7 & 0\end{array}$ & 78 & 8 & 0 & 75 & 40 & 77 & 60 & 76 & 00 & & 0 & & 40 & 70 \\
\hline 6 & & 0 & 70 & 1 & .00 & 63 & 70 & 70 & 70 & 72 & 00 & & & & 31 & 100 \\
\hline 7 & & & 64 & 8 & 30 & 57 & 100 & 65 & 70 & 68 & 00 & & & & 7 & 0 \\
\hline 8 & & & 48 & 3 & 33 & 0 & & 60 & 80 & 63 & 00 & & & & 0 & \\
\hline 9 & & & & 0 & & & & 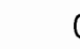 & & 56 & 00 & & & & & \\
\hline \multirow[t]{2}{*}{10} & & & & & & & & & & 0 & & & & & & \\
\hline & & B4 & & $\mathrm{Cl}$ & & $\mathrm{C2}$ & & $\mathrm{C} 3$ & & $\mathrm{C4}$ & & $\mathrm{D} 1$ & & D2 & & D3 \\
\hline$\overline{\mathrm{DAH}}$ & $\div S$ & $\div F$ & $\% S \div$ & $\div \mathrm{F}$ & $\div \mathrm{S}$ & $\div \mathrm{F}$ & $\div S$ & $\div F$ & $\frac{25}{6}$ & $S \div F$ & $\div \mathrm{S}$ & $S \div F$ & $\div S$ & $\div \mathrm{F}$ & $\% S$ & $\div \mathrm{F}$ \\
\hline 31 & 100 & 70 & 100 & 0 & 100 & 30 & 100 & 10 & 100 & 10 & 100 & 0 & 100 & 0 & 100 & 10 \\
\hline 4 & 72 & 60 & 97 & 0 & 53 & 50 & 45 & 30 & 54 & 0 & 98 & 0 & 0 & 0 & 69 & 30 \\
\hline 5 & 68 & 80 & 96 & 0 & 47 & 70 & 34 & 40 & 0 & & 97 & 0 & & & 65 & 100 \\
\hline 6 & 65 & 90 & 96 & 0 & 40 & 50 & 26 & 37 & & & 97 & 0 & & & 61 & 80 \\
\hline 7 & 60 & 100 & 94 & 0 & 30 & 50 & . 0 & & & & 97 & 0 & & & 55 & 90 \\
\hline 8 & 53 & 70 & 93 & 0 & 18 & 60 & & & & & 96 & 0 & & & 48 & 90 \\
\hline 9 & 6 & 67 & 92 & 0 & 0 & & & & & & 94 & 0 & & & 38 & 100 \\
\hline \multirow[b]{3}{*}{$\overline{\mathrm{DAH}}$} & 0 & & 37 & 0 & & & & & & & & 0 & & & 4 & 100 \\
\hline & $\overline{D 4}$ & & E1 & & E2 & & E3 & & $\mathrm{E} 4$ & & F1 & & F2 & & F3 & \\
\hline & $\% S^{\circ}$ & & $\% S \div F$ & & $\% S \div 5$ & & $\div S$ & $\div \mathrm{F}$ & $\div S$ & $\% \mathrm{~F}$ & $\div S$ & $\div \mathrm{F}$ & $\% S$ & $\% \mathrm{~F}$ & $\% 5$ & $\% F$ \\
\hline 31 & 100 & 0 & 100 & 0 & 100 & 0 & 100 & 0 & 100 & 0 & 100 & 0 & 100 & 0 & 100 & 20 \\
\hline 4 & 52 & 20 & 64 & 0 & 91 & 0 & 33 & 40 & 55 & 0 & 66 & 0 & 5 & 0 & 40 & 30 \\
\hline 5 & 45 & 90 & 54 & 0 & 33 & 60 & 23 & 0 & 50 & 45 & 62 & 0 & 0 & & 10 & 045 \\
\hline 6 & 37 & 100 & 43 & 0 & 23 & 100 & 2 & 0 & 11 & 0 & 56 & 0 & & & & 0 \\
\hline 7 & 3 & 0 & 34 & 0 & 5 & 50 & 0 & & 0 & & 50 & 0 & & & & \\
\hline 8 & 0 & & 23 & 0 & 0 & 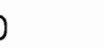 & & & & & 38 & 0 & & & & \\
\hline 9 & & & & 0 & & & & & & & 0 & & & & & \\
\hline 10 & & & & 0 & & & & & & & & & & & & \\
\hline
\end{tabular}


Table 3 cont.

\begin{tabular}{|c|c|c|c|c|c|c|c|c|c|}
\hline & F4 & & 31 & & 32 & & 3 & & 74 \\
\hline$\overline{\mathrm{DAH}}$ & $\% S \div F$ & $\% \bar{S}$ & $\div \mathrm{F}$ & $\div S$ & $\div \mathrm{F}$ & $\div S$ & $\% F$ & $\div S$ & $\% F$ \\
\hline 3 & 100 & 100 & 0 & 100 & 70 & 100 & 40 & 100 & 70 \\
\hline 4 & 0 & 55 & 0 & 84 & 90 & 76 & 10 & 67 & 71 \\
\hline 5 & & 46 & 0 & 82 & 100 & 73 & 100 & 8 & 0 \\
\hline 6 & & 40 & 0 & 80 & 100 & 70 & 100 & 0 & \\
\hline 7 & & 31 & 0 & 77 & 80 & 15 & 90 & & \\
\hline 8 & & 8 & 0 & 73 & 90 & 0 & & & \\
\hline 9 & & 0 & & 68 & 90 & & & & \\
\hline 10 & & & & 60 & 94 & & & & \\
\hline
\end{tabular}

Table 4. Combined survival results from trial 2 showing day after hatch, range, mean, and standard deviation.

\begin{tabular}{lccc}
\hline DAH & Range & Mean & SD \\
3 & $100-100$ & 100 & 0 \\
4 & $0-98$ & 59 & 27 \\
5 & $0-97$ & 47 & 32 \\
6 & $0-97$ & 38 & 33 \\
7 & $0-97$ & 29 & 33 \\
8 & $0-96$ & 22 & 31 \\
9 & $0-94$ & 13 & 29 \\
10 & $0-60$ & 4 & 13
\end{tabular}

EXPERIMENT 2, TRIAL 1.

The second experiment, first trial, in this series was run from May 18 through June 2, 1996. This first of the "green water" experiments was conducted using one individual female $\mathrm{x}$ male cross, with 5 replicates of each treatment. The female in this cross, which did not have a tag (tags are lost occasionally) was crossed with fish number 430 (male), $114 \mathrm{~mL}$ of eggs were extruded at 10 am on May 16, $50 \%$ of which floated. 
Table 5. Combined survival results from experiment 2, trial 1 showing day after hatch, range, mean, and standard deviation of the fed replicates. The unfed controls are not included.

\begin{tabular}{llll}
\hline DAH & Range & Mean & SD \\
3 & $91-100$ & 99 & 2 \\
4 & $87-100$ & 98 & 3 \\
5 & $49-100$ & 92 & 15 \\
6 & $45-99$ & 91 & 17 \\
7 & $34-98$ & 85 & 18 \\
8 & $27-98$ & 83 & 21 \\
9 & $19-98$ & 80 & 24 \\
10 & $0-98$ & 75 & 30 \\
11 & $0-97$ & 73 & 30 \\
12 & $0-95$ & 69 & 31 \\
13 & $0-94$ & 61 & 35 \\
14 & $0-92$ & 48 & 37 \\
\hline
\end{tabular}

Table 6. Results of clear control (no algae, unfed) treatment experiment 2 , trial 1 showing day after hatch, percent survival, percent of daily sampling with food in gut for the 28 replicates from 7 parental crosses. \%s for percent survival. $\%$ f for percent of daily sample which had food in gut. DAH for day after hatch.

Table 6 . Clear Controls

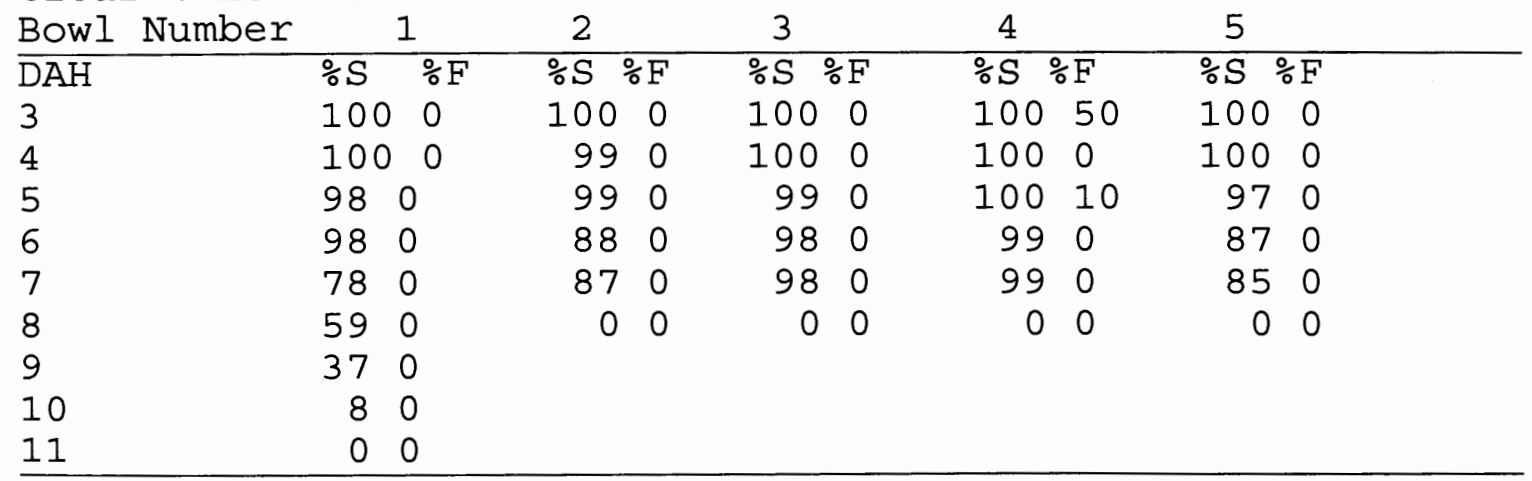


Table 7. Results of clear control (no algae, unfed) treatment experiment 2 , trial 1 showing day after hatch, percent survival, percent of daily sampling with food in gut for the 28 replicates from 7 parental crosses. $\% S$ for percent survival. $\%$ f for percent of daily sample which had food in gut. DAH for day after hatch.

Table 7 .

Green Controls Bowl number 1

\begin{tabular}{|c|c|c|c|c|c|c|c|}
\hline Bowl & number & 1 & & 2 & & 3 & 5 \\
\hline$\overline{\mathrm{DAH}}$ & $\because S$ & $\% \mathrm{~F}$ & $\frac{\partial}{\partial S}$ & $\frac{}{\circ} F$ & $\because \mathrm{S}$ & $\div \mathrm{F}$ & $\div S \div F$ \\
\hline 3 & 100 & 0 & 100 & 10 & 100 & 20 & See note 1 \\
\hline 4 & 100 & 10 & 100 & 20 & 100 & 0 & \\
\hline 5 & 100 & 0 & 100 & 30 & 100 & 0 & \\
\hline 6 & 100 & 0 & 100 & 0 & 99 & 0 & \\
\hline 7 & 100 & 0 & 94 & 60 & 99 & 0 & \\
\hline 8 & 0 & 0 & 81 & 0 & 0 & 0 & \\
\hline 9 & & & 56 & 25 & & & \\
\hline 10 & & & 0 & 0 & & & \\
\hline
\end{tabular}
rotifers added to them. Once rotifers were introduced to controls with green water, it became impossible to remove $100 \%$ of them.

Table 8. Results of rinsed clear (no algae, fed rinsed rotifers) treatment experiment 2 , trial 1 showing day after hatch, percent survival, percent of daily sampling with food in gut for the 28 replicates from 7 parental crosses. \%S for percent survival. $\%$ for percent of daily sample which had food in gut. DAH for day after hatch. 
Table 8

Rinsed clear

Bowl number

\begin{tabular}{|c|c|c|c|c|c|c|c|c|c|c|}
\hline Bowl & number & 1 & & 2 & 3 & & 4 & & 5 & \\
\hline$\overline{\mathrm{DAH}}$ & $\div S$ & $\% \mathrm{~F}$ & $\div S$ & $\% \mathrm{~F}$ & $\div S$ & $F$ & $\div S$ & $5 \mathrm{~F}$ & $\% \mathrm{~S}$ & 5 \\
\hline 3 & 100 & 0 & 91 & 20 & 100 & 40 & 100 & 50 & 98 & 50 \\
\hline 4 & 100 & 70 & 87 & 50 & 100 & 60 & 100 & 50 & 98 & 100 \\
\hline 5 & 100 & 70 & 82 & 80 & 98 & 80 & 99 & 50 & 95 & 70 \\
\hline 6 & 99 & 0 & 75 & 20 & 94 & 10 & 99 & 40 & 91 & 40 \\
\hline 7 & 94 & 80 & 67 & 40 & 76 & 70 & 96 & 70 & 87 & 60 \\
\hline 8 & 88 & 80 & 57 & 80 & 72 & 90 & 96 & 90 & 86 & 100 \\
\hline 9 & 83 & 70 & 44 & 80 & 68 & 100 & 96 & 70 & 83 & 90 \\
\hline 10 & 81 & 80 & 38 & 50 & 62 & 80 & 94 & 70 & 81 & 40 \\
\hline 11 & 79 & 70 & 29 & 70 & 57 & 60 & 93 & 70 & 79 & 70 \\
\hline 12 & 75 & 90 & 15 & 86 & 47 & 80 & 92 & 100 & 73 & 80 \\
\hline 13 & 70 & 100 & 0 & & 36 & 80 & 0 & & 68 & 100 \\
\hline 14 & 62 & 100 & & & 20 & 100 & & & 60 & 95 \\
\hline
\end{tabular}

Table 9. Results of rinsed green (algae added, fed rinsed rotifers) treatment experiment 2, trial 1 showing day after hatch, percent survival, percent of daily sampling with food in gut for the 28 replicates from 7 parental crosses. \%s for percent survival. $\%$ F for percent of daily sample which had food in gut. DAH for day after hatch.

Table 9 .

Rinsed Green

Bowl Number 1

\begin{tabular}{|c|c|c|c|c|c|c|c|c|c|}
\hline$\overline{\mathrm{DAH}}$ & $\div \mathrm{S}$ & $\div \mathrm{F}$ & $\div S \div F$ & $\frac{\circ 5}{\circ S}$ & $\div \mathrm{F}$ & $\div \mathrm{S}$ & $\frac{2}{5 F}$ & $\div \mathrm{OS}$ & $\% \mathrm{~F}$ \\
\hline 3 & 99 & 70 & Note 1 & 99 & 50 & 100 & 70 & 98 & 70 \\
\hline 4 & 98 & 100 & & 98 & 90 & 100 & 100 & 98 & 90 \\
\hline 5 & 51 & 80 & & 98 & 70 & 99 & 90 & 97 & 80 \\
\hline 6 & 47 & 100 & & 98 & 100 & 99 & 80 & 97 & 90 \\
\hline 7 & 42 & 100 & & 96 & 90 & 98 & 80 & 96 & 90 \\
\hline 8 & 36 & 100 & & 93 & 80 & 98 & 90 & 96 & 90 \\
\hline 9 & 27 & 100 & & 92 & 100 & 98 & 100 & 96 & 100 \\
\hline 10 & 0 & & & 91 & 90 & 96 & 100 & 95 & 100 \\
\hline 11 & & & & 90 & 100 & 96 & 100 & 94 & 100 \\
\hline 12 & & & & 88 & 100 & 95 & 100 & 93 & 100 \\
\hline 13 & & & & 86 & 100 & 94 & 90 & 92 & 90 \\
\hline 14 & & & & 82 & 100 & 92 & 100 & 90 & 100 \\
\hline
\end{tabular}


Note 1. Bowl 2 of the rinsed green treatment was discarded when a miscount occurred, the end result being too many larvae were stocked in this bowl.

Table 10. Results of not rinsed clear (no algae added, fed unrinsed rotifers) treatment experiment 2, trial 1 showing day after hatch, percent survival, percent of daily sampling with food in gut for the 28 replicates from 7 parental crosses. $\frac{\circ}{S}$ for percent survival. $\%$ F for percent of daily sample which had food in gut. DAH for day after hatch.

Table 10.

Not Rinsed Clear

\begin{tabular}{|c|c|c|c|c|c|c|c|c|c|}
\hline Bowl & Number 1 & & 2 & & 3 & & & & \\
\hline$\overline{\mathrm{DAH}}$ & $\div S \% F$ & $\div S$ & $\div \mathrm{F}$ & $\div \mathrm{S}$ & $\div \mathrm{F}$ & $\% \mathrm{~S}$ & $5 \mathrm{~F}$ & $\% \mathrm{~S}$ & $F$ \\
\hline 3 & 9930 & 99 & 20 & 99 & 0 & 99 & 0 & 100 & 0 \\
\hline 4 & 9960 & 98 & 80 & 99 & 90 & 99 & 60 & 99 & 70 \\
\hline 5 & 9890 & 96 & 100 & 99 & 80 & 98 & 100 & 98 & 90 \\
\hline 6 & 9740 & 96 & 90 & 99 & 80 & 98 & 70 & 97 & 70 \\
\hline 7 & 9080 & 89 & 80 & 91 & 90 & 94 & 90 & 93 & 70 \\
\hline 8 & 8970 & 88 & 80 & 85 & 80 & 93 & 100 & 92 & 90 \\
\hline 9 & $88 \quad 80$ & 87 & 80 & 79 & 100 & 91 & 100 & 91 & 80 \\
\hline 10 & $84 \quad 60$ & 84 & 60 & 76 & 90 & 89 & 80 & 90 & 70 \\
\hline 11 & 80100 & 81 & 70 & 73 & 100 & 87 & 100 & 89 & 100 \\
\hline 12 & $75 \quad 70$ & 75 & 90 & 68 & 70 & 85 & 100 & 87 & 100 \\
\hline 13 & 6460 & 70 & 100 & 62 & 90 & 82 & 80 & 84 & 100 \\
\hline 14 & $\begin{array}{ll}55 \quad 72 \\
\end{array}$ & 0 & & 52 & 100 & 78 & 88 & 80 & 100 \\
\hline
\end{tabular}

Table 11. Results of not rinsed green (algae added, fed unrinsed rotifers) treatment experiment 2, trial 1 showing day after hatch, percent survival, percent of daily sampling 
with food in gut for the 28 replicates from 7 parental crosses. $\% S$ for percent survival. $\%$ F for percent of daily sample which had food in gut. DAH for day after hatch.

Table 11.

Not Rinsed Green

\begin{tabular}{|c|c|c|c|c|c|c|c|c|c|c|}
\hline Bowl & number & 1 & & 2 & & 3 & & 4 & & 5 \\
\hline$\overline{\mathrm{DAH}}$ & $\div S$ & $\div \mathrm{F}$ & $\div \mathrm{S}$ & $\% F$ & $\% \mathrm{~S}$ & $\% \mathrm{~F}$ & $\div S$ & $\% \mathrm{~F}$ & $\% S$ & $\% F$ \\
\hline 3 & 100 & 0 & 100 & 20 & 99 & 60 & 99 & 40 & 99 & 50 \\
\hline 4 & 100 & 100 & 100 & 90 & 99 & 90 & 99 & 100 & 99 & 80 \\
\hline 5 & 99 & 80 & 95 & 90 & 98 & 60 & 99 & 100 & 49 & 80 \\
\hline 6 & 99 & 90 & 94 & 100 & 98 & 70 & 99 & 90 & 45 & 100 \\
\hline 7 & 98 & 100 & 93 & 90 & 91 & 90 & 98 & 100 & 34 & 100 \\
\hline 8 & 98 & 90 & 90 & 80 & 89 & 90 & 98 & 70 & 27 & 100 \\
\hline 9 & 98 & 100 & 89 & 100 & 88 & 100 & 98 & 100 & 19 & 100 \\
\hline 10 & 98 & 100 & 88 & 100 & 86 & 100 & 98 & 100 & 0 & \\
\hline 11 & 97 & 70 & 86 & 90 & 84 & 90 & 97 & 90 & & \\
\hline 12 & 95 & 100 & 83 & 100 & 82 & 100 & 93 & 100 & & \\
\hline 13 & 94 & 80 & 80 & 90 & 78 & 100 & 92 & 80 & & \\
\hline 14 & 92 & 100 & 75 & 100 & 72 & 100 & 0 & & & \\
\hline
\end{tabular}

EXPERIMENT 2, TRIAL 2 .

Experiment 2, trial 2 was conducted between October 2, 1996 and October 22, 1996. This experiment was the largest of the two year series, using 3 parental crosses, 4 treatments with 5 repetitions of each treatment for a total of 60 bowls.

"1" series of eggs were from fish number 123 (female) crossed with fish number 270 (male). The spawning took place on $10 / 7 / 96$. 
"2" series of eggs were from fish number 373 (female)

crossed with fish number 270 (male). These fish were spawned on $10 / 5 / 96$.

"3" series of eggs were from fish number 29 (female) crossed with fish number 270 (male). Spawning took place on 10/2/96, at 9:30 am, $16 \mathrm{mls}$ of eggs were extruded and $100 \%$ of these floated.

Table 12. Results of cross 1 fed green (algae added, fed rinsed rotifers) treatment experiment 2, trial 2 showing day after hatch, percent survival, percent of daily sampling with food in gut. $\% S$ for percent survival. $\% F$ for percent of daily sample which had food in gut. DAH for day after hatch.

Table 12 .

Cross \#1, Experiment 2, trial 2, Fed with algae added.

\begin{tabular}{|c|c|c|c|c|c|c|c|c|}
\hline Bowl & number & 1 & 2 & 3 & & 4 & & 5 \\
\hline$\overline{\mathrm{DAH}}$ & $\div S$ & $\% \mathrm{~F}$ & $\div S \div F$ & $\div \mathrm{S}$ & $\div \mathrm{F}$ & $\div S$ & $\because F$ & $\div S \div F$ \\
\hline 3 & 100 & 80 & $100 \quad 20$ & 100 & 50 & 99 & 60 & 10090 \\
\hline 4 & 100 & 50 & $90 \quad 20$ & 99 & 50. & 99 & 40 & 10090 \\
\hline 5 & 100 & 50 & 110 & 79 & 100 & 64 & 20 & $47 \quad 50$ \\
\hline 6 & 94 & 80 & 0 & 25 & 60 & 24 & 80 & 34 \\
\hline 7 & 82 & 100 & & 15 & 33 & 17 & 100 & 2490 \\
\hline 8 & 80 & 90 & & 0 & & 0 & & 0 \\
\hline 9 & 76 & 100 & & & & & & \\
\hline 10 & 72 & 90 & & & & & & \\
\hline 11 & 13 & 100 & & & & & & \\
\hline 12 & 0 & & & & & & & \\
\hline
\end{tabular}


Table 13. Results of cross 1 fed no green (algae not added, fed rinsed rotifers) treatment experiment 2, trial 2 showing day after hatch, percent survival, percent of daily sampling with food in gut. \%S for percent survival. $\% F$ for percent of daily sample which had food in gut. DAH for day after hatch.

Table 13

Cross \#1, experiment 2, trial 2, fed, no algae.

\begin{tabular}{|c|c|c|c|c|c|c|c|c|c|c|}
\hline Bowl & Number & 1 & & 2 & & 3 & & 4 & & 5 \\
\hline$\overline{\mathrm{DAH}}$ & $\div S$ & $\% \mathrm{~F}$ & $\div \mathrm{S}$ & $\% \mathrm{~F}$ & $\div 5$ & $\% F$ & $\div S$ & $\% F$ & $\div S$ & $\% \mathrm{~F}$ \\
\hline 3 & 98 & 30 & 99 & 10 & 100 & 20 & 100 & 60 & 100 & 60 \\
\hline 4 & 97 & 40 & 99 & 70 & 100 & 0 & 100 & 40 & 100 & 50 \\
\hline 5 & 91 & 30 & 98 & 60 & 68 & 0 & 85 & 60 & 100 & 40 \\
\hline 6 & 68 & 80 & 68 & 70 & 13 & 0 & 58 & 60 & 72 & 80 \\
\hline 7 & 53 & 80 & 54 & 80 & 0 & & 27 & 60 & 63 & 80 \\
\hline 8 & 46 & 100 & 24 & 90 & & & 18 & 0 & 46 & 80 \\
\hline 9 & 40 & 80 & 12 & 80 & & & 0 & & 30 & 100 \\
\hline 10 & 32 & 100 & 0 & & & & & & 21 & 100 \\
\hline 11 & 0 & & & & & & & & 0 & \\
\hline
\end{tabular}

Table 14. Results of cross 1 unfed green (algae added, unfed) treatment experiment 2, trial 2 showing day after hatch, percent survival, percent of daily sampling with food in gut. $\% S$ for percent survival. $\% F$ for percent of daily sample which had food in gut. DAH for day after hatch.

Table 14

Cross \#1, experiment 2, trial 2, control algae.

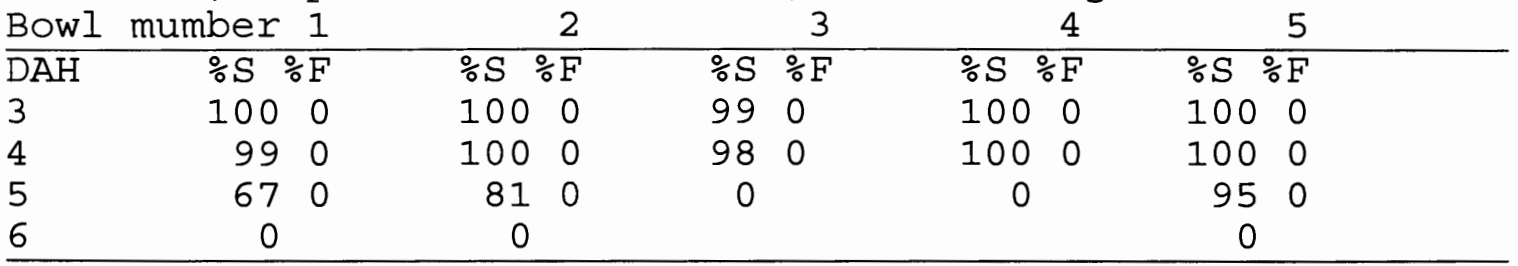


Table 15. Results of cross 1 unfed clear (no algae added, unfed) treatment experiment 2, trial 2 showing day after hatch, percent survival, percent of daily sampling with food in gut. \%S for percent survival. \%F for percent of daily sample which had food in gut. DAH for day after hatch.

Table 15

Cross \#1, experiment 2, trial 2, control no algae.

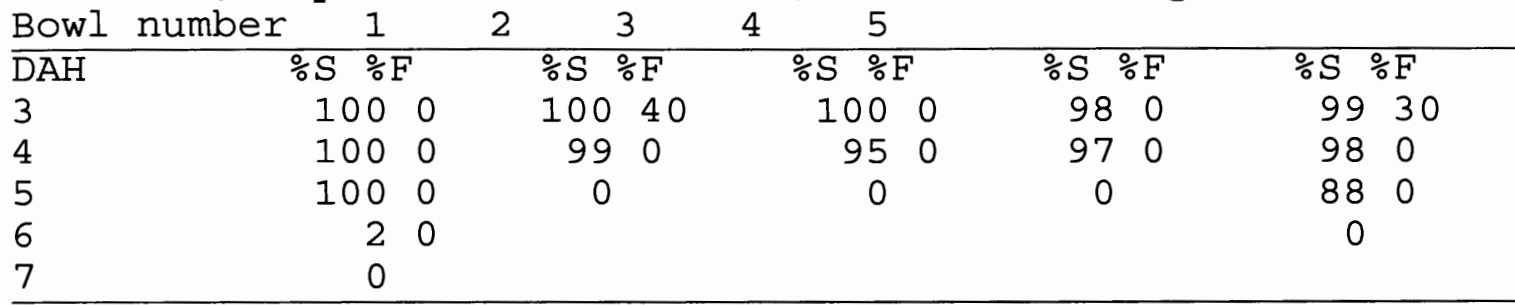

Table 16. Results of cross 2 fed green (algae added, fed rinsed rotifers) treatment experiment 2, trial 2 showing day after hatch, percent survival, percent of daily sampling with food in gut. \%S for percent survival. $\% F$ for percent of daily sample which had food in gut. DAH for day after hatch.

Table 16.

Cross \#2, experiment 2, trial 2, Fed green.

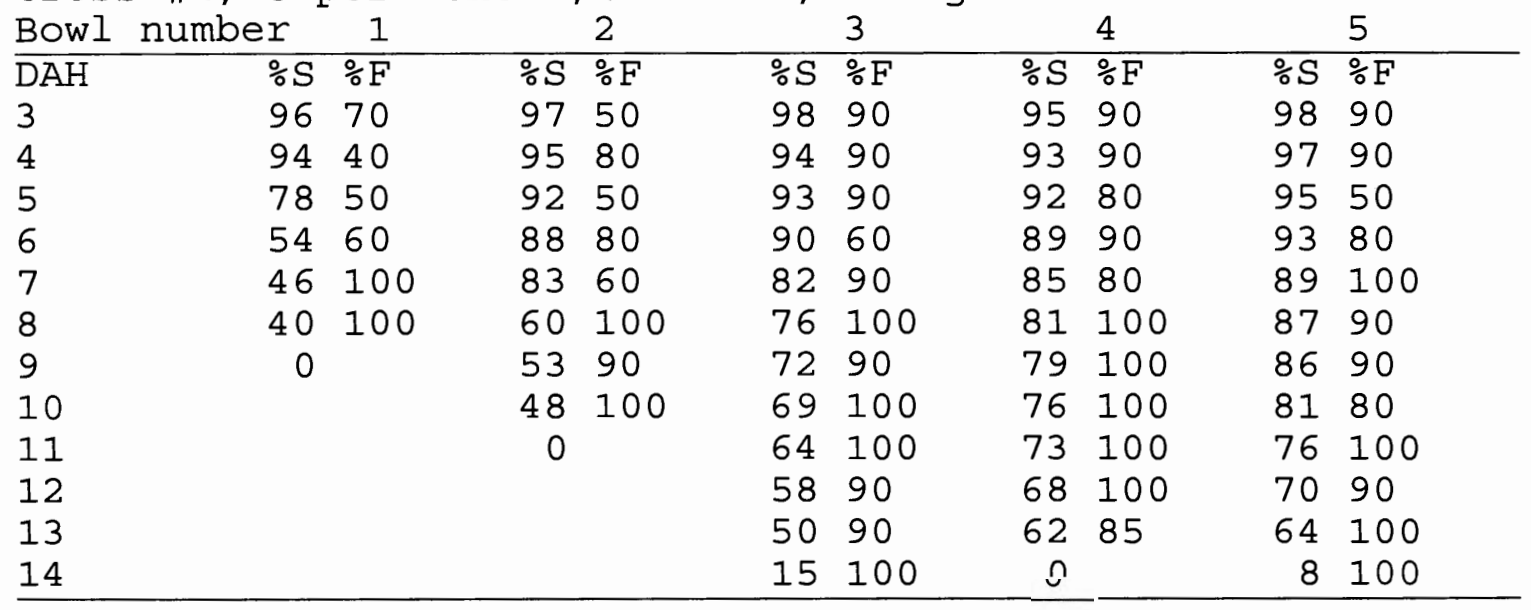


Table 17. Results of cross 2 fed clear (no algae added, fed rinsed rotifers) treatment experiment 2, trial 2 showing day after hatch, percent survival, percent of daily sampling with food in gut. \%S for percent survival. $\%$ for percent of daily sample which had food in gut. DAH for day after hatch

Table 17 .

Cross \#2, experiment 2, trial 2, fed-clear.

\begin{tabular}{|c|c|c|c|c|c|c|c|c|c|c|c|}
\hline Bowl & Number & 1 & & 2 & & & & & & \multicolumn{2}{|c|}{5} \\
\hline$\overline{\mathrm{DAH}}$ & & $\div S$ & $\div F$ & $\div S$ & $\% F$ & $\div S$ & $\div \mathrm{F}$ & $\div S$ & $\div F$ & $\div S$ & $\div \mathrm{F}$ \\
\hline 3 & & 98 & 70 & 99 & 60 & 100 & 60 & 99 & 10 & 99 & 20 \\
\hline 4 & & 96 & 70 & 99 & 20 & 99 & 50 & 98 & 0 & 99 & 60 \\
\hline 5 & & 89 & 40 & 98 & 50 & 95 & 40 & 94 & 20 & 94 & 60 \\
\hline 6 & & 78 & 70 & 88 & 60 & 92 & 70 & 88 & 10 & 72 & 50 \\
\hline 7 & & 40 & 70 & 75 & 80 & 50 & 60 & 87 & 100 & 51 & 100 \\
\hline 8 & & 31 & 90 & 70 & 75 & 32 & 70 & 0 & & 38 & 80 \\
\hline 9 & & 24 & 80 & 0 & & 23 & 33 & & & 30 & 70 \\
\hline 10 & & 14 & 100 & & & & 0 & & & 19 & 100 \\
\hline 11 & & 0 & & & & & & & & & 0 \\
\hline
\end{tabular}

Table 18. Results of cross 2 clear control (no algae added, unfed) treatment experiment 2, trial 2 showing day after hatch, percent survival, percent of daily sampling with food in gut. \%S for percent survival. $\% F$ for percent of daily sample which had food in gut. DAH for day after hatch.

Table 18

Cross 2, experiment 2, trial 2, clear control.

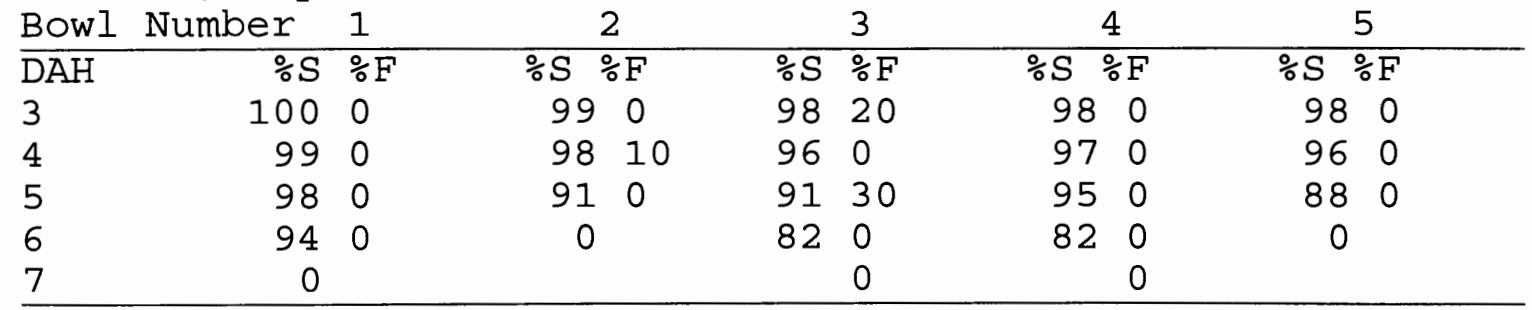


Table 19. Results of cross 2 green control (algae added, unfed) treatment experiment 2, trial 2 showing day after hatch, percent survival, percent of daily sampling with food in gut. $\% S$ for percent survival. $\% F$ for percent of daily sample which had food in gut. DAH for day after hatch.

Table 19.

Cross 2, experiment 2, trial 2, green control. Bowl number

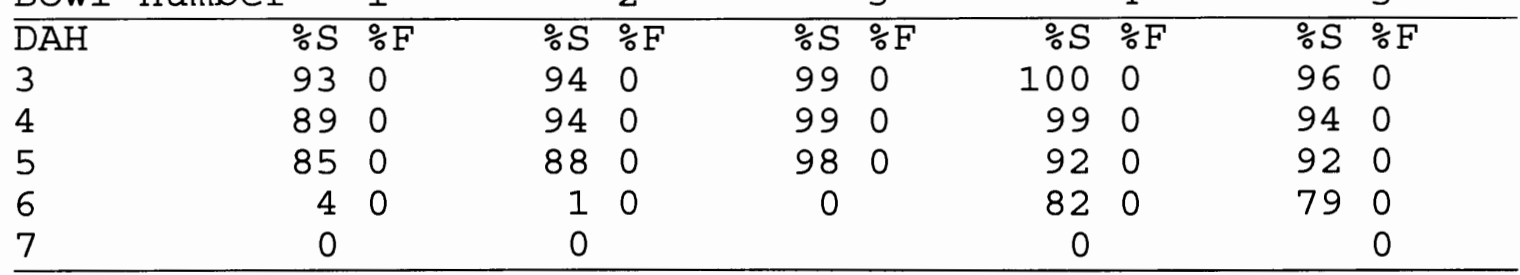

Table 20. Results of cross 3 fed green (algae added, fed rinsed rotifers) treatment experiment 2 , trial 2 showing day after hatch, percent survival, percent of daily sampling with food in gut. \%S for percent survival. $\% \mathrm{~F}$ for percent of daily sample which had food in gut. DAH for day after hatch.

Table 20 .

Cross 3, experiment 2, trial 2, fed-green.

\begin{tabular}{|c|c|c|c|c|c|c|c|c|c|c|}
\hline Bowl & number & 1 & & 2 . & & 3 & & 4 & & 5 \\
\hline$\overline{\mathrm{DAH}}$ & $\div S$ & $\div \mathrm{F}$ & $\div S$ & $\% \mathrm{~F}$ & $\div \mathrm{S}$ & $\% \mathrm{~F}$ & $\% \mathrm{~S}$ & $\% F$ & $\div S$ & $\% F$ \\
\hline 3 & 100 & 80 & 100 & 60 & 99 & 40 & 94 & 60 & 100 & 10 \\
\hline 4 & 99 & 60 & 100 & 100 & 98 & 80 & 93 & 60 & 100 & 20 \\
\hline 5 & 98 & 60 & 100 & 100 & 96 & 40 & 92 & 100 & 98 & 80 \\
\hline 6 & 87 & 10 & 95 & 80 & 87 & 60 & 68 & 80 & 87 & 20 \\
\hline 7 & 84 & 40 & 89 & 60 & 70 & 100 & 61 & 100 & 81 & 60 \\
\hline 8 & 77 & 80 & 83 & 80 & 75 & 100 & 54 & 80 & 65 & 80 \\
\hline 9 & 75 & 80 & 81 & 80 & 73 & 80 & 47 & 60 & 61 & 100 \\
\hline 10 & 73 & 100 & 80 & 100 & 69 & 100 & 42 & 100 & 58 & 80 \\
\hline 11 & 70 & 100 & 78 & 100 & 65 & 100 & 37 & 80 & 54 & 80 \\
\hline 12 & 67 & 100 & 76 & 100 & 61 & 80 & 31 & 80 & 49 & 75 \\
\hline 13 & & 0 & 73 & 100 & 57 & 100 & 23 & 80 & & 0 \\
\hline 14 & & & & 0 & 51 & 100 & 23 & 100 & & \\
\hline
\end{tabular}


Table 21. Results of cross 3 fed clear (no algae added, fed rinsed rotifers) treatment experiment 2 , trial 2 showing day after hatch, percent survival, percent of daily sampling with food in gut. \%S for percent survival. $\% F$ for percent of daily sample which had food in gut. DAH for day after hatch.

Table 21 .

Cross 3, experiment 2, trial 2, fed clear.

\begin{tabular}{|c|c|c|c|c|c|c|c|c|c|c|}
\hline Bowl & number & 1 & & 2 & & 3 & & 4 & & 5 \\
\hline$\overline{\mathrm{DAH}}$ & $\div \mathrm{S}$ & $\div \mathrm{F}$ & $\div S$ & $\% \mathrm{~F}$ & $\div 5$ & $\div \mathrm{F}$ & $\because 5$ & $\div F$ & $\div S$ & $\div F$ \\
\hline 3 & 100 & 40 & 99 & 0 & 100 & 40 & 99 & 20 & 100 & 10 \\
\hline 4 & 100 & 20 & 99 & 60 & 99 & 40 & 99 & 20 & 99 & 20 \\
\hline 5 & 98 & 60 & 98 & 60 & 94 & 60 & 95 & 40 & 98 & 40 \\
\hline 6 & 62 & 60 & 84 & 80 & 38 & 20 & 47 & 40 & 38 & 60 \\
\hline 7 & 50 & 40 & 74 & 80 & 27 & 40 & 38 & 40 & 28 & 40 \\
\hline 8 & 38 & 100 & 72 & 60 & 20 & 0 & 32 & 0 & 22 & 33 \\
\hline 9 & 31 & 60 & 70 & 80 & 9 & 33 & 0 & & 0 & \\
\hline 10 & 25 & 100 & 66 & 100 & 0 & & & & & \\
\hline 11 & 17 & 100 & 63 & 100 & & & & & & \\
\hline 12 & 0 & & 59 & 60 & & & & & & \\
\hline 13 & & & 43 & 60 & & & & & & \\
\hline 14 & & & 36 & 100 & & & & & & \\
\hline
\end{tabular}

Table 22. Results of cross 3 green control (algae added, unfed) treatment experiment 2 , trial 2 showing day after hatch, percent survival, percent of daily sampling with food in gut. $\%$ f for percent. survival. $\% F$ for percent of daily sample which had food in gut. DAH for day after hatch.

Table 22 .

Cross 3, experiment 2, trial 2, green control.

\begin{tabular}{|c|c|c|c|c|c|c|c|c|c|c|}
\hline Bowl & Number & 1 & & 2 & & 3 & & 4 & & 5 \\
\hline$\overline{\mathrm{DAH}}$ & $\div S$ & $\% \mathrm{~F}$ & $\% \mathrm{~S}$ & $\div \mathrm{F}$ & $\div S$ & $\div F$ & $\div S$ & $\% \mathrm{~F}$ & $\div S$ & $\div \mathrm{F}$ \\
\hline 3 & 100 & 0 & 99 & 0 & 99 & 0 & 100 & 0 & 100 & 0 \\
\hline 4 & 99 & 20 & 99 & 0 & 98 & 20 & 98 & 0 & 99 & 0 \\
\hline 5 & 81 & 0 & 98 & 0 & 70 & 0 & 88 & 0 & 88 & 0 \\
\hline 6 & 16 & 0 & 44 & 0 & 12 & 0 & 22 & 0 & 28 & 0 \\
\hline 7 & 0 & & 0 & & 0 & & 0 & & & 0 \\
\hline
\end{tabular}


Table 23. Results of cross 3 clear control (no algae added, unfed) treatment experiment 2, trial 2 showing day after hatch, percent survival, percent of daily sampling with food in gut. $\% S$ for percent survival. $\% F$ for percent of daily sample which had food in gut. DAH for day after hatch.

Table 23.

Cross 3, experiment 2, trial 2, clear control.

\begin{tabular}{|c|c|c|c|c|c|c|c|c|c|c|}
\hline Bowl & number & 1 & & 2 & & 3 & & 4 & & 5 \\
\hline$\overline{\mathrm{DAH}}$ & $\div S$ & $\div F$ & $\div \mathrm{S}$ & $\div \mathrm{F}$ & $\div \mathrm{S}$ & $\div \mathrm{F}$ & $\div \mathrm{S}$ & $\div \mathrm{F}$ & $\div S$ & $\div \mathrm{F}$ \\
\hline 3 & 99 & 0 & 98 & 0 & 99 & 0 & 99 & 0 & 100 & 0 \\
\hline 4 & 98 & 0 & 97 & 0 & 98 & 0 & 94 & 0 & 100 & 0 \\
\hline 5 & 90 & 0 & 82 & 0 & 88 & 0 & 80 & 0 & 87 & 0 \\
\hline 6 & 44 & 0 & 32 & 0 & 5 & 0 & 6 & 0 & 26 & 0 \\
\hline 7 & 0 & & 0 & & 0 & & 0 & & 0 & \\
\hline
\end{tabular}

\section{EXPERIMENT 3.}

This final trial of the series was conducted from February 25 to March 18, 1997. The parental cross was fish number 109 (female) crossed with fish number 108 (male). Spawning was on February 25, 1997, 84 Ml of eggs were expressed, of which $100 \%$ were floating after fertilization. Numbers of CFU reported here was obtained by applying three

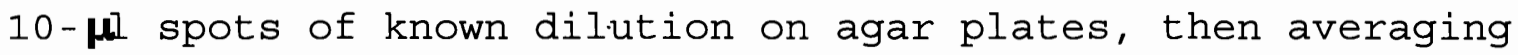
the numbers obtained. Plating of culture water was done every other day beginning on 0 DAH. In this experiment food in gut was not quantified. Disolved oxygen (DO) levels were measured and mortalities were counted and removed twice daily (just after lights came on in the morning and just before they went off in the evening). Measurement of Do did not commence untill 4 DAH due to problems with the meter. 
Ammonia (measured as ppm NH3-N), nitrite (measured as ppm NO2-N) and $\mathrm{pH}$ were measured every other day beginning on 1 DAH. Unfed replicate number 1 was discarded when it inadvertently became contaminated with rotifers.

Table 24. Shows results for fed replicate number 1 in experiment 3. DAH = Days After Hatch. To make these tables easier to read, exponential notation 10x was left out, e.g., $1.5-5$ equals $1.5 \times 10-5$. TCBS is thiosulfate-citrate-bile salts-sucrose agar which selects for Vibrio spp. No entry for any particular day under the agars indicates that there were no CFU for that days sample. Mortality on 0 DAH equals hatch mortality, mortalities 0-2 DAH was recorded once daily in the morning.

Table 24

Fed replicate number 1

Mortality Marine Agar TCBS Agar Ammonia Nitrite DO ppm $\mathrm{DAH} \quad \mathrm{AM}$

$\mathrm{PM}$ $\mathrm{CFU}$

CFU

ppm

ppm

AM PM

\begin{tabular}{|c|c|c|c|c|c|c|c|c|c|c|}
\hline 0 & 74 & & 1.6 & -5 & & & & & & \\
\hline 1 & 19 & & & & & & $<0.2$ & & & \\
\hline 2 & 0 & & 1.1 & -4 & 3.3 & -2 & & & & \\
\hline 3 & 5 & 0 & & & & & $<0.2$ & & & \\
\hline 4 & 0 & 0 & 1.5 & -6 & 3.3 & -2 & & & 6.0 & 5.5 \\
\hline 5 & 0 & 1 & & & & & 0.3 & $<0.05$ & 5.5 & 6.5 \\
\hline 6 & 3 & 1 & 3.2 & -5 & & & & & 5.0 & 6.5 \\
\hline 7 & 0 & 0 & & & & & 0.6 & $<0.05$ & 5.5 & 5.5 \\
\hline 8 & 0 & 1 & 3.2 & -5 & & & & & 5.0 & 6.0 \\
\hline 9 & 1 & 0 & & & & & 1.0 & $<0.05$ & 5.5 & 5.5 \\
\hline 10 & 0 & 0 & 2.3 & -4 & & & & & 5.5 & 6.0 \\
\hline 11 & 0 & 0 & & & & & 0.8 & $<0.05$ & 5.5 & 5.0 \\
\hline 12 & 0 & 0 & 2.8 & -4 & & & & & 5.0 & 5.5 \\
\hline 13 & 0 & 0 & & & & & 0.8 & 0.3 & 5.5 & 5.5 \\
\hline 14 & 0 & 0 & 6.3 & -3 & & & & & 6.0 & \\
\hline
\end{tabular}


Table 25. Shows results for fed replicate number 2 in experiment 3. DAH = Days After Hatch. To make these tables easier to read, exponential notation $10 x$ was left out, e.g., 1.5 -5 equals $1.5 \times 10-5$. TCBS is thiosulfate-citrate-bile salts-sucrose agar which selects for Vibrio spp. No entry for any particular day under the agars indicates that there were no CFU for that days sample. Mortality on 0 DAH equals hatch mortality, mortalities 0-2 DAH was recorded once daily in the morning.

Table 25

Fed replicate number 2

Mortality Marine Agar TCBS Agar Ammonia Nitrite DO ppm

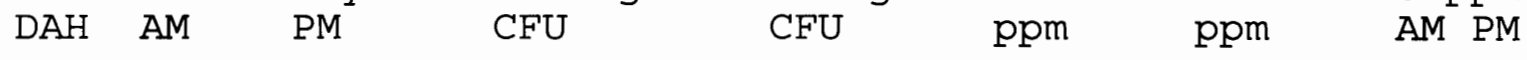

\begin{tabular}{|c|c|c|c|c|c|c|c|c|c|c|}
\hline 0 & 38 & & 2.6 & -5 & 3.3 & -5 & & & & \\
\hline 1 & 2 & & & & & & $<0.2$ & & & \\
\hline 2 & 0 & & 1.2 & -4 & 1.0 & -3 & & & & \\
\hline 3 & 2 & 0 & & & & & $<0.2$ & & & \\
\hline 4 & 1 & 0 & 7.0 & -5 & & & & & 5.8 & 5.0 \\
\hline 5 & 1 & 0 & & & & & 0.5 & $<0.05$ & 5.0 & 6.0 \\
\hline 6 & 0 & 0 & 6.0 & -5 & & & & & 5.0 & 6.0 \\
\hline 7 & 0 & 0 & & & & & 0.6 & $<0.05$ & 5.5 & 5.5 \\
\hline 8 & 1 & 0 & 1.5 & -5 & & & & & 4.5 & 5.5 \\
\hline 9 & 0 & 1 & & & & & 2.0 & $<0.05$ & 5.0 & 5.5 \\
\hline 10 & 0 & 0 & 7.0 & -3 & & & & & 5.0 & 5.0 \\
\hline 11 & 0 & 0 & & & & & 0.8 & $<0.05$ & 5.5 & 5.5 \\
\hline 12 & 0 & 0 & 1.2 & -2 & & & & & 5.0 & 5.0 \\
\hline 13 & 0 & 0 & & & & & 0.8 & 0.3 & 5.5 & 5.5 \\
\hline 14 & 0 & & 1.2 & -2 & & & & & 6.0 & \\
\hline
\end{tabular}


Table 26. Shows results for fed replicate number 3 in experiment 3. DAH = Days After Hatch. To make these tables easier to read, exponential notation 10x was left out, e.g., $1.5-5$ equals $1.5 \times 10-5$. TCBS is thiosulfate-citrate-bile salts-sucrose agar which selects for Vibrio spp. No entry for any particular day under the agars indicates that there were no CFU for that days sample. Mortality on 0 DAH equals hatch mortality, mortalities 0-2 DAH was recorded once daily in the morning.

Table 26

Fed replicate number 3

Mortality Marine Agar TCBS Agar Ammonia Nitrite DO ppm DAH AM PM CFU

CFU ppm ppm

AM PM

\begin{tabular}{|c|c|c|c|c|c|c|c|c|c|c|}
\hline 0 & 42 & & 1.6 & -5 & & & & & & \\
\hline 1 & 9 & & & & & & $<0.2$ & & & \\
\hline 2 & 1 & & 8.3 & -3 & & & & & & \\
\hline 3 & 2 & 0 & & & & & $<0.2$ & & & \\
\hline 4 & 1 & 0 & 1.5 & -6 & & & & & 6.0 & 5.5 \\
\hline 5 & 0 & 0 & & & & & 0.4 & $<0.05$ & 5.5 & 6.0 \\
\hline 6 & 1 & 1 & 5.1 & -5 & 3.3 & -4 & & & 5.5 & 6.0 \\
\hline 7 & 0 & 0 & & & & & 0.6 & $<0.05$ & 5.5 & 5.5 \\
\hline 8 & 0 & 1 & 5.6 & -3 & 3.0 & -2 & & & 5.5 & 5.5 \\
\hline 9 & 0 & 0 & & & & & 1.0 & $<0.05$ & 5.0 & 5.0 \\
\hline 10 & 1 & 0 & 1.2 & -2 & & & & & 5.5 & 5.5 \\
\hline 11 & 0 & 0 & & & & & 0.8 & $<0.05$ & 5.5 & 5.5 \\
\hline 12 & 0 & 0 & 1.5 & -2 & & & & & 5.0 & 5.5 \\
\hline 13 & 0 & 0 & & & & & 0.8 & 0.3 & 4.5 & 5.5 \\
\hline 14 & 0 & & 2.5 & -2 & & & & & 6.0 & \\
\hline
\end{tabular}


Table 27. Shows results for fed replicate number 4 in experiment 3. Larvae in this replicate wwere all dead on 12 DAH. DAH = Days After Hatch. To make these tables easier to read, exponential notation $10 x$ was left out, e.g., $1.5-5$ equals $1.5 \times 10-5$. TCBS is thiosulfate-citrate-bile saltssucrose agar which selects for Vibrio spp. No entry for any particular day under the agars indicates that there were no CFU for that days sample. Mortality on 0 DAH equals hatch mortality, mortalities 0-2 DAH was recorded once daily in the morning.

Table 27

Fed replicate number 4 Mortality Marine Agar TCBS Agar Ammonia Nitrite Do ppm

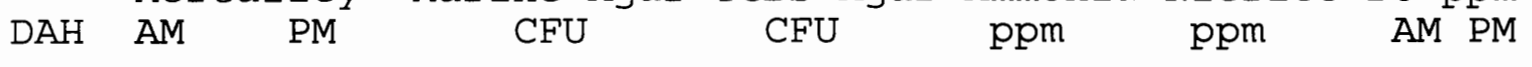

\begin{tabular}{|c|c|c|c|c|c|c|c|c|c|}
\hline 0 & 19 & & 1.4 & -5 & & & & & \\
\hline 1 & 8 & & & & & $<0.2$ & & & \\
\hline 2 & 8 & & 1.3 & -4 & & & & & \\
\hline 3 & 3 & 0 & & & & $<0.2$ & & & \\
\hline 4 & 1 & 0 & 6.0 & -3 & & & & 6.0 & 5.8 \\
\hline 5 & 0 & 1 & & & & 0.4 & $<0.05$ & 5.0 & 6.0 \\
\hline 6 & 0 & 0 & 4.7 & -4 & & & & 5.0 & 6.0 \\
\hline 7 & 0 & 0 & & & & 0.6 & $<0.05$ & 5.5 & 6.0 \\
\hline 8 & 3 & 0 & 5.6 & -3 & $3 \cdot 3-4$ & & & 5.0 & 5.5 \\
\hline 9 & 9 & 7 & & & & 1.0 & $<0.05$ & 5.5 & 5.5 \\
\hline 10 & 3 & 2 & 4.6 & -4 & & & & 5.0 & 5.5 \\
\hline 11 & 1 & 0 & & & & 0.8 & $<0.05$ & 5.5 & 5.5 \\
\hline 12 & 4 & 0 & 1.5 & -3 & & & & 5.5 & \\
\hline 13 & & & & & & & & & \\
\hline 14 & & & & & & & & & \\
\hline
\end{tabular}


Table 28. Shows results for fed replicate number 5 in experiment 3. DAH = Days After Hatch. To make these tables easier to read, exponential notation $10 \mathrm{x}$ was left out, e.g., 1.5 -5 equals $1.5 \times 10-5$. TCBS is thiosulfate-citrate-bile salts-sucrose agar which selects for vibrio spp. No entry for any particular day under the agars indicates that there were no CFU for that days sample. Mortality on 0 DAH equals hatch mortality, mortalities 0-2 DAH was recorded once daily in the morning.

Table 28

Fed replicate number 5

Mortality Marine Agar TCBS Agar Ammonia Nitrite DO ppm $\begin{array}{llllllll}D A H & \mathrm{AM} & \mathrm{PM} & \mathrm{CFU} & \mathrm{CFU} & \mathrm{ppm} & \mathrm{ppm} & \mathrm{AM}\end{array}$

\begin{tabular}{|c|c|c|c|c|c|c|c|c|}
\hline 0 & 26 & & 7.0 & -4 & $3.0-5$ & & & \\
\hline 1 & 14 & & & & & $<0.2$ & & \\
\hline 2 & 10 & & 2.5 & -2 & & & & \\
\hline 3 & 7 & 1 & & & & $<0.2$ & & \\
\hline 4 & 3 & 0 & 1.3 & -4 & & & & 6.05 .0 \\
\hline 5 & 0 & 2 & & & & 0.6 & $<0.05$ & $5.5 \quad 6.0$ \\
\hline 6 & 0 & 1 & 2.1 & -3 & & & & $5.5 \quad 5.5$ \\
\hline 7 & 0 & 0 & & & & 0.6 & $<0.05$ & 5.56 .0 \\
\hline 8 & 1 & 0 & 3.0 & -3 & & & & 5.56 .0 \\
\hline 9 & 1 & 1 & & & & 3.0 & $<0.05$ & $5.5 \quad 5.5$ \\
\hline 10 & 2 & 0 & 1.2 & -2 & & & & $5.5 \quad 5.5$ \\
\hline 11 & 0 & 0 & & & & 0.8 & $<0.05$ & $5.5 \quad 5.5$ \\
\hline 12 & 0 & 0 & 1.5 & -2 & & & & 5.55 .5 \\
\hline 13 & 0 & 0 & & & & 0.8 & 0.3 & 5.05 .5 \\
\hline 14 & 0 & & 2.4 & -2 & & & & 6.0 \\
\hline
\end{tabular}


Table 29. Shows results for unfed replicate number 2 in experiment 3. DAH = Days After Hatch. To make these tables easier to read, exponential notation 10x was left out, e.g., $1.5-5$ equals $1.5 \times 10-5$. TCBS is thiosulfate-citrate-bile salts-sucrose agar which selects for Vibrio spp. No entry for any particular day under the agars indicates that there were no CFU for that days sample. Mortality on 0 DAH equals hatch mortality, mortalities 0-2 DAH was recorded once daily in the morning.

Table 29

Unfed replicate number 2 Mortality DAH AM PM Marine Agar TCBS Agar Ammonia Nitrite DO ppm

\begin{tabular}{|c|c|c|c|c|c|c|c|}
\hline DAR & $A M$ & $F[1$ & Cro & $C F O$ & ppili & ppm & $A \sqrt{1}$ \\
\hline 0 & 28 & & $1.2-3$ & $3.0-5$ & & & \\
\hline 1 & 9 & & & & $<0.2$ & & \\
\hline 2 & 0 & & $1.2-2$ & $3.0-4$ & & & \\
\hline 3 & 2 & 0 & & & $<0.2$ & & \\
\hline 4 & 0 & 0 & $2.5-2$ & $3.0-4$ & & & 6.06 .0 \\
\hline 5 & 1 & 3 & & & $<0.2$ & & 5.06 .5 \\
\hline 6 & 0 & 2 & $4.8-2$ & & & & $5.5 \quad 7.5$ \\
\hline 7 & 1 & 4 & & & $<0.2$ & & $5.5 \quad 6.5$ \\
\hline 8 & 6 & 5 & $2.2-2$ & & & & 5.56 .0 \\
\hline 9 & 24 & 11 & & & 3.0 & $<0.05$ & 5.05 .5 \\
\hline 10 & 5 & & $2.9-2$ & & & & 5.5 \\
\hline
\end{tabular}

Table 30. Shows results for unfed replicate number 3 in experiment 3. DAH = Days After Hatch. To make these tables easier to read, exponential notation 10x was left out, e.g., $1.5-5$ equals $1.5 \times 10-5$. TCBS is thiosulfate-citrate-bile salts-sucrose agar which selects for Vibrio spp. No entry 
for any particular day under the agars indicates that there were no CFU for that days sample. Mortality on 0 DAH equals hatch mortality, mortalities 0-2 DAH was recorded once daily in the morning.

Table 30.

Unfed replicate number 3

Mortality Marine Agar TCBS Agar Ammonia Nitrite DO ppm

$\begin{array}{llllllll}D A H & A M & P M & C F U & C F U & \text { ppm } & \text { ppm } & \text { AM PM }\end{array}$

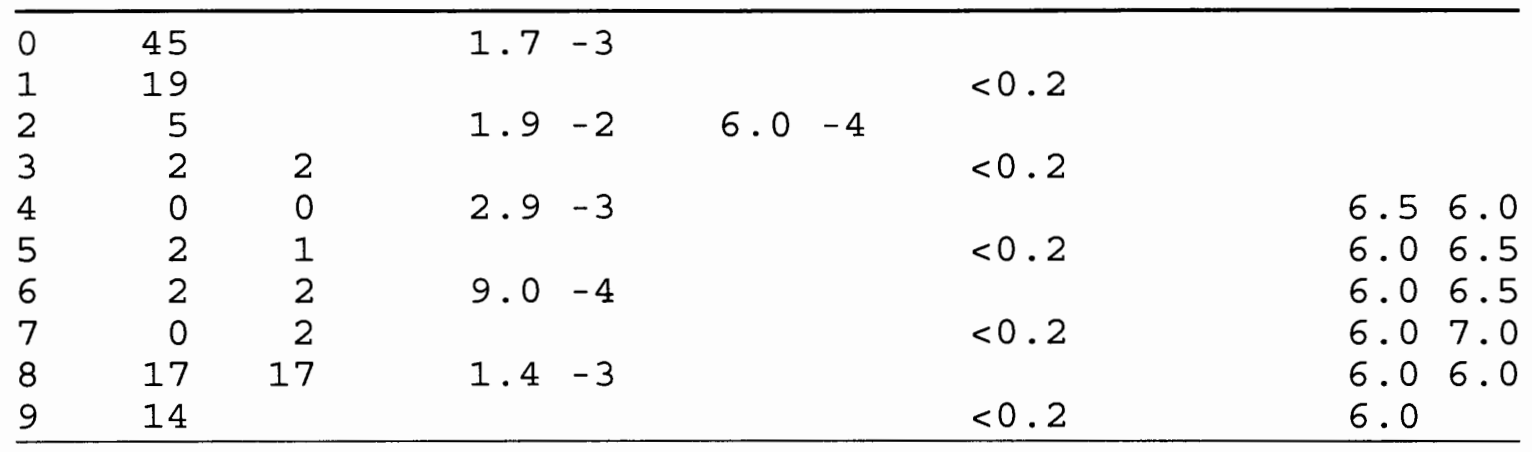

Table 31. Shows results for unfed replicate number 4 in experiment 3. DAH = Days After Hatch. To make these tables easier to read, exponential notation $10 x$ was left out, e.g., $1.5-5$ equals $1.5 \times 10-5$. TCBS is thiosulfate-citrate-bile salts-sucrose agar which selects for Vibrio spp. No entry for any particular day under the agars indicates that there were no CFU for that days sample. Mortality on 0 DAH equals hatch mortality, mortalities 0-2 DAH was recorded once daily in the morning. 
Table 31.

Unfed replicate number 4

Mortality Marine Agar TCBS Agar Ammonia Nitrite DO ppm

\begin{tabular}{|c|c|c|c|c|c|c|c|c|c|c|}
\hline $\mathrm{DAH}$ & $A M$ & $P M$ & $\mathrm{CF}$ & & CF & PU & ppm & ppm & & $1 \mathrm{PM}$ \\
\hline 0 & 27 & & 2.0 & -3 & 3.0 & -5 & & & & \\
\hline 1 & 14 & & & & & & $<0.2$ & & & \\
\hline 2 & 0 & & 8.0 & -3 & 3.0 & -4 & & & & \\
\hline 3 & 2 & 0 & & & & & $<0.2$ & & & \\
\hline 4 & 0 & 0 & 6.0 & -3 & 3.0 & -4 & & & 6.0 & 6.5 \\
\hline 5 & 1 & 0 & & & & & $<0.2$ & & 6.0 & 7.5 \\
\hline 6 & 0 & 0 & 5.9 & -2 & & & & & 6.0 & 7.0 \\
\hline 7 & 0 & 6 & & & & & $<0.2$ & & 5.5 & 7.0 \\
\hline 8 & 1 & 12 & 3.3 & -2 & & & & & 5.5 & 6.5 \\
\hline 9 & 35 & 3 & & & & & $<0.2$ & & 5.5 & 6.0 \\
\hline 10 & 4 & & 4.5 & -2 & & & & & 6.0 & \\
\hline
\end{tabular}

Table 32. Shows results for unfed replicate number 5 in experiment 3. $\mathrm{DAH}=$ Days After Hatch. To make these tables easier to read, exponential notation $10 x$ was left out, e.g., 1.5-5 equals $1.5 \times 10-5$. TCBS is thiosulfate-citrate-bile salts-sucrose agar which selects for vibrio spp. No entry for any particular day under the agars indicates that there were no CFU for that days sample. Mortality on 0 DAH equals hatch mortality, mortalities $0-2$ DAH was recorded once daily in the morning. 
Table 32 .

Unfed replicate number 5

Mortality Marine Agar TCBS Agar Ammonia Nitrite Do ppm

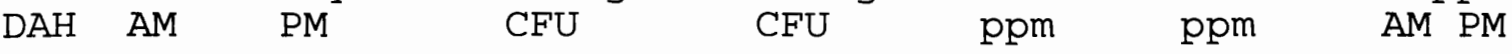

\begin{tabular}{|c|c|c|c|c|c|c|c|c|c|}
\hline 0 & 31 & & 1.0 & -3 & & & & & \\
\hline 1 & 6 & & & & & & $<0.2$ & & \\
\hline 2 & 3 & & 1.2 & -2 & 1.0 & -3 & & & \\
\hline 3 & 4 & 0 & & & & & $<0.2$ & & \\
\hline 4 & 0 & 3 & 1.6 & -3 & & & & 6.0 & 6.5 \\
\hline 5 & 0 & 0 & & & & & $<0.2$ & 5.5 & 7.0 \\
\hline 6 & 0 & 3 & 2.9 & -2 & & & & 6.0 & 6.0 \\
\hline 7 & 0 & 0 & & & & & $<0.2$ & 5.5 & 7.0 \\
\hline 8 & 6 & 8 & 5.8 & -2 & & & & 5.5 & 6.5 \\
\hline 9 & 32 & 3 & & & & & $<0.2$ & 5.5 & 6.0 \\
\hline 10 & 3 & & 6.9 & -2 & & & & 6.0 & \\
\hline
\end{tabular}

Table 33. Shows results for bacterial testing of rotifer and alga cultures, and negative control in experiment 3 . $\mathrm{DAH}=$ Days After Hatch. To make these tables easier to read, exponential notation $10 x$ was left out, e.g., $1.5-5$ equals 1.5 5 10-5. TCBS is thiosulfate-citrate-bile salts-sucrose agar which selects for Vibrio spp. No entry for any particular day under the agars indicates that there were no CFU for that days sample..

Table 33 .

Background and introduced bacteria

\begin{tabular}{|c|c|c|c|c|c|c|c|c|}
\hline & Rotife & $r$ cult & are & & Algae & culture & Blank & \\
\hline $\mathrm{DAH}$ & Marine & agar & TCBS & & Marine & agar & Marine & agar \\
\hline 0 & 2.0 & -5 & & & & & 5.3 & -3 \\
\hline 2 & 5.6 & -3 & 1.3 & -3 & 3.2 & -2 & 2.1 & -3 \\
\hline 4 & 3.9 & -2 & 5.6 & -3 & 1.1 & -4 & 4.6 & -4 \\
\hline 6 & 1.0 & -2 & 2.6 & -3 & 3.0 & -3 & 3.1 & -2 \\
\hline 8 & 3.1 & -2 & 1.3 & -3 & 4.6 & -2 & 2.5 & -2 \\
\hline 10 & 6.3 & -4 & 3.0 & -3 & 3.7 & -4 & 7.3 & -3 \\
\hline 12 & 2.5 & -2 & 2.0 & -3 & 3.7 & -2 & 7.0 & -3 \\
\hline 14 & 7.6 & -3 & & & 3.5 & -2 & 1.1 & -2 \\
\hline
\end{tabular}




\section{APPENDIX III \\ STATISTICAL FORMULAS TABLES AND GRAPHS}

Omega squared:

$$
\dot{\omega}^{2}=\frac{S S_{A}-(a-1) M S_{S / i}}{S S_{\text {TotaI }}+M S_{S / A}}
$$

The general linear model for the ANOVA:

$$
Y_{i j k}=\mu_{t}+\boldsymbol{\alpha}_{i}+\boldsymbol{\beta}_{j}+(\boldsymbol{\alpha} \boldsymbol{\beta})_{i j}+\boldsymbol{\epsilon}_{i j k}
$$

Coefficient of Variation:

$$
C V=\frac{S D}{M e a n} X 100
$$

Experiment 1, trial 1, ANOVA of cross on survival at $10 \mathrm{DAH}$, without controls included.

\begin{tabular}{lrlrcc} 
Source & SS & DF & MS & F-Ratio & P \\
\hline Cross & 4108.67 & 3 & 1369.56 & 1.38 & 0.317 \\
Error & 7940.00 & 8 & 992.50 & & \\
Total & 12048.67 & 11 & & & \\
\hline
\end{tabular}

Experiment 1, trial 1, regression of average of food in gut during daily sampling on days when larvae were alive, on survival at $10 \mathrm{DAH}$, controls not included.

$Y=-11.420+0.833 X \cdot r^{2}=0.24$.

ANOVA

\begin{tabular}{lrrrcc} 
Source & \multicolumn{1}{c}{ SS } & DF & MS & F-Ratio & P \\
\hline Regression & 2853.50 & 1 & 2853.5 & 3.103 & 0.109 \\
Residual & 9195.18 & 10 & 919.52 & & \\
Total & 12048.67 & 11 & & & \\
\end{tabular}


Experiment 1, trial 2, ANOVA of cross on survival at $10 \mathrm{DAH}$, without controls included.

\begin{tabular}{lccccc} 
Source & SS & DF & MS & F-Ratio & P \\
\hline Cross & 1010.29 & 6 & 168.38 & 0.978 & 0.48 \\
Error & 2410.67 & 14 & 172.19 & & \\
Total & 3420.95 & 20 & & & \\
\hline
\end{tabular}

Experiment 1, trial 2, regression of average of food in gut during daily sampling on days when larvae were alive, on survival at $10 \mathrm{DAH}$, controls not included.

$Y=-3.56+0.108 X \cdot r^{2}=0.14$.

ANOVA

\begin{tabular}{lrcccc} 
Source & \multicolumn{1}{c}{ SS } & DF & MS & F-Ratio & P \\
\hline Regression & 476.07 & 1 & 476.07 & 3.07 & 0.10 \\
Residual & 2944.88 & 19 & 154.99 & & \\
Total & 3420.95 & 20 & & & \\
\hline
\end{tabular}

Experiment 2, trial 1, ANOVA of algae and rinse on survival without controls at $10 \mathrm{DAH}$.

\begin{tabular}{lccrcc} 
Source & SS & DF & MS & F-Ratio & P \\
\hline Algae & 150.22 & 1 & 150.22 & 0.14 & 0.71 \\
Rinsed & 336.01 & 1 & 336.01 & 0.32 & 0.58 \\
Interaction & 115.31 & 1 & 115.31 & 0.11 & 0.74 \\
Error & 15631.00 & 15 & 1042.07 & & \\
Total & 16232.542 & 18 & & & \\
\hline
\end{tabular}

Experiment 2, trial 1, ANOVA of algae and rinse on survival without controls at $14 \mathrm{DAH}$.

\begin{tabular}{lrrrrr} 
Source & \multicolumn{1}{c}{ SS } & DF & \multicolumn{1}{c}{ MS } & F-Ratio & P \\
\hline Algae & 1235.01 & 1 & 1235.01 & 0.85 & 0.37 \\
Rinsed & 48.19 & 1 & 48.19 & 0.03 & 0.86 \\
Interaction & 2155.11 & 1 & 2155.11 & 1.49 & 0.24 \\
Error & 21692.00 & 15 & 1446.13 & & \\
Total & 25130.31 & 18 & & & \\
\hline
\end{tabular}


Experiment 2, trial 1, clear water treatments regression of average food in gut of daily sample (when survival was greater than zero) and survival at $10 \mathrm{DAH}$.

$Y=-23.07+1.40 X . r^{2}=0.39$.

ANOVA

\begin{tabular}{lrlccc} 
Source & SS & DF & MS & F-Ratio & P \\
\hline Regression & 955.73 & 1 & 955.73 & 5.05 & 0.06 \\
Residual & 1515.18 & 8 & 189.40 & & \\
Total & 2470.90 & 9 & & & \\
\hline
\end{tabular}

Experiment 2, trial 1, green water treatments regression of average food in gut of daily sample (when survival was greater than zero) and survival at $10 \mathrm{DAH}$.

$Y=374.08+-3.40 X . r^{2}=0.05$.

ANOVA

\begin{tabular}{lrlrcc} 
Source & \multicolumn{1}{c}{ SS } & DF & MS & F-Ratio & P \\
\hline Regression & 702.19 & 1 & 702.19 & 0.38 & 0.56 \\
Residual & 12934.03 & 7 & 1847.72 & & \\
Total & 13636.22 & 8 & & & \\
\hline
\end{tabular}

Experiment 2, trial 2, ANOVA of algae and rinse on survival without controls at $10 \mathrm{DAH}$.

\begin{tabular}{lrlrrc} 
Source & SS & DF & MS & F-Ratio & P \\
\hline Cross & 4243.47 & 2 & 2121.73 & 3.642 & 0.04 \\
Algae & 8036.03 & 1 & 8036.03 & 13.79 & 0.00 \\
Interaction & 3144.27 & 2 & 1572.13 & 2.70 & 0.09 \\
Error & 13982.40 & 24 & 582.60 & & \\
Total & 29406.17 & 29 & & & \\
\hline
\end{tabular}

Experiment 2, trial 2, ANOVA of algae and rinse on survival without controls at $14 \mathrm{DAH}$.

\begin{tabular}{lrrrrc} 
Source & \multicolumn{1}{c}{ SS } & DF & \multicolumn{1}{c}{ MS } & F-Ratio & P \\
\hline Cross & 673.27 & 2 & 336.63 & 2.48 & 0.10 \\
Algae & 124.03 & 1 & 124.03 & 0.92 & 0.35 \\
Interaction & 73.27 & 2 & 36.63 & 0.27 & 0.77 \\
Error & 3254.80 & 24 & 135.62 & & \\
Total & 4125.37 & & & & \\
\hline
\end{tabular}


Experiment 2, trial 2, clear water treatments regression of average food in gut of daily sample (when survival was greater than zero) and survival at $10 \mathrm{DAH}$.

$Y=-14.30+0.51 X . r^{2}=0.33$.

\section{ANOVA}

Source

Regression 1624.80

Residual

3289.60

DF

MS

F-Ratio

$\frac{P}{0.03}$

Total

$4914.40 \quad 14$

Experiment 2, trial 2, green water treatments regression of average food in gut of daily sample (when survival was greater than zero) and survival at $10 \mathrm{DAH}$.

$Y=-38.86+1.15 X \cdot r^{2}=0.44$

\section{ANOVA}

Source

Regression

Residual

Total

$$
\text { SS }
$$

9236.66

16455.73

DF

13

14
253.05 6.42 
Green water treatments (algae added) all experiments, regression analysis of percentage of good eggs at time of fertilization on survival at $10 \mathrm{DAH}$.

$\mathrm{Y}=0.71+-0.002 \mathrm{X} \cdot r^{2}=0.02$.

ANOVA

Source

Regression

Residual

Total

\begin{tabular}{lllll}
\multicolumn{1}{c}{ SS } & DF & \multicolumn{1}{c}{ MS } & F-Ratio & P \\
\hline 0.004 & 1 & 0.004 & 0.05 & 0.84 \\
0.26 & 3 & 0.09 & & \\
0.27 & & & &
\end{tabular}


Figure 1. Experiment 1 trials 1 (upper graph) \& 2 (lower graph). Average food in gut during daily sampling (when survival was greater than zero) on the $\mathrm{X}$ axis, survival percentage at $10 \mathrm{DAH}$ on the $\mathrm{Y}$ axis. 


\section{Experiment 1, Trial 1}

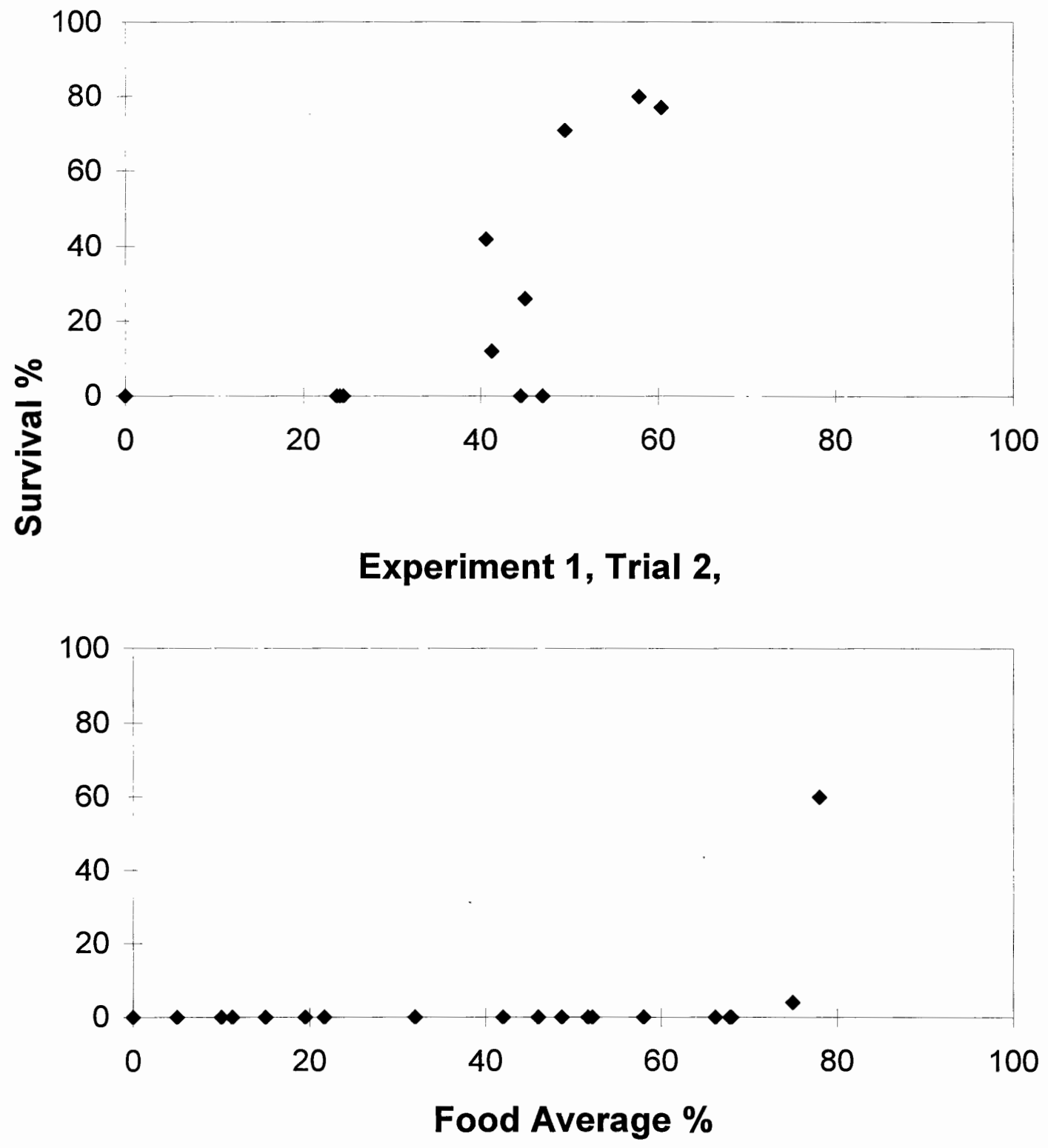

Figure 1 
Figure 2. Experiment 2 trial 1, clear water treatments (upper graph) and green water treatments (lower graph). Average food in gut during daily sampling (when survival was greater than zero) on the $\mathrm{X}$ axis, survival percentage at 10 $\mathrm{DAH}$ on the $\mathrm{Y}$ axis. 


\section{Experiment 2, Trial 1,}

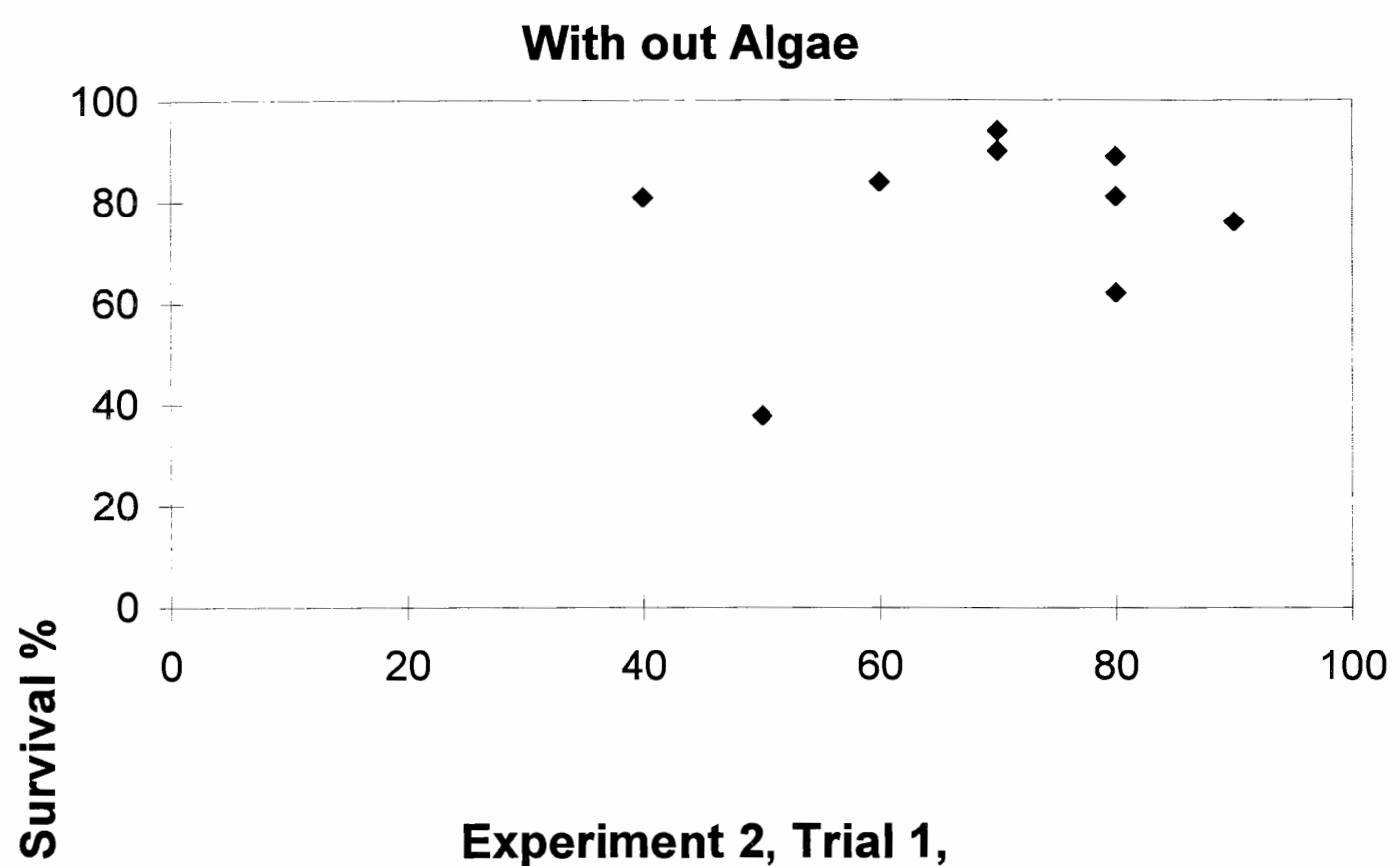

With Algae

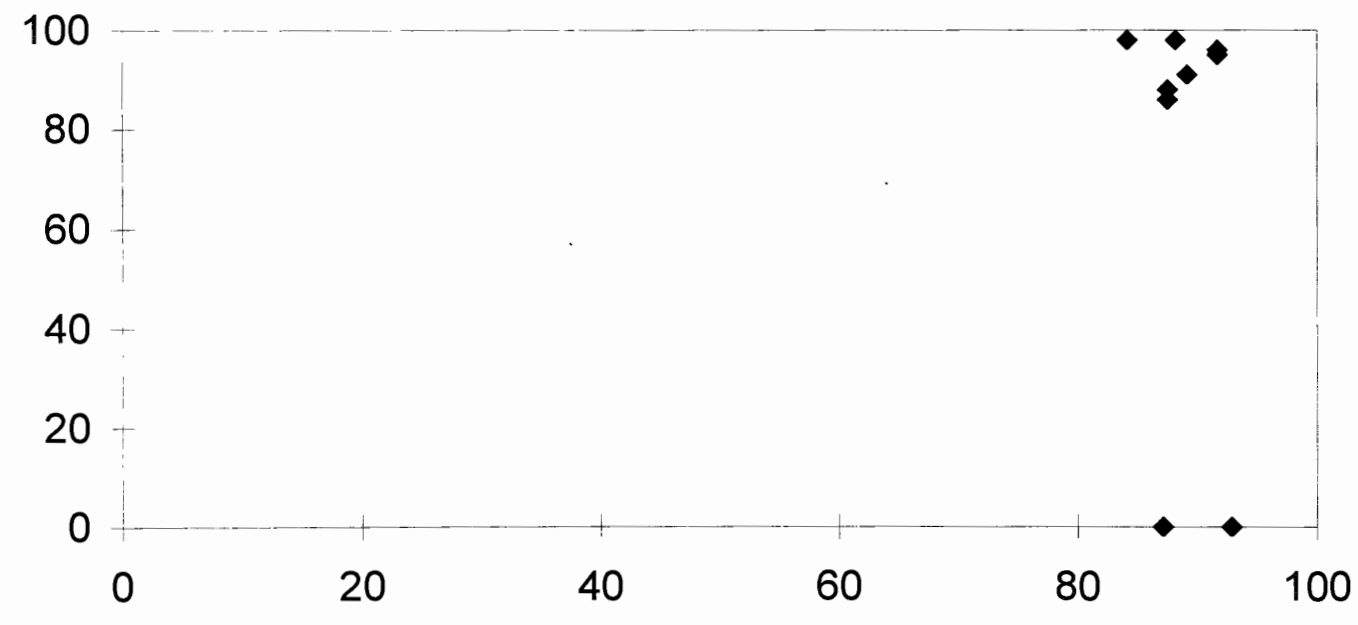

Food Average $\%$

Figure 2 
Figure 3. Experiment 2 trial 2, clear water treatments (upper graph) and green water treatments (lower graph). Average food in gut during daily sampling (when survival was greater than zero) on the $\mathrm{X}$ axis, survival percentage at 10 DAH on the $Y$ axis. 


\section{Experiment 2, Trial 2,}

\section{With out Algae}

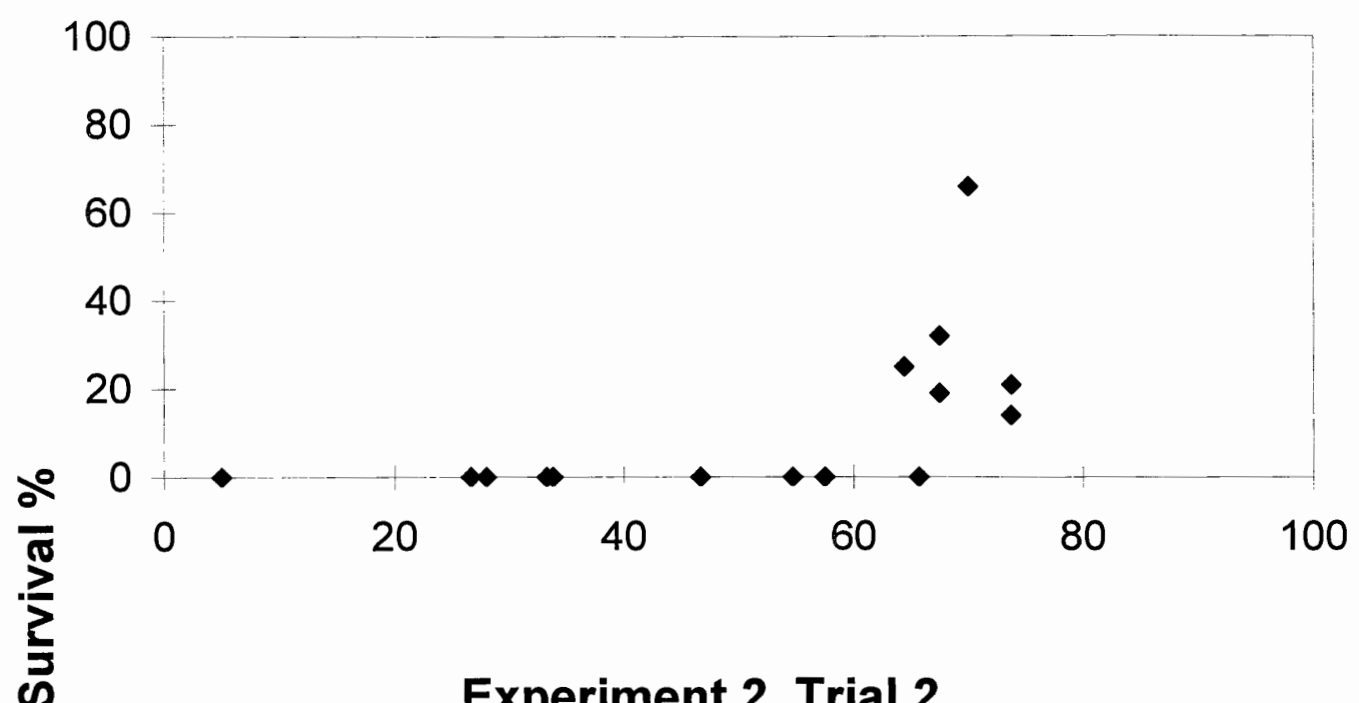

Experiment 2, Trial 2,

with Algae

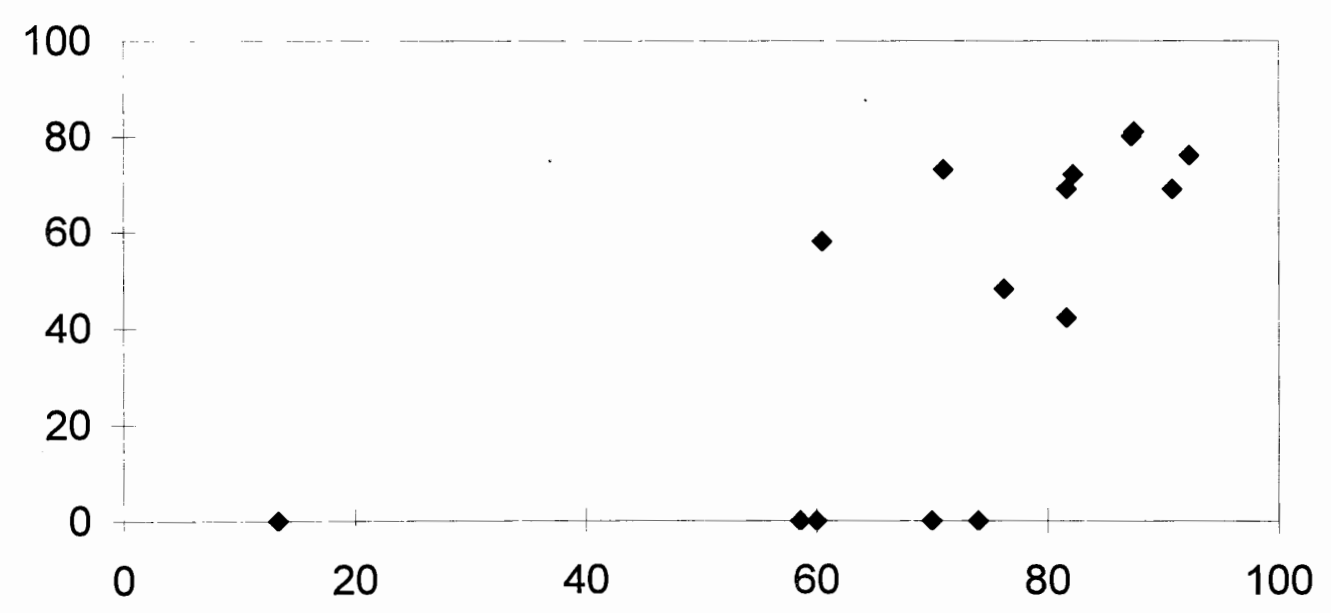

Food Average \%

Figure 3 


\section{BIBLIOGRAPHY}

Able, K.W. \& S.C. Kaiser. (1994) Synthesis of Summer Flounder Habitat Parameters. NOAA coastal ocean program decision analysis series No. 1. NOAA coastal ocean office, Silver Spring, MD. $68 \mathrm{pg}$.

Al-Maghazachi, S.J. \& R. Gibson. (1984) The developmental stages of larval turbot, Scophthalmus maximus (L.). Journal of Experimental Marine Biology and Ecology 82:35-51.

Andrades, J.A., J. Becerra \& P. Fernandez-Llebrez. (1996) Skeletal deformities in larval, juvenile and adult stages of cultured gilthead sea bream (Sparus aurata L.). Aquaculture $141: 1-11$.

Angulo, L., D. Garcia, C. Bolano, F. Grana \& M. YRiveiro.(1988) Caracterizacion de la flora bacteriana asociada a los cultivos de rodaballo (Scophthalmus maximus). Thalassas $6: 83-87$.

Anthony, R. (1910) The cultivation of the turbot. Proceedings of the 4th International Fishery Congress, Washington, 1908, Pt. 2. Published as Bulletin of the United States Bureau of Fisheries 28:861-870.

Appelbaum, S. (1985) Rearing of the dover sole, Solea solea L., through its larval stages using artificial diets. Aquaculture 49:209-221.

Appelbaum, S., J.W. Adron, S.G. George, A.M. Mackie \& B.J.S. Pirie. (1983) On the development of the olfactory and the gustatory organs of the Dover sole, Solea solea, during metamorphosis. Journal of the Marine Biological Association of the United Kingdom 63:97-108.

Austin, B., E. Baudet \& M. Stobie. (1992) Inhibition of bacterial fish pathogens by Tetraselmis suecica. Journal of Fish Disease 15:55-61.

Austin, B. (1983) Bacterial microflora associated with a coastal, marine fish-rearing unit. Journal of the Marine Biological Association of the United Kingdom 63:585-592.

Baker, E.P. \& D.A. Bengtson. (1996) Effects of dietary fatty acid enrichment on survival, growth and pigmentation of summer flounder, Paralichthys dentatus, early life stages. World Aquaculture Society Conference. (Abstract) Pg. 21. 
Baragi, V. \& R.T. Lovell. (1986) Digestive enzyme activities in striped bass from first feeding through larval development. Transactions of the American Fisheries Society $115: 478-484$.

Beck, A.D. \& D.A. Bengtson. (1982) International study on Artemia XXII: Nutrition in aquatic toxicology-Diet quality of geographical strains of the brine shrimp, Artemia. Aquatic toxicology and Harzard Assessment: Fifth Conference, ASTM STP 766. J.G. Pearson, R.B. Foster, \& W.E. Bishop, Eds. American Society for Testing and Materials. pp. 161-169.

Benavente, G.P. \& F.J. Gatesoupe (1987) Bacteria associated with cultured rotifers and artemia are detrimental to larval turbot, Scophthalmus maximus L. Aquacultural Engineering $7: 289-293$.

Bengtson, D.A. (1993) A comprehensive program for the evaluation of artificial diets. Journal of the World Aquaculture Society 24 (2) : 285-293.

Berlinsky, D.L., W. King, T.I.J. Smith, R.D. Hamilton, J. Holloway \& C.V. Sullivan. (1996) Induced ovulation of southern flounder Paralichthys lethostigma using gonadotropin releasing hormone analogue implants. Journal of the World Aquaculture Society $27(2): 143-152$.

Bisbal, G.A. \& D.A. Bengtson. (1995) Effects of delayed feeding on survival and growth of summer flounder Paralichthys dentatus larvae. Marine Ecology Progress Series 121:301-306.

Bisbal, G.A. \& D.A. Bengtson. (1995) Development of the digestive tract in larval summer flounder. Journal of Fish Biology $47: 277-291$.

Bisbal, G.A. (1993). Early feeding in larval summer flounder, Paralichthys dentatus: gut development and starvation effects. Ph.D. dissertation, University of Rhode Island, Kingston, RI 02881, $138 \mathrm{pp}$.

Bisbal, G.A. \& D.A. Bengtson (1994) Description of the starving condition in summer flounder, Paralichthys dentatus, early life history stages. Fishery Bulletin $93: 217-230$.

Boehlert, G.W. \& J.B. Morgan (1985) Turbidity enhances feeding abilities of larval Pacific herring, clupea harengus pallasi. Hydrobiologia 123:161-170. 
Bromage, N., M. Bruce, N. Basavaraja, K. Rana, R. Shields, C. Young, J. Dye, P. Smith, M. Gillespie \& J. Gamble. (1994) Egg quality determinants in finfish: The role of overripening with special reference to the timing of stripping in the atlantic halibut Hippoglossus hippoglossus. Journal of the World Aquaculture Society 25(1):13-21.

Buckley, L.J., A.S. Smigielski, T.A. Halavik, E.M. Caldarone, B.R. Burns \& G.C. Lawrence. (1991) Winter flounder Pseudopleuronectes americanus reproductive success. I. Among-location variability in size and survival of larvae reared in the laboratory. Marine Ecology Progress Series $74: 117-124$.

Cousin, J.C.B. \& F. Baudin-Laurencin. (1987) Histological alterations observed in turbot, Scophthalmus maximus L., from days 15 to 40 after hatching. Aquaculture 67:218-220.

Cousin, J.C.B., G. Balouet \& F. Baudin-Laurencin. (1986) Alterations histologiques chez des larves de turbot (Scophthalmus maximus L.) en elevage intensif. Aquaculture $52: 173-189$.

Cowles, M. \& C. Davis. (1982). On the origins of the .05 level of statistical significance. American Psychologist $37(5): 553-558$.

Crawford, C.M. (1986) Development of eggs and larvae of the flounders Rhombosolea tapirina and Ammotretis rostratus (Pisces:Pleuronectidae). Journal of Fish Biology 29:325-334.

Dabrowski, K.R. (1986) Mini-review, Ontogenetical aspects of nutritional requirements in fish. Comparative Biochemistry and Physiology 85A(4):639-655.

Daniels, H.V., D.L. Berlinsky, R.G. Hodson \& C.V. Sullivan. (1996). Effects of stocking density, salinity and light intensity on growth and survival of southern flounder Paralichthys lethostigma larvae. Journal of the World Aquaculture Society 27(2):153-159.

Devauchelle, N., J.C. Alexandre, N. Le Corre \& Y. Letty. (1987) Spawning of sole (Solea solea) in captivity. Aquaculture 66:125-147.

Devauchelle, N., J.C. Alexandre, N. Le Corre \& Y. Letty (1988) Spawning of turbot (Scophthalmus maximus) in captivity. Aquaculture 69:159-184. 
Dhert, P., P. Lavens, M. Dehasque \& P. Sorgeloos. (1994) Improvements in the larviculture of turbot scophthalmus maximus:zootechnical and nutritional aspects, possibility for disease control. In Turbot Culture: Problems and prospects. P. Lavens \& R.A.M. Remmerswaal (Eds). European Aquaculture Society. Special Publication No. 22, Gent, Belgium.

Eda, H., R. Murashige, Y. Oozeki, A. Hagiwara, B. Eastham, P. Bass, C.S. Tamaru \& C.S. Lee. (1990) factors affecting intensive larval rearing of striped mullet, Mugil cephalus. Aquaculture $91: 281-294$.

Fournie, J.W. \& J.K. Summers. (1996) Prevalence of gross pathological abnormalities in estaurine fishes. Transactions of the American Fisheries Society 125:581-590.

Fukuhara, O. (1986) Morphological and functional development of japanese flounder in early life stage. Bulletin of the Japanese Society of Scientific Fisheries 52(1):81-91.

Fukuhara, O. (1988) Morphological and functional development of larval and juvenile Limanda yokohamae (Pisces: Pleuronectidae) reared in the laboratory. Marine Biology $99: 271-281$.

Gallagher, M.L., L. Paramore, D. Alves \& R. Rulifson. (In Prep) Phospholipid and fatty acid composition of wild and cultured striped bass (Morone saxatilis) eggs. Written for Journal of Fish Biology.

Gatesoupe, F.-J. (1990) The continuous feeding of turbot larvae, Scophthalmus maximus, and control of the bacterial environment of rotifers. Aquaculture 89:139-148.

Gilderhus, P.A. \& L.L. Marking. (1987). Comparative efficacy of 16 anesthetic chemicals on rainbow trout. North American Journal of Fisheries Management. 7:288-292.

Govoni, J.J., G.W. Boehlert \& Y. Watanabe. (1986) The physiology of digestion in fish larvae. Environmental Biology of Fishes. $16(1-3): 59-77$.

Govoni, J.J. (1981) Alimentary canal development and its relation to the early life history of spot, Leiostomas xanthurus. Rapports et Proces-verbaux des Reunions Conseil internationale pour L'Exploration de la Mer 178:314-315.

Gudger, E.W. (1935) Two partially ambicolorate flatfishes (Heterosomata) I.-A summer flounder, Paralichthys dentatus. II.-A rusty dab, Limanda ferruginea. American Museum

Novitiates. No. $768.8 \mathrm{pg}$. 
Gulbrandsen J. (1996) Effects of spatial distribution of light on prey ingestion of atlantic halibut larvae. Journal of Fish Biology $48: 478-483$.

Hernandez-Cruz, C.M., M. Salhi, H. Fernansez-Plalacios \& M.S. Izquierdo. (1994) Improvements in the culture of Spartus aurata L. larvae in relation to the use of antibiotics, phytoplankton and rearing system. Aquaculture $124: 269-274$.

Houde, E.D. (1978) Critical food concentrations for larvae of three species of subtropical marine fishes. Bulletin of Marine Science. 28(3):395-411.

Howell, B.R. \& A.P. Scott. (1989) Ovulation cycles and postovulatory deterioration of eggs of the turbot (Scophthalmus maximus L.). Rapports et Proces-verbaux des Reunions Conseil internationale pour L'Exploration de la Mer 191:21-26.

Howell, B.R. (1979) Experiments of the rearing of larval turbot, Scophthalmus maximus L. Aquaculture 18:215-225.

Humason, G.L. (1962) Animal Tissue Techniques. W.H. Freeman $\&$ Co.

Iida, Y., K. Masumura, T. Nakai, M. Sorimachi \& M. Matsuda. (1989) A viral disease in larvae and juveniles of the japanese flounder Paralichthys olivaceus. Journal of Aquatic Animal Health. 1:7-12.

Job, S.D. \& D.R. Bellwood. (1996) Visual acuity and feeding in larval Premnas biaculeatus. Journal of Fish Biology $48: 952-963$.

Jones, A., R.A. Prickett \& M.T. Douglas. (1981) Recent developments in techniques for rearing marine flatfish larvae, particually turbot (Scophthalmus maximus L.) on a pilot commercial scale. Rapports et Proces-verbaux des Reunions Conseil internationale pour L'Exploration de la Mer $178: 522-526$.

Jones, A. (1973) Observations on the growth of turbot larvae Scophthalmus maximus L. reared in the laboratory. Aquaculture 2:149-155.

Kanazawa, A. (1993) Nutritional mechanisms involved in the occurrence of abnormal pigmentation in hatchery-reared flatfish. Journal of the World Aquaculture Society $24(2): 162-166$. 
Kellam S.J. \& J.M. Walker (1989) Antibacterial activity from marine microalgae in laboratory culture. British Phycology Journal. $24: 191-194$

Keppel, G. (1991) Design and Analysis, A researchers Handbook. 3ed ed. Prentice Hall.

Kjelmeland, K., B.H. Pedersen \& E.M. Nilssen. (1988) Trypsin content in intestines of herring larvae, Clupea harengus, ingesting inert polystyrene spheres or live crustacea prey. Marine Biology. $98: 331-335$.

Kjorsvik, E., A. Mangor-Jensen, \& I. Holmefjord (1990) Egg quality in fishes. Advances in Marine Biology. 26:71-113.

Kjorsvik, E., T. van der Meeren, H. Kryvi, J. Arnfinnson \& P.G. Kvenseth. (1991) Early development of the digestive tract of cod larvae, Gadus morhua L., during start-feeding and starvation. Journal of Fish Biology $38: 1-15$.

Klein-MacPhee, G. (1981) Effects of stocking density on survival of laboratory cultured summer flounder

(Paralichthys dentatus) larvae. Rapports et Proces-verbaux des Reunions Conseil internationale pour L'Exploration de la Mer 178:505-506.

Lavens, P., P. Sorgeloos, P. Dhert \& B. Devresse. (1995) Larval foods. In Broodstock Management and Egg and Larval Quality. N.R. Bromage \& R.J. Roberts(Eds). Blackwell Science, Oxford.

Leger, P., D.A. Bengtson, P. Sorgeloos, K.L. Simpson \& A.D. Beck. (1987) The Nutritional Value of Artemia: a review. In Artemia research and its applications. Vol 3. P. Sorgeloos, D.A. Bengtson, W. Decleir \& E. Jaspers (Eds) Universa Press, Wetteren, Belgium.

Levin, M.A., R.E. Wolke \& V.J. Cabelli. (1972) Vibrio anguillarum as a cause of disease in winter flounder (Pseudopleuronectes americanus). Canadian Journal of Microbiology. 18:1585-1592.

Lubzens, E., A. Tandler \& G. Minkoff. (1989) Rotifers as food in aquaculture. Hydrobiologia 186/187:387-400.

Martin, F.D., \& G.E. Drewry. (1978) Development of Fishes of the Mid-Atlantic Bight. An atlas of egg, larval and juvenile stages. Vol 6. F.D. Martin \& G.E. Drewry (Eds). Fish and Wildlife Service, Department of the Interior. 
Meeren, T. v.d. (1991) Algae as first food for cod larvae, Gadus morhua L.: filter feeding or ingestion by accident? Journal of Fish Biology 39:225-237.

Minkoff, G., \& A.P. Broadhurst. (1994) Intensive production of turbot, Scophthalmus maximus, fry. In Turbot culture: Problems and prospects. P. Lavens \& R.A.M. Remmerswaal (Eds). European Aquaculture Society. Special Publication No. 22, Gent, Belgium.

Morrison, C.M. \& C.A. MacDonald. (1995) Normal and abnormal jaw development of the yolk-sac larva of atlantic halibut Hippoglossus hippoglossus. Diseases of Aquatic Animals. 22:173-184.

Morse, W.W. (1981) Reproduction of the summer flounder, Paralichthys dentatus (L.) Journal of Fish Biology 19:189203.

Naas, K.E., T. Næss, \& T. Harboe (1992) Enhanced first feeding of halibut larvae (Hippoglossus hippoglossus L.) in green water. Aquaculture 105:143-156.

Naess, T., T. Harboe, A. Mangor-Jensen, K.E. Naas \& B. Norberg. (1996) Successful first feeding of atlantic halibut larvae from photoperiod-manipulated broodstock. Progressive Fish Culturist 58:212-214.

Nankee, R.L. (1981) Observations of deformed fish larvae in Long Island Sound and Niantic Bay, Connecticut. Rapports et Proces-verbaux des Reunions Conseil internationale pour L'Exploration de la Mer $178: 355-356$.

Nicholas, J.L., E. Robic \& D. Ansquer. (1989) Bacterial flora associated with a trophic chain consisting of microalgae, rotifers and turbot larvae:influence of bacteria on larval survival. Aquaculture 83:237-248.

NOAA/NMFS. (1993). Fisheries of the U.S. U.S. Department of Commerce. Silver Spring, MD.

O'Connell, C.P. (1981) Development of organ systems in the northern anchovy, Engraulis mordax, and other teleosts. American Zoologist 21:429-446.

Olesen, J.O. \& F. Minck. (1983) A technical solution to the mass-culturing of larval turbot. Aquacultural Engineering $2: 1-12$. 
Padros, F., G. Minkoff, R. Sala \& S. Crespo. (1993) Histopathological events throughout the development of turbot (Scophthalmus maximus L.) larvae. Journal of Comparative Pathology 109:321-334.

Parker, S.P. (Ed.) Synopsis and Classification of Living Organisms. McGraw-Hill Book Co. New York.

Perez Benavente, G. \& F.J. Gatesoupe. (1988) Bacteria associated with cultured rotifers and artemia are detrimental to larval turbot, Scophthalmus maximus L. Aquacultural Engineering $7: 289-293$.

Pittman, K., A.B. Skiftesvik \& L. Berg. (1990) Morphological and behavioral development of halibut, Hippoglossus

hippoglossus (L.) larvae. Journal of Fish Biology 37:455472 .

Planas, M. (1994) R\&D on production systems. In Turbot culture: Problems and prospects. P. Lavens \& R.A.M. Remmerswaal (Eds). European Aquaculture Society. Special Publication No. 22, Gent, Belgium.

Powell, A.B. \& T. Henley. (1995) Egg and larval development of laboratory-reared gulf flounder, Paralichthys albigutta, and southern flounder, P. lethostigma (Pisces, Paralichthyidae). Fishery Bulletin 93:504-515.

Qasim, S.Z. (1955) Rearing experiments on marine teleost larvae and evidence of their need for sleep. Nature 175:217218 .

Reitan, K.I., J.R. Rainuzzo, G. Oie \& Y. Olsen. (1993) nutritional effects of algal addition in first-feeding of turbot (Scophthalmus maximus L.) larvae. Aguaculture $118: 257-275$.

Scott, A.P. \& S.M. Baynes. (1978) Effect of algal diet and temperature on the biochemical composition of the rotifer, Brachionus plicatilis. Aquaculture 14:247-260.

Segner, H., V. Storch, M. Reinecke \& W. Kloas. (1994) the development of functional digestive and metabolic organs in turbot, Scophthalmus maximus. Marine Biology 119:471-486.

Shelbourne, J.E. (1964) The artificial propagation of marine fish. Advances in Marine Biology 2:1-83.

Skiftesvik A.B. (1992) Changes in behavior at onset of exogenous feeding in marine fish larvae. Canadian Journal of Fishery and Aquatic Science 49:1570-1572. 
Skjermo, J. \& O. Vadstein. (1993) Characterization of the bacterial flora of mass cultivated Brachionus plicatilis. Hydrobiologia 255/256:185-191.

Smigielski, A.S. (1975) Hormone-induced spawning of the summer flounder and rearing of the larvae in the laboratory. Progressive Fish Culturist $37(1): 3-8$.

Smith, W.G. \& M.P. Fahay. (1970) Description of eggs and larvae of the summer flounder, Paralichthys dentatus. research Reports of the United States Bureau of Sport Fishery and Wildlife. 75:21 pp.

Sokal, R.R. \& F.J. Rohlf. (1969) Biometry. The principles and practice of statistics in biological research. W.H. Freeman \& Co.

Strottrup, J.G., K. Gravningen, \& N.H. Norsker. (1995) The role of different algae in the growth and survival of turbot larvae (Scophthalmus maximus L.) in intensive rearing systems. International Council on Exploration of the sea Marine Science Symposium. 201:173-186.

Suquet, M., R. Billard, J. Cosson, Y. Normant \& C. Fauvel. (1995) Artificial insemination in turbot (Scophthalmus maximus) : determination of the optimal sperm to egg ratio and time of gamete contact. Aquaculture 133:83-90.

Tamaru, C.S., R. Murashige, \& C-S Lee. (1994) The paradox of using background phytoplankton during the larval culture of striped mullet, Mugil cephalus L. Aquaculture 119:167-174.

Tanasomwang, V., \& K. Muroga. (1988) Intestinal microflora of larval and juvenile stages in japanese flounder

(Paralichthys olivaceus). Fish Pathology 23(2):77-83.

Toranzo, A.E., B. Novoa; J.L. Romalde, S. Nunez, S. Devesa, E. Marino, R. Silva, E. Martinez, A. Figueras \& J.L. Barja. (1993) Microflora associated with healthy and diseased turbot (Scophthalmus maximus) from three farms in northwest Spain. Aquaculture 114:189-202.

Watanabe, T., \& V. Kiron. (1994) Prospects in larval fish dietetics. A review. Aquaculture 124:223-251.

Wyatt, T. (1972). Some effects of food density on the growth and behavior of plaice larvae. Marine Biology 14:210-216. 